\title{
From me needs knee to knee needs me
}

Citation for published version (APA):

van der Sluis, G. (2018). From me needs knee to knee needs me: transition of perioperative care for people that chose to have total knee replacement surgery by augmenting activity and personalized functional goalsetting. [Doctoral Thesis, Maastricht University]. Zalsman Groningen BV. https://doi.org/10.26481/dis.20181109gs

Document status and date:

Published: 01/01/2018

DOI:

10.26481/dis.20181109gs

Document Version:

Publisher's PDF, also known as Version of record

\section{Please check the document version of this publication:}

- A submitted manuscript is the version of the article upon submission and before peer-review. There can be important differences between the submitted version and the official published version of record.

People interested in the research are advised to contact the author for the final version of the publication, or visit the DOI to the publisher's website.

- The final author version and the galley proof are versions of the publication after peer review.

- The final published version features the final layout of the paper including the volume, issue and page numbers.

Link to publication

\footnotetext{
General rights rights.

- You may freely distribute the URL identifying the publication in the public portal. please follow below link for the End User Agreement:

www.umlib.nl/taverne-license

Take down policy

If you believe that this document breaches copyright please contact us at:

repository@maastrichtuniversity.nl

providing details and we will investigate your claim.
}

Copyright and moral rights for the publications made accessible in the public portal are retained by the authors and/or other copyright owners and it is a condition of accessing publications that users recognise and abide by the legal requirements associated with these

- Users may download and print one copy of any publication from the public portal for the purpose of private study or research.

- You may not further distribute the material or use it for any profit-making activity or commercial gain

If the publication is distributed under the terms of Article $25 \mathrm{fa}$ of the Dutch Copyright Act, indicated by the "Taverne" license above, 


\section{From me needs knee to knee needs me}

Transition of perioperative care for people that chose to have total knee replacement surgery by augmenting activity and personalized functional goalsetting 
Layout

Rick Timmerman, prickelt<

\section{Cover}

Carine Braakenburg, Met Caracter

Printed by

Zalsman Groningen BV

\section{Copyright}

(C) Geert van der Sluis, Wijnjewoude 2018

No part of this book may be reproduced or transmitted in any form or by any means, without prior permission in writing by the author, or when appropriate, by the publishers of the publications.

\section{Photo cover}

Nij Smellinghe, Drachten

ISBN

978-90-9031241-5 


\title{
From me needs knee to knee needs me
}

\author{
Transition of perioperative care for people that chose to \\ have total knee replacement surgery by augmenting activity \\ and personalized functional goalsetting
}

\begin{abstract}
Proefschrift
Ter verkrijging van de graad van doctor aan de Universiteit Maastricht, op gezag van de Rector Magnificus, Prof. Dr. Rianne M. Letschert, volgens het besluit van het College van Decanen, in het openbaar te verdedigen op vrijdag 9 november 2018 om 14.00 uur
\end{abstract}

door

Geert van der Sluis 


\section{Promotor}

Prof. Dr. N.L.U van Meeteren

\section{Copromotoren}

Dr. R.A. Goldbohm

Dr. T.J. Hoogeboom

\section{Beoordelingscommissie}

Prof. Dr. L.W. van Rhijn (voorzitter)

Prof. Dr. R.A. de Bie

Prof. Dr. R.G.H.H. Nelissen

Prof. Dr. W.F. Buhre

Prof. Dr. M.A.A.J. van den Bosch 


\section{Table of Contents}

Chapter 2 What augmented physical activity and empowerment can bring patients receiving total knee replacement: Content, implementation and comparative effectiveness of a new functiontailored care pathway in a routine care setting.

Published in: Biomedical research international 2015

Chapter 3 Challenges for development of shared decision making before and after total knee replacement surgery: a scoping review. Under review: Patient education and counseling

Chapter 4 Development of a Risk Stratification Model for Delayed Inpatient Recovery of Physical Activities in Patients Undergoing Total Hip Replacement.

Published in: Journal of orthopedic and sports physiotherapy 2016;46:135-143

Chapter 5 Preoperative functional mobility as an independent determinant of inpatient functional recovery after total knee replacement in three time periods that coincided with clinical pathway changes. Published in: Bone and Joint Journal 2017; 2, 211-217

Chapter 6 Prediction and visual presentation of speed of inpatient recovery of functional activities after total knee replacement based on preoperative patient characteristics.

Under review: Journal of physiotherapy

Dankwoord 

General introduction 


\section{General introduction}

The number of patients whose osteoarthritis complaints have been relieved by means of total knee replacement (TKR) has increased substantially in recent years. In 1992, 4,916 TKR operations were carried out in the Netherlands and this volume increased to 14,565 operations in 2005. ${ }^{1}$ Today, more than 18,000 patients are scheduled for a TKR in the Netherlands every year ${ }^{1}$. According to demographic trends, the expectation is that the number of patients opting for a TKR will further increase to 58,000 in $2030 .^{1}$

Osteoarthritis is the most common joint disorder in older people. In $90 \%$ of all TKR procedures, knee osteoarthritis was the diagnosis. ${ }^{2,3}$ Prior to the introduction of TKR surgery in the 1970s, people with advanced knee osteoarthritis were not able to function properly and became housebound. ${ }^{3}$ Today, in most cases, people with a knee prosthesis can function normally in their living environment. Therefore, TKR surgery can be seen as a game changer.

In the early 1990s in the Netherlands, patients stayed on average 11 days in hospital for a TKR. ${ }^{4}$ After the introduction of clinical care pathways, such as Joint care ${ }^{\circledast}$, in the late 1990 s, the length of stay in the hospital after TKR decreased to 5 days. ${ }^{4}$ With the introduction of fasttrack pathways, which are currently used in the Netherlands, the length of stay has decreased even further. 5,6 A length of stay of 2-3 days, including the day of surgery, is common; a substantial percentage of the younger patient population is treated in day-case surgery and this percentage is increasing..$^{7-12}$

This thesis describes the development, implementation and effectiveness of the transition of care for patients undergoing TKR from Joint care towards a function-tailored, fasttrack care model. The transition took place for all total joint replacements (knee and hip) in the Nij Smellinghe hospital, a regional hospital in Drachten, the Netherlands, between 2009 and 2016. With the exception of chapter 4, which was based on data from total hip replacement, this thesis is restricted to TKR. During the transition period, two distinct, major changes were introduced in the applied care pathways. Figure 1 simplifies the transition of care and shows the key elements of these changes for patients undergoing TKR, at the start of the transition and in the current (i.e. 2017) situation: (1) the aim of the cure and care, (2) the way decisions are made and (3) the way the care is delivered. These key elements will be described and explained in more detail below. 


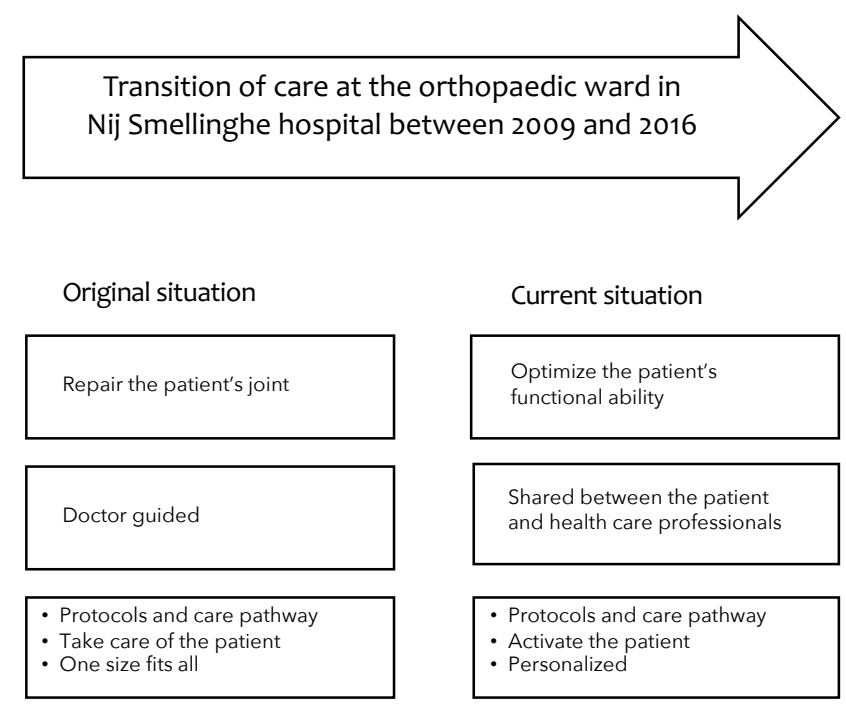

Figure 1. Simplified depiction of the care transition on the orthopaedic ward of the Nij Smellinghe hospital.

\section{Aim of cure and care}

Until 2009, most patients admitted to the hospital ward for TKR surgery were already wearing pyjamas before surgery; they were asked to lie in bed and wait for the nursing staff to transport their bed to the operation room. After surgery, patients stayed in bed for one or two days, with continuous passive motion exercises as their main activity. Today, patients undergoing total knee replacement walk to the operation room themselves. Within 4 hours after surgery, they begin to work on independently bathing and dressing themselves and attempting functional activities such as transfers, walking and climbing stairs with, when necessary based on the patient's capacity, a physiotherapist or nurse as a coach beside them.

After the introduction of TKR in the 1970s, the main goal of replacing a knee joint was to "repair" an osteoarthritic knee. The interventions and activities focused on patients' anatomical structures and physiological systems (i.e., body functioning according to the WHO's International Classification of Functioning, disability and health, ICF). ${ }^{15}$ For example, physical therapy after TKR aimed at enhancing knee range of motion and improving muscle functioning as main conditions for walking capacity. ${ }^{4}$ The surgery was performed with a strong focus on reducing pain, as pain is often an important complaint of patients with knee osteoarthritis.

However, the spectrum of problems that patients with knee osteoarthritis experience is often broader than just pain. For example, these patients also experience problems with functioning in their living environment and especially participating in activities. 
Although surgical procedures can enhance a person's functional abilities and quality of life, complications in recovery of activities and participation and adverse medical events are not negligible. ${ }^{16,17}$ Despite the development of TKR as a routine procedure, the reality is that the outcome is not favourable for every patient undergoing this treatment. ${ }^{18,19}$ Hawker et al. (2013) demonstrated, in a frail and older population, that TKR did not lead to a clinically meaningful improvement in the level of pain and patient-reported physical functioning in half of their investigated population. ${ }^{20}$ Moreover, Beswick et al. (2012) showed that $17-34 \%$ of their patients who underwent TKR reported moderate to severe chronic pain at the time that full recovery had been expected. ${ }^{18}$

Surgery and anaesthesia are major stressors for the physiological and psychological system of a person, causing mostly reversible but sometimes irreversible functional decline. ${ }^{21}$ Frail elderly people, who already have a lower resilience, are more at risk of responding inadequately to surgical stress due a lack of physiological reserves and may exceed a "critical level" of dissability.,21 Perhaps this functional decline due to surgical stress is one of the explanations for the disappointing outcome of TKR in some patients.

In addition, healthcare management and the hospital environment are likely to contribute to the development of hospital-related deconditioning, particularly among older hospitalized patients. ${ }^{24}$ In the past, we observed in our hospital ward that patients often showed passive coping attitudes, which were supported by the healthcare professionals in a hospital environment that did not stimulate activity. ${ }^{13}$ Such passive attitudes, however, do not match the current idea of health, which promotes self-management and adaptation to challenges in life, such as major surgery. ${ }^{14}$ Covinsky et al. found that at least $30 \%$ of hospitalized patients of 70 years or older were discharged from the hospital with a new disability that was absent before hospitalization. ${ }^{17}$ They recognized that hospitalization factors like low mobility, enforced dependence and little encouragement to become independent largely contributed to the development of these newly acquired hospital-related disabilities. ${ }^{17}$ With such new disability, the patient loses part of his independence, which often has serious consequences in the short term and possibly even in the long term. Low mobilization and lack of physiotherapy interventions are regarded as the most important factors contributing to iatrogenic disability. ${ }^{24}$ For example, Brown et al. showed that older patients are inactive $83 \%$ of the time they are hospitalized, about 20 hours a day. ${ }^{13}$ Kortebein suggested in 2008 that interventions should be developed to activate older hospitalized patients, with prevention of hospital-related disability as the main focus. ${ }^{25}$

Therefore, besides state-of-the-art surgical treatment, a new care pathway was introduced to avoid sedentary behaviour in patients undergoing TKR in the Nij Smellinghe hospital and to promote and implement an active culture and infrastructure during and around their hospitalization period with a prominent and active role for the patient. The effectiveness of this new pathway, which we called the function-tailored care pathway, compared with the original Joint care pathway is investigated in chapter 2. 


\section{Decision making}

In the past, if a patient suffered from knee pain with complaints regarding his/her functioning, the orthopaedic surgeon was typically the one to decide whether to perform TKR surgery or not, based on his diagnostics (mainly $x$-ray) and clinical reasoning. The age of the patient (too young or too old) was often an exclusion criterion for the surgeon, as was the presence of comorbidities.

But patients with episodes of knee problems are not primarily asking their doctor for a $T K R$, but seeking solutions for the limitations and pain they experience during their work, leisure time and in their living environment. An intervention suitable for one patient may not always be the best treatment for another patient. Each patient attaches different importance to functional ability and pain. Therefore the patient and healthcare professional should explicitly decide together what is the best treatment option, taking into account the patient's wishes and future perspective of functioning and the chance of complications and expected relief of the functional problems. ${ }^{26}$ To facilitate this decision making process, healthcare professionals are increasingly providing their patients with knee complaints with information about all possible healthcare solutions, thus not only the surgical option. This also means that the patient is provided with information about the option of doing nothing. Therefore, it may happen that older, fragile patients with a relatively high surgery risk nevertheless choose to undergo surgical treatment, whereas younger patients may refrain from surgery.

This approach reflects current ideas about evidence-based medicine; the Sicily statement on evidence-based medicine from 2005 stated that evidence-based practice requires that decisions about health care are based on the best available, current, valid and relevant evidence, made by those receiving care, and informed by the tacit and explicit knowledge of those providing care, within the context of available resources. ${ }^{27}$

As the goal is to help the patient achieve optimal functioning, which is obviously subjective, clear insight into the patient's preferences, values and needs is necessary. These are important issues in patient-centred care, the pinnacle of which is the use of shared decision making (SDM). ${ }^{28}$ It is important for an adequate SDM process that the patients are provided with suitable information on risks and benefits of the intervention and that their preferences and desired outcomes are clear to themselves as well as to their relatives and to the professional(s) involved in their care. Oosting et al., however, observed in a case study among patients undergoing total hip replacement that patients' values and preferences were different from those of the healthcare professionals and informal caregivers. Therefore it is worthwhile to develop methods that help patients, relatives and health care professionals jointly define desired (functional) goals, accommodating the values and preferences of the patients. ${ }^{29}$ An adequate SDM process therefore requires high-quality communication between patient and healthcare professional. ${ }^{30,31}$ Hoffmann et al. elaborate on five simple questions that can be used to guide patients and professionals through the SDM process: (1) What will happen if we 
wait and watch; (2) what are the test and treatment options; (3) what are the benefits and harms of each option; (4) how do the benefits and harms weigh up for the patient; and (5) does the patient have enough information to make a choice? ? $^{30}$

However, little is known about the state-of-the-art of applying SDM to patients who are considering, undergoing and recovering from a TKR. SDM is not (yet) the standard in the current care pathway for TKR in our hospital, although we have tried to make a transition from a more paternalistic decision making model, which was led by the orthopaedic surgeon and his clinical reasoning, to a model in which the patient and orthopaedic surgeon explore all potential treatment options together. Currently, the patient's wishes and preferences are taken into consideration much more in the decision making process. Furthermore, by using functional goal setting, patients and physiotherapists have a greater opportunity to discuss and make decisions together about discharge planning and destination. Our long term goal is to apply SDM throughout the total patient journey with the help of a well-established SDM model. To support the transition to applying SDM in our daily care, it is valuable to have an overview of the current scientific knowledge on SDM for patients who are considering TKR. Therefore a literature review was performed to explore the scientific literature on the use, content and shortcomings of SDM in patients undergoing a TKR (chapter 3).

In the light of optimizing SDM in our hospital, we also developed a new model to predict the speed of inpatient recovery of physical activities after TKR based on preoperative patient characteristics. Unlike usual prediction models, which often present predicted individual outcomes as 'yes' or 'no' increased risk, we think it may be more intelligible for patients and therefore helpful in a more patient-oriented decision making process to present individual predictions to patients as probabilities of each possible outcome. ${ }^{32,33}$ The development and graphic presentation of such a prediction model is described in chapter 6.

\section{Delivery of care}

In the original Joint care ${ }^{\circledast}$ pathway, a patient was admitted to the hospital ward together with five fellow patients one day prior to surgery. This day was used to share information with the healthcare professionals involved in the cure or care of these patients. Moreover, patients received information by watching videos about the surgical procedure and the content of the care program during hospitalization. On the day of surgery, the patient did not eat or drink and was transported in bed with an empty stomach to the operation room. On the day of surgery, the patient stayed in bed. From the first day after surgery the program was organized as a timetable, with certain activities at specific time points. After five days, patients were supposed to be ready for discharge to either their home or to an inpatient rehabilitation facility. Today patients undergo a preoperative screening, which includes a functional mobility assessment, four weeks prior to surgery. On the day of the surgery, the patient is admitted to 
the hospital two hours prior to surgery, takes a preoperative energy drink on an empty stomach, and walks to the operation room. Ambulation starts at most four hours after surgery in an active hospital culture and environment, where participation and socialization are also promoted. The moment and destination of discharge is determined based on personalized functional goal setting and the monitored progress in recovery of activities.

The original Joint care ${ }^{\circledR}$ pathway aimed at improving management and logistics of care processes. Clinical guidelines displayed goals for patients and provided the corresponding ideal sequence and timing of staff actions to achieve those goals with optimal efficiency. ${ }^{34}$ Before the introduction of Joint care ${ }^{\circledast}$ at Nij Smellinghe, cure and care for patients undergoing TKR was fragmentally organized and financed accordingly without a preventive approach. ${ }^{35}$ By optimizing the management and logistics of preventive and care processes, risk of medical errors and complications was supposed to decrease and the (cost-)effectiveness of the surgical treatment was supposed to increase. ${ }^{36}$ Consequently, cure and care in Joint care was well organized and documented in guidelines and protocols. ${ }^{36,37}$ Medical doctors, nurse practitioners, nurses, physiotherapists, and other health professionals were organized in a collaborative inter-professional team, knowing and respecting each other's specific complementary role and competences. The implementation of the Joint care ${ }^{\varpi}$ pathway for patients undergoing hip and knee replacement was indeed accompanied by a reduction in resource utilization and healthcare costs, without compromises in patient outcome parameters, according to research conducted in two other Dutch hospitals. ${ }^{4,34}$

Joint care ${ }^{\circledR}$ was designed as a clinical pathway intended for groups of patients, which implies that every patient was treated in the same manner, despite the already well-known differences between patients. To document these differences, we implemented already in 2009 a preoperative screening of functional mobility performed by a physiotherapist for all patients undergoing TKR surgery. We also started daily monitoring of inpatient recovery of activities after surgery. The main goal was to explore the course of the functional mobility of our patients around the surgical procedure. Another important goal was to objectively document the variability of our patients' preoperative functional mobility and its consequences for recovery after surgery, as suggested by Malani in 2009. ${ }^{16}$

Scrutinizing the data collected over more than two years revealed that patients were quite heterogeneous with respect to their preoperative characteristics and the speed of their postoperative short-term recovery of activities. As a consequence, we changed the care pathway for total joint replacement to accommodate the differences in the patient population by using the available pre- and postoperative data to personalize the new care pathway. From this moment on, the preoperative screening and postoperative assessment of functional mobility were integrated into the new care pathway. At the same time, we also integrated new insights into the adverse effects of hospitalization and immobility into the care pathway, as described before. These changes represented the first transition in the delivery of care for patients undergoing TKR and are documented in chapter 2. 
To personalize the care pathway, i.e. to adjust it to the potential recovery capacity of a patient, it is necessary to provide insight into the probable scenarios of the individual recovery journey of a patient undergoing TKR to both the patient and his informal caregivers as well as to the healthcare professionals. ${ }^{30,31}$ In our hospital, we therefore developed and subsequently improved models to predict a patient's speed of inpatient recovery of activities after TKR based on patient characteristics collected before surgery. ${ }^{38,39}$ In chapter 4 , we studied our ability to predict whether a patient undergoing total hip replacement is at high risk of delayed inpatient recovery. In chapter 5 we investigated whether preoperative functional mobility, in line with the findings in the total hip replacement population, is an independent determinant of delayed inpatient recovery of activities after TKR. A further improvement of the prediction model is described in chapter 6.

In addition, we want patients to be active as often and as much as possible, especially during hospitalization. ${ }^{6,21}$ Therefore, according to the literature, patients - beside becoming active throughout the day - should start with therapeutic exercise training as soon as possible, preferably on the day of surgery. ${ }^{6,10,21}$ This training should be provided within a proactive and activating culture and infrastructure on the orthopaedic ward and also at home after discharge. ${ }^{11}$ Therefore, on the orthopaedic ward catheters, drains and drips are absent or are ambulatory managed and removed as soon as possible. Moreover, during the daytime, patients are constantly working on their daily live activities, such as washing, dressing, walking, and eating, in order to be optimally prepared for an independent and safe return to their home situation. ${ }^{11}$ However, activating patients as soon as possible will only succeed when the surgical physiological stress response is reduced. Patients will probably not be able to walk or perform activities of daily life (ADL) if they have an unacceptable level of postoperative pain, unstable blood pressure, dizziness or nausea. ${ }^{7}$ To minimize these responses to surgical stress, we implemented fast-track surgery as the medical standard as a subsequent transition of the care pathway. Fast-track surgery is based on the philosophy that a surgical treatment should have minimal impact on the body and soul of the patient. ${ }^{9}$ By implementing fast-track surgery in our function-tailored care pathway, we wanted to achieve the safest and most rapid (functional) recovery possible of patients after TKR. Fast-track surgery has solutions for pain management strategies, perioperative nutritional management, reduction of anxiety, rehabilitation strategies and blood transfusion strategies. ${ }^{9}$ These state-of-the-art medical strategies and the function-tailored model of care (with a strong focus on activation of patients) are supposed to achieve a successful outcome of surgery for each patient and were therefore combined into a new care pathway at the orthopaedic ward of the Nij Smellinghe hospital. We call this third care pathway the fast-track pathway, and it is described in chapter 5 . 


\section{Practical execution of the transition}

A learning-by-doing approach and the researcher-in-residence model (embedded-science model) were used to reform the care at the orthopaedic ward of our hospital. This model of transition management is a useful and robust strategy for accelerating and guiding social innovation processes. ${ }^{40} \mathrm{~A}$ common feature of this approach is the concept of co-creating knowledge between researchers and practitioners and the use of different participatory approaches. ${ }^{41}$ These approaches share common aspects, including the desire to solve practical problems in a collaborative way and emphasis on reflection and collective inquiry. ${ }^{41}$ Embedded science is based on the premise that knowledge is collected and created "on the ground" through daily interaction and negotiation with practitioners, managers and patients about clinical problems and possible solutions. ${ }^{42}$ This embedded science model will provide better insight into the issues affecting these stakeholders, it will be more relevant to the local context, and it will therefore be more easily incorporated into changes in practice. ${ }^{42}$

\section{Research aim}

This thesis describes the development, implementation and effectiveness of the transition of care for patients undergoing TKR from Joint care ${ }^{\circledR}$ towards a function-tailored, fast-track care model. Our goal was to shift from a care process organized in a clinical care pathway that aimed at improving management and logistics of care processes towards an individualized care pathway aimed at augmenting the patient's physical activity during hospitalization, while minimizing the physiological surgical stress response. 


\section{Outline of thesis}

Chapter 2 reports on the process and the effects of the introduction of the newly developed function-tailored care pathway, compared with the Joint care pathway ${ }^{\oplus}$, for patients undergoing TKR in our hospital. The purpose of the new care pathway is to mobilize the patients as quickly and as often as possible. Moreover, the new care pathway is tailored to the patient's physical performance using systematic preoperative screening and postoperative monitoring of inpatient recovery of activities.

Chapter 3 aims, with a scoping review design, to gather insight into the state-of-the-art of SDM among patients considering, undergoing or recovering from TKR surgery. Therefore, we explored the scientific literature on the use and content of SDM in patients considering, undergoing or recovering from a TKR and compared it with a well-established shared decision model. Besides this, we want also to establish what patients considering, undergoing or recovering from TKR need and what they find important before they can participate in SDM.

Chapter 4 describes the development of a risk stratification model in patients undergoing total hip replacement. With this model it is possible to identify which patients are at increased risk of delayed inpatient recovery of activities after total hip replacement.

Chapter 5 investigates whether preoperative functional mobility is an independent determinant of delayed inpatient recovery of activities after TKR. The novel aspect of our approach is that we investigated whether the association depends on postoperative circumstances and provided perioperative care in the three time periods that coincided with clinical pathway changes.

Chapter 6 describes an improvement of the prediction model, in particular the way in which the predictions are reported. Instead of reporting the risk of delayed (or fast) recovery for a specific patient as increased or not, we report the probability of each possible outcome for that patient. The purpose of such a model is to allow a patient to better understand his chances to recover more slowly or faster than normal, compared to the result of a -black and white- risk stratification model.

Chapter 7 is the general discussion of this thesis. In this chapter we will reflect on the main results and some methodological and practical issues, followed by recommendations for daily practice and directions for future research.

Chapter 8 is a valorisation addendum and will estimate the social and economical impact of the results of this thesis for the Nij Smellinghe hospital, but also elsewhere in the Netherlands. 


\section{References}

1. Otten R, van Roermund PM, Picavet HSJ. [Trends in the number of knee and hip arthroplasties: considerably more knee and hip prostheses due to osteoarthritis in 2030]. Ned Tijdschr Geneeskd. 2010;154:A1534.

2. Hawker GA. Who, when, and why total joint replacement surgery? The patient's perspective. Curr Opin Rheumatol. 2006;18(5):526-530. doi:10.1097/01.bor.0000240367.62583.51.

3. Katz JN. Parachutes and Preferences--A Trial of Knee Replacement. N Engl J Med. 2015;373(17):1668-1669. doi:10.1056/NEJMe1510312.

4. Pilot $P$, Bogie R, Draijer WF, Verburg AD, van Os JJ, Kuipers H. Experience in the first four years of rapid recovery; is it safe? Injury. 2006;37 Suppl 5:S37-40. doi:10.1016/S0020-1383(07)70010-4.

5. van der Sluis G, Goldbohm RA, Bimmel R, et al. What augmented physical activity and empowerment can bring to patients receiving total knee replacement: content, implementation, and comparative effectiveness of a new function-tailored care pathway in a routine care setting. Biomed Res Int. 2015;2015:745864. doi:10.1155/2015/745864.

6. Hoogeboom TJ, Dronkers JJ, Hulzebos EHJ, van Meeteren NLU. Merits of exercise therapy before and after major surgery. Curr Opin Anaesthesiol. 2014;27(2):161-166. doi:10.1097/ACO.0000000000000062.

7. Husted H, Lunn TH, Troelsen A, Gaarn-Larsen L, Kristensen BB, Kehlet H. Why still in hospital after fast-track hip and knee arthroplasty? Acta Orthop. 2011;82(6):679-684. doi:10.3109/17453674.2011.636682.

8. Pitter FT, Jørgensen CC, Lindberg-Larsen M, Kehlet H. Postoperative morbidity and discharge destinations after fast-track hip and knee arthroplasty in patients older than 85 years. Anesth Analg. 2016;122(6):18071815. doi:10.1213/ANE.0000000000001190.

9. Kehlet H. Fast-track hip and knee arthroplasty. Lancet. 2013;381(9878):1600-1602. doi:10.1016/S01406736(13)61003-X.

10. Thienpont $\mathrm{E}$, Lavand'homme $\mathrm{P}$, Kehlet $\mathrm{H}$. The constraints on day-case total knee arthroplasty: the fastest fast track. Bone Joint J. 2015;97-B(10_Supple_A):40-44. doi:10.1302/0301-620X.97B10.36610.

11. Wainwright T, Middleton R. An orthopaedic enhanced recovery pathway. Curr Anaesth Crit Care. 2010;21(3):114-120. doi:10.1016/j.cacc.2010.01.003.

12. Hartog YM den, Mathijssen NM, Vehmeijer SB. Reduced length of hospital stay after the introduction of a rapid recovery protocol for primary THA procedures. Acta Orthop. 2013;84(5):444-447. doi:10.3109/17453674.2013.838657.

13. Brown CJ, Redden DT, Flood KL, Allman RM. The Underrecognized Epidemic of Low Mobility During Hospitalization of Older Adults. J Am Geriatr Soc. 2009;57(9):1660-1665. doi:10.1111/j.15325415.2009.02393.x.

14. Huber M, Knottnerus JA, Green L, et al. How should we define health? Bmj. 2011;343(jul26 2):d4163-d4163. doi:10.1136/bmj.d4163.

15. Pollard B, Dixon D, Dieppe P, Johnston M. Measuring the ICF components of impairment, activity limitation and participation restriction: an item analysis using classical test theory and item response theory. Health Qual Life Outcomes. 2009;7:41. doi:10.1186/1477-7525-7-41.

16. Malani PN. Functional status assessment in the preoperative evaluation of older adults. JAMA. 2009;302(14):1582-1583. doi:10.1001/jama.2009.1453.

17. Covinsky KE, Pierluissi E, Story THEPS. Hospitalization-Associated Disability " She Was Probably Able to Ambulate, but I' m Not Sure." J Am Med Assoc A. 2011;306(16):1782-1793. doi:10.1001/jama.2011.1556.

18. Beswick AD, Wylde V, Gooberman-Hill R, Blom A, Dieppe P. What proportion of patients report long-term pain after total hip or knee replacement for osteoarthritis? A systematic review of prospective studies in unselected patients. BMJ Open. 2012;2(1):e000435. doi:10.1186/s12891-015-0469-6.

19. Hawker GA, Badley EM, Borkhoff CM, et al. Which patients are most likely to benefit from total joint arthroplasty? Arthritis Rheum. 2013;65(5):1243-1252. doi:10.1002/art.37901.

20. Hawker GA, Croxford R, Davis AM, et al. Predictors of suboptimal patient outcome following total joint arthroplasty. Osteoarthr Cartil. 2011;19:S153.

http://www.embase.com/search/results?subaction=viewrecord\&from=export\&id=L70571783.

21. Hulzebos EHJ, van Meeteren NLU. Making the elderly fit for surgery. Br J Surg. 2015:n/a-n/a. doi:10.1002/bjs.10033.

22. No Title.

23. Falvey JR, Mangione KK, Stevens-lapsley JE. Deconditioning : 2017;95(9). 
24. Sourdet S, Lafont C, Rolland Y, Nourhashemi F, Andrieu S, Vellas B. Preventable latrogenic Disability in Elderly Patients During Hospitalization. J Am Med Dir Assoc. 2015;16(8):674-681. doi:10.1016/j.jamda.2015.03.011.

25. Kortebein P, Symons TB, Ferrando A, et al. Functional Impact of 10 Days of Bed Rest in Healthy Older Adults. 2017;63(10):1076-1081.

26. Losina E, Katz JN. Editorial: Total Joint Replacement Outcomes in Patients With Concomitant Comorbidities: A Glass Half Empty or Half Full? Arthritis Rheum. 2013;65(5):1157-1159. http://search.ebscohost.com/login.aspx?direct=true\&db=cin20\&AN=104278805\&site=ehost-live.

27. Dawes M, Summerskill W, Glasziou $P$, et al. Sicily statement on evidence-based practice. BMC Med Educ. 2005;5(1):1. doi:10.1186/1472-6920-5-1.

28. Barry MJ, Edgman-Levitan S. Shared Decision Making - The Pinnacle of Patient-Centered Care. N Engl J Med. 2012;(366):780-781. doi:10.1056/NEJMp1109283.

29. Oosting E, Dronkers J, Hoogeboom T, et al. Personal meaning in relation to daily functioning of a patient in physical therapy practice : narratives of a patient, a family member, and physical therapist. Disabil Rehabil. 2017;0(0):000. doi:10.1080/09638288.2017.1290153.

30. Hoffmann TC, Légaré F, Simmons MB, et al. Shared decision making: what do clinicians need to know and why should they bother? Med J Aust. 2014;201(1):35-39. doi:10.5694/mja14.00002.

31. Hargraves I, Montori VM. Decision aids, empowerment, and shared decision making. Bmj. 2014;349(sep25 6):g5811-g5811. doi:10.1136/bmj.g5811.

32. Gigerenzer G, Edwards A. Simple tools for understanding risks: from innumeracy to insight. BMJ Br Med J. 2003;327(7417):741-744. doi:10.1136/bmj.327.7417.741.

33. Edwards A, Elwyn G, Mulley A. Explaining risks: turning numerical data into meaningful pictures. Bmj. 2002;324(7341):827-830. doi:10.1136/bmj.324.7341.827.

34. Pilot P, Engelen M, Dreessen F. Critical pathway for hip and knee arthroplasty: Faster home due to multidisciplinary cooperation. J Integr Care Pathways. 2006;10:59-62. http://icp.sagepub.com/content/10/2/59.short.

35. Herzlinger RE, Schleicher SM, Mullangi S. Health care delivery innovations that integrate care? Yes!: But integrating what? JAMA - J Am Med Assoc. 2016;315(11):2016-2017. doi:10.1001/jama.2016.0505.

36. Segal O, Bellemans J, Van Gerven E, et al. Important variations in the content of care pathway documents for total knee arthroplasty may lead to quality and patient safety problems. J Eval Clin Pract. 2013;19(1):1115. doi:10.1111/j.1365-2753.2011.01760.x.

37. Barbieri a, Vanhaecht K, Van Herck P, et al. Effects of clinical pathways in the joint replacement: a metaanalysis. BMC Med. 2009;7:32. doi:10.1186/1741-7015-7-32.

38. Beneciuk JM, Bishop MD, George SZ. Clinical prediction rules for physical therapy interventions: a systematic review. Phys Ther. 2009;89(2):114-124. doi:10.2522/ptj.20080239.

39. Childs JD, Cleland J a. Development and application of clinical prediction rules to improve decision making in physical therapist practice. Phys Ther. 2006;86(1):122-131.

40. Loorbach D, Rotmans J. The practice of transition management: Examples and lessons from four distinct cases. Futures. 2010;42(3):237-246. doi:10.1016/j.futures.2009.11.009.

41. Marshall M, Pagel C, French C, et al. Moving improvement research closer to practice: the Researcher-inResidence model. BMJ Qual Saf. 2014;23(10):801-805. doi:10.1136/bmjqs-2013-002779.

42. Vindrola-Padros C, Pape T, Utley M, Fulop NJ. The role of embedded research in quality improvement: a narrative review. BMJ Qual Saf. 2016:bmjqs-2015-004877. doi:10.1136/BMJQS-2015-004877. 


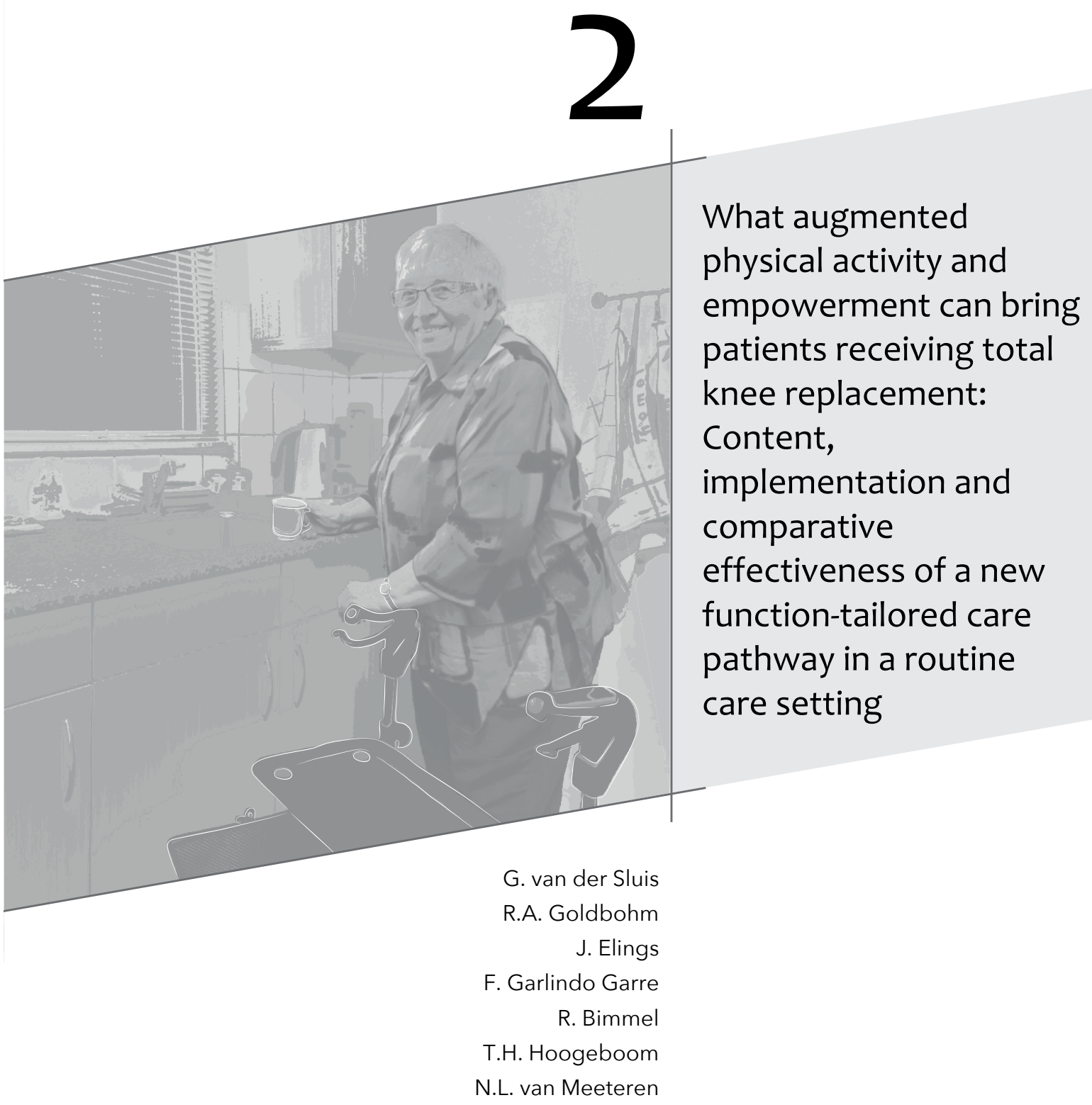

Biomedical research international (2015);

2015:745864 


\section{Abstract}

\section{Background}

In the routine setting of the 20-bed orthopaedic ward of a regional hospital in the Netherlands, we developed, implemented, and evaluated a new, function-tailored perioperative care pathway for patients receiving total knee replacement (TKR), aimed at faster functional recovery by reduction of inactivity and stimulation of self-efficacy of the patients.

\section{Methods}

To assess effectiveness, we compared, using prospectively collected data from medical files, patient groups before $(n=127)$ and after $(n=108)$ introduction of the new care pathway with respect to time to recovery of physical functioning during hospitalisation (five milestones), length of hospital stay (LoS), referrals to an inpatient rehabilitation facility, and readmissions. Multivariable regression was used to adjust results for differences between the two groups in preoperatively assessed risk factors for delayed recovery.

\section{Results}

Comparison of patient groups before $(n=127)$ and after $(n=108)$ introduction of the tailored care pathway showed that the tailored rehabilitation pathway decreased the time to recovery of physical functioning (from 4.5 to 4.1 days, $p<0.05$ ), the mean LoS (from 5.2 days to 4.2 days, $p<0.01$ ).

\section{Conclusion}

We demonstrated that the introduction of a function-tailored care pathway shortens the hospital stay and accelerates the recovery of physical functioning. 


\section{Background}

Osteoarthritis is the most common joint disorder of older people and is the most common indication for total knee replacement (TKR). ${ }^{1}$ The success of arthroplasty depends not only on effective surgery but also on adequate postoperative rehabilitation of the patient. ${ }^{2}$ Although total joint replacement is successful in the majority of patients, it is associated with serious medical risks, diminished functional capacity, and potentially persistent pain. ${ }^{3-5}$ As with all medical interventions, steps should be taken to minimise the risk of serious adverse medical events. For example, bed rest and inactivity are harmful for patients, in particular for elderly or frail patients, in terms of disability and loss of functional capacity. ${ }^{6}$ Brown et al (2009) showed that older patients are inactive $83 \%$ of the time they are hospitalised; about 20 hours a day. ${ }^{7}$ Current attitudes to hospitalisation are likely to foster inactivity and to reinforce passive coping strategies among patients.

There is a plethora of evidence demonstrating that to counterbalance prolonged hospitalisation and physical inactivity, therapists should initiate postoperative rehabilitation as soon as possible after TKR surgery. $8,9,10$ To ensure a discharge that is both timely and adequate, both therapist and patient need to monitor the patient's progress of achieving functional independence, even before the patient is admitted to the hospital. ${ }^{11}$ Ideally, such is clearly described in an interdisciplinary clinical care pathway ${ }^{12}$ and the patient is stimulated to selfmanage their recovery. ${ }^{13}$

Along these lines, we developed and implemented a new, function-tailored care pathway to rehabilitate TKR patients. The goals of the pathway are to reduce the bed rest period to 4 hours postoperatively, to set realistic short-term rehabilitation goals based on relevant functional milestones, and to improve the patient's self-efficacy by stimulating an active coping attitude and environment (staff and infrastructure) during hospitalisation. Our pathway is distinct from other care pathways, as its focus lies on the functional ability of patients undergoing surgery rather than on successful surgery and post-operative care of patients with a disease. ${ }^{14}$

In this paper, we describe the content and implementation of the function-tailored care pathway. Our aim was to study whether a function-tailored care pathway compared to the usual care situation before its introduction was able to reduce the time needed to achieve functional independence during hospital stay and length of in-hospital stay. 


\section{Patients and methods}

\section{Setting}

Nij Smellinghe, Drachten, the Netherlands, is a small regional hospital with 320 beds. The orthopaedic ward has 20 clinical beds and 150 primary TKR are performed annually. The healthcare team in charge of the treatment of patients scheduled for elective TKR and other major elective and traumatic orthopaedic surgery consists of four orthopaedic surgeons, four nurse practitioners, four physiotherapists, and thirty-five nurses.

\section{Usual care for elective TKR before implementation of the new, tailored care pathway}

The key elements of the usual care pathway were as follows. Two weeks prior to surgery patients were informed on the operation and hospital admission procedure during a group session. Preoperative screening was performed by an anaesthesiologist. All patients were admitted one day before surgery. The relevant information on the patient was collected during the preoperative screening and on the day of admission (e.g., interview about functional and social status, blood samples, relevant anaesthetic information etc.). During the hospital stay, the patient was rehabilitated according to a protocol organised as a time table, treating every patient in the same manner, "one size fits all". The inpatient rehabilitation programme consisted of training of transfers, ambulation and stair climbing.

According to this protocol, if no complications arose, each TKR patient was to be mobilised 24 hours after surgery and discharged home 4 days after the day of surgery. If availability of informal care was insufficient to allow safe return home, patients were discharged to a rehabilitation centre 4 days after surgery.

This usual care protocol was adopted from joint care ${ }^{\circledR}$ principles, which is a standard care protocol for patients undergoing total hip- and total knee surgery.

\section{The new function-tailored care pathway for elective TKR}

The elements of the newly developed function-tailored care pathway were introduction of:

1. preoperative screening of physical functioning,

2. postoperative monitoring of recovery of physical functioning,

3. fast track tailored rehabilitation,

4. communication with the patient to improve self-efficacy, and

5. improvement of collaboration, communication, and knowledge of the health professionals involved. The elements are described in more detail below. 
1. Preoperative screening of physical functioning

Physical functioning of patients was screened preoperatively by a physiotherapist at the same session as the anaesthesiologist carried out the preoperative medical screen. Physical functioning was assessed with the 6-minute walk test (6MWT), ${ }^{15}$ the Timed Up and Go test (TUG), ${ }^{16}$ and the De Morton Mobility Index ${ }^{17}$ as well as several questionnaires, i.e. the Western Ontario and McMaster Universities Arthritis Index (WOMAC), ${ }^{18}$ pain perception by use of the visual analogue scale (VAS), ${ }^{19}$ and the Identification of Seniors At Risk (ISAR). Validated instruments were used for the assessments and all physiotherapists at the orthopaedic ward were trained to apply and record these according to the guidelines on structured forms, which were included in the patient's medical file.

\section{Assessment of postoperative functional recovery during hospital stay}

Measurement of functional milestones enabled the physiotherapist to assess whether and when a patient can function independently and allowed tailoring of treatment goals to individual patients. ${ }^{20,21}$ The MILAS (Modified lowa Levels of Assistance Scale) was used daily to monitor the recovery of physical function. The data were collected according to the guidelines for the instruments, entered on structured forms and included in the patient's medical file.

\section{Fast track tailored rehabilitation}

In order to minimise postoperative immobilisation, we implemented "fast track" rehabilitation principles. ${ }^{8-10}$ From the day of surgery until discharge the patient received physiotherapy tailored to the patient's capacity to regain relevant functional activities. This was organised as follows: Patients were allowed to stay in bed for 4 hours after surgery. From day 0 (day of surgery) until discharge all patients received physiotherapy at least twice daily, including weekends. If necessary to achieve treatment goals, patients were treated more frequently. The frequency and content of the rehabilitation depended on the specific problems experienced by the patient while trying to achieve relevant functional milestones (e.g. muscle weakness, coping strategies, fear avoidance, motor learning capacities etc.) The postoperative physiotherapy consisted of: 1) Exercises to improve the range of motion of the knee joint (starts at the day of surgery); 2) muscle exercises in sitting and standing position to regain muscle feeling/power (starts day of surgery); 3) exercising the functional milestones to retrieve functional independence (assessed daily with the MILAS, starts day of surgery). 
4. Communication with the patient to improve self-efficacy

As the rationale behind the function-tailored clinical pathway was to increase patients' selfefficacy, the primary purpose of patient communication was to manage and influence patient expectations. We organised a group session two weeks before surgery, as part of the preoperative screening procedure, to inform patients about the procedures and expectations around surgery and hospitalisation and to answer questions. During hospitalisation, communication with the patient was directed at identifying patients' needs to function independently in his home environment and to achieve shared decisions between patient and health professional. A second group session was held on the second postoperative day, during which patients were involved in rehabilitation decisions after discharge. In both sessions and during individual contacts, emphasis was on encouraging patients to manage their own recovery and to have confidence in their own abilities. ${ }^{22}$

5. Improvement of collaboration, communication, and knowledge of the health professionals involved

The overall aim was to improve the expertise of the interdisciplinary team with respect to physical functioning and rehabilitation principles, and to improve collaboration and communication within the team. The process was guided by three principles: (I) value for the patient, (II) patient-specific problems (e.g., preoperative functional status, coping strategies, context, etc.) restrict involvement of each specific health profession, and (III) focus on (recovery of) physical functioning. In this new situation, the nursing staff-under the supervision of a physiotherapist- was charged with the mobilisation of patients. ${ }^{22}$

Moreover, consensus was reached on discharge criteria, namely when: 1) the orthopaedic surgeon and anaesthesiologist had completed their medical treatment; 2) functional recovery (functional milestones) was adequate for the discharge destination and 3) adequate care could be provided in time at the discharge destination.

To ensure a successful implementation of these elements, we used an implementation strategy developed by Groll et al. ${ }^{23}$ This strategy comprises four steps, with its specific interventions, in order to introduce a change in healthcare procedures: 1. orientation, 2. insight, 3. acceptation and 4. changing.

We carried out these four steps for each specific element of the new care pathway. In figure 1, the details of the complete implementation strategy and time schedule are depicted using a pat-plot. ${ }^{24}$ The first two elements of the new care pathway were implemented in April 2009, to gain insight into the characteristics of the TKR patient population, including their functional status during the perioperative period. The remaining elements, aimed at changing the delivered treatment and care, were subsequently introduced in September 2010. 


\begin{tabular}{|c|c|c|c|c|}
\hline Timeline & Physical therapist & Nursing staff & $\begin{array}{c}\text { Orthopaedic } \\
\text { surgeon }\end{array}$ & $\begin{array}{c}\text { Hospital } \\
\text { management }\end{array}$ \\
\hline January 2009 & $A^{*}$ & & & \\
\hline February 2009 & $\mathrm{~B}^{\star}$ & & & \\
\hline March 2009 & $C^{*}$ & $D^{*}$ & $D^{*}$ & \\
\hline April 2009 & $A^{\#}$ & & & \\
\hline January 2010 & & & & $\mathrm{~B}^{\#}$ \\
\hline June 2010 & $E^{*}$ & $E^{*}$ & & \\
\hline September 2010 & $C^{\#} D^{\#}$ & $C^{\#} D^{\#}$ & $C^{\#} D^{\#}$ & \\
\hline November 2010 & $\mathrm{~F}^{\star}$ & $\mathrm{F}^{\star}$ & & \\
\hline December 2010 & & & & $\mathrm{G}^{*}$ \\
\hline January 2011 & $\mathrm{H}^{*}$ & $\mathrm{H}^{*}$ & & \\
\hline March 2011 & $1^{*}$ & $1^{\star}$ & & \\
\hline June 2011 & $I^{*}$ & $1^{*}$ & & \\
\hline September 2011 & $I^{\star}$ & $I^{\star}$ & & \\
\hline
\end{tabular}

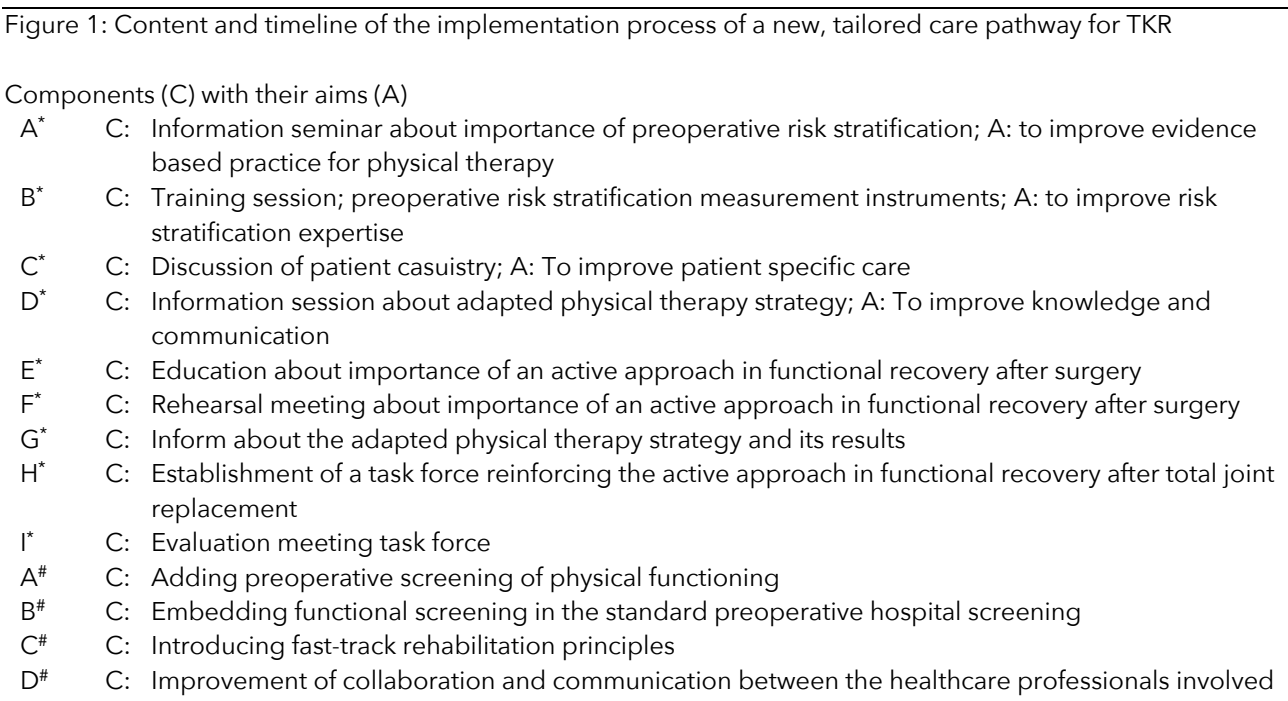

\section{Design and patients}

To evaluate the effectiveness of the new function-tailored care pathway, we used an observational cohort study design, comparing preoperative characteristics prospectively collected during the screening and outcome measures of the TKR patient groups taken in for surgery before and after introduction of the third, fourth, and fifth components of the new care pathway. Data were anonymously retrieved from the medical files of all 235 patients, except one, who underwent elective primary TKR between 1 April 2009 and 1 November 2011 ( $n=127$ 'usual' care, data from April 2009-September 2010; $n=108$ function-tailored care, data from October 2010-November 2011). As one medical file could not be retrieved at the time of data extraction, this patient was excluded. According to Dutch law review by a medical ethical committee was not required for this type of research. 


\section{Outcome measurements}

To assess effectiveness of the function-tailored care pathway we measured 1. recovery of physical functioning, defined as the time (in days) between the end of surgery to the day when physical functioning was considered regained according to MILAS (i.e., score of $\leq 6$ ); 2 . hospital LoS, defined as the time (in days) between the day of surgery to hospital discharge; 3 . the patient's discharge destination; and 4. readmission within 12 weeks of discharge.

The MILAS is a modified version of the lowa Levels of Assistance Scale (ILAS), which assesses the capability of patients to perform safely four activities of daily life (namely, supine to sit, sit to stand, walking, and stair climbing) and rates the amount of assistance needed. The MILAS adds a fifth activity, namely, the transfer from sit to supine. ${ }^{25}$ Scores range from 0 to 30 , with scores of six or lower being considered to reflect recovery of physical function. As many patients were already discharged before they were tested for their ability to climb stairs, the cut-off was set before the last MILAS milestone (i.e. stair climbing) was achieved.

To assess patient satisfaction, we also reviewed the returned questionnaires that are routinely send out to patients on the orthopaedic ward (mainly for total hip and knee replacements and hip fractures) on the day of discharge.

Furthermore, we carried out a semi-structured interview with representatives of the involved healthcare professionals (mostly two per discipline). For this semi structured interview we used the method described by Baarda et al. The interviewer (GvdS) developed and applied an 'interview guide', i.e. a list of questions and topics that need to be covered during the conversation, in a particular order. We mostly followed this guide, but followed topical trajectories in the conversation that deviated from the guide when we thought this was appropriate. Each interview was transcribed verbatim and the transcripts were coded and analysed $^{26}$. Because this qualitative research was not the main focus of this study, only a summary of important findings will be shown in the result section.

\section{Statistical analysis}

Descriptive statistics were computed for the demographic, preoperative and postoperative variables. Differences between the two patient groups were tested with independent $\mathrm{t}$ - and chi-squared tests. As in all epidemiological studies, investigation of and adjustment for confounders is an important part of the data-analysis. Based on previous research using more variables available from the same dataset, we identified a number of predictors of the outcome, in particular functional recovery. These predictors are considered potential confounders and become true confounders that have to be adjusted for if their distribution differs between the two patient groups. We used multivariable regression techniques to adjust for these differences in relevant preoperative characteristics between the two care groups. First, we used a tobit regression model to test whether the tailored care pathway was effective in reducing the number of days to recovery of physical functioning. We used this model 
because we did not have information on recovery of physical functioning after day 7; all patients with a recovery longer than 7 days were assumed to be censored. Second, an analysis of variance (ANOVA) was used to test whether the function-tailored care pathway reduced LoS. This variable was not normally distributed and thus data were logarithmically transformed to meet the model assumptions. Lastly, a logistic regression model was used to test whether the proportion of people going to a rehabilitation clinic changed after implementation of the function-tailored care pathway. To account for any differences in the risk of prolonged recovery between the two groups of patients who underwent TKR before and after implementation of the function-tailored care pathway in September 2010, determinants of this risk, namely, age, body mass index (BMI), TUG, and ISAR (manuscript in preparation) were included in the model. ${ }^{27}$ Statistical significance was set at $p<0.05$ (two sided). With 110 patients per group, we were able to detect a small to medium effect size (Cohen's $d=0.4$ ) with $80 \%$ power (alpha of 0.05, two-sided). The statistical package STATA version 11.2 (StataCorp. 2009. Statistical Software: Release 11.2. College Station, TX: Stata Corporation) was used for the analyses.

\section{Results}

\section{Comparative effectiveness}

The preoperative characteristics and postoperative outcomes of the patients who underwent TKR before and after the introduction of tailored care pathway are presented in Table 1. 


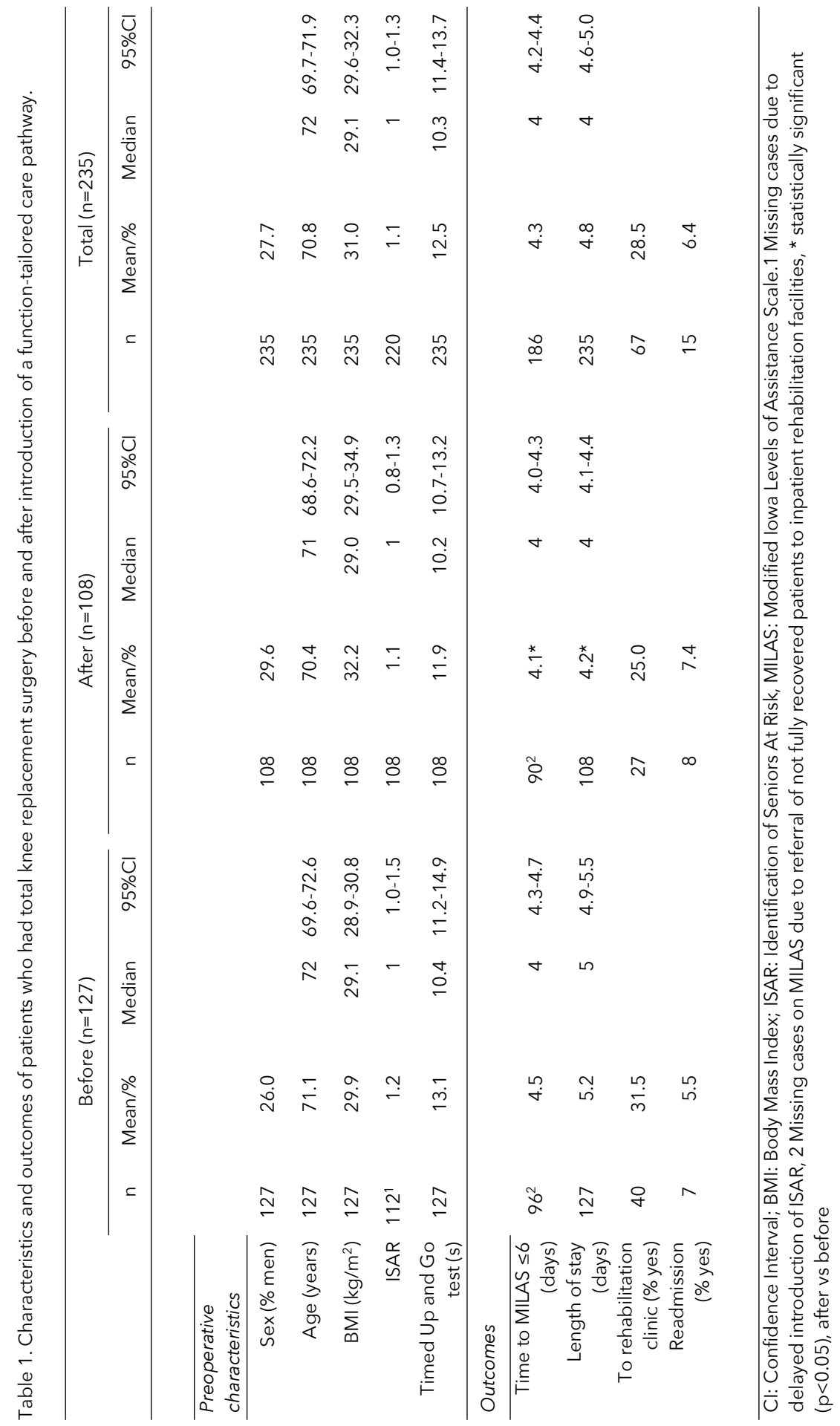


No patients were excluded, except for one patient from whom the medical record could not be found at the time of data extraction. The two groups differed in terms of recovery (time to MILAS $\leq 6)$, LoS, and referral to inpatient rehabilitation facilities, but also in some of the determinants of risk of delayed recovery, i.e. sex, age, BMI, TUG, and ISAR. The patients who received 'usual' care were older (mean 71 vs. 70 years respectively) and took longer to perform the TUG (13.1 vs. 11.9 seconds respectively); the mean BMI was higher in the tailored care group (32 vs. $30 \mathrm{~kg} / \mathrm{m}^{2}$, respectively).

Data for recovery of physical functioning after surgery, as assessed with the MILAS, were available for $79 \%$ of the patients $(76 \%$ and $83 \%$ in the 'usual' and tailored care groups, respectively). The main reason for missing data was referral of not fully recovered patients to inpatient rehabilitation facilities. The patients in the tailored care group attained a MILAS sum score of six or less 0.5 days earlier than the patients in the usual care group $(p=0.02)$ (Table 2 ).

Table 2. Difference in the number of days to functional recovery (according to MILAS $\leq 6$ ) between TKR patients undergoing surgery before $(n=111)$ and after $(n=104)$ introduction of a function-tailored care pathway, adjusted for preoperative characteristics (multivariable tobit regression analysis).

\begin{tabular}{lcrr}
\hline Independent variables & Coefficient (days) & $95 \% \mathrm{Cl}$ \\
\hline & & & -0.09 \\
After vs before & $-0.54^{*}$ & -0.99 & 0.09 \\
Age $(\mathrm{y})$ & $0.06^{\star *}$ & 0.04 & 0.10 \\
BMI $\left(\mathrm{kg} / \mathrm{m}^{2}\right)$ & $0.05^{*}$ & 0.01 & 0.54 \\
ISAR & $0.30^{*}$ & 0.07 & 0.15 \\
TUG (s) & $0.11^{\star *}$ & 0.06 & \\
\end{tabular}

BMI: Body Mass Index; ISAR: Identification of Seniors At Risk; TUG: Timed Up and Go test ${ }^{*} p<0.05,{ }^{\star *} p<0.01$

Moreover, the mean LoS was also shorter in the tailored care group (Table 3), with a $87 \%$ (exp $(-0.14)=0.87)$ decrease in the geometric mean of LoS. Without log transformation of LoS, the mean decrease amounted to 1 day (data not shown). 
Table 3. Difference in length of stay (logarithm days) between TKR patients undergoing surgery before $(n=111)$ and after $(n=104)$ introduction of a function-tailored care pathway, adjusted for preoperative characteristics (multivariable regression analysis).

\begin{tabular}{lcrr}
\hline Independent variables & Coefficient & $95 \% \mathrm{Cl}$ \\
\hline & & -0.200 & -0.080 \\
After vs before & $-0.140 * *$ & -0.000 & 0.008 \\
Age (y) & 0.004 & -0.001 & 0.011 \\
BMI $\left(\mathrm{kg} / \mathrm{m}^{2}\right)$ & 0.005 & 0.054 & 0.114 \\
ISAR & $0.084^{*}$ & -0.010 & 0.001
\end{tabular}

BMI: Body Mass Index; ISAR: Identification of Seniors At Risk; TUG: Timed Up and Go test * $p<0.05,{ }^{\star \star} p<0.01$

The tailored care pathway was not associated with a change in the probability of discharge to a rehabilitation facility (odds ratio $0.64,95 \% \mathrm{Cl} 0.32-1.26$ ). Lastly, there were 7 (5.5\%) and 8 $(7.4 \%)$ readmissions in the usual and tailored care groups, respectively (non-significant) (Table $4)$.

Table 4. Differences in the probability of referral to inpatient rehabilitation facilities between TKR patients undergoing surgery before $(n=111)$ and after $(n=104)$ the introduction of a function-tailored care pathway, adjusted for preoperative characteristics (multivariable logistic regression).

\begin{tabular}{|c|c|c|c|}
\hline Independent variables & Odds Ratio & \multicolumn{2}{|c|}{$95 \% \mathrm{Cl}$} \\
\hline After vs before & 0.64 & 0.32 & 1.26 \\
\hline Age (y) & $1.12^{\star \star}$ & 1.06 & 1.18 \\
\hline BMI $\left(\mathrm{kg} / \mathrm{m}^{2}\right)$ & 1.02 & 0.98 & 1.05 \\
\hline ISAR & 1.07 & 0.78 & 1.47 \\
\hline TUG (s) & 1.05 & 0.99 & 1.12 \\
\hline
\end{tabular}

BMI: Body Mass Index; ISAR: Identification of Seniors At Risk; TUG: Timed Up and Go test * $p<0.05,{ }^{\star \star} p<0.01$

Differences between the two care groups in recovery of physical functioning and LoS did not vary significantly across categories of the baseline variables (age, gender, BMI, TUG, and ISAR, data not shown). The returned patient questionnaires (response rate 23\%) showed no difference in patient satisfaction between the two care pathways (data not shown). 


\section{Acceptance by the staff}

Analysis of the semi-structured interviews for the health professionals revealed that orthopaedic surgeons were surprised that screening patients' physical functioning before surgery could contribute to a tailored and therefore more efficient discharge policy of the patient. They also found that setting functional goals considerably improved the care and recovery of patients who had undergone TKR. Nurse practitioners mentioned similar aspects and added that they experienced a greater responsibility for the perioperative care and discharge planning of patients undergoing TKR. Physiotherapists mentioned the increased focus on measurable physical functioning and the interdisciplinary responsibility for patients' functional recovery as most important benefit of the new care pathway. The nursing staff was positive about the extension of their job description with basic tasks aimed at patient rehabilitation, although some nurses doubted their ability to perform these tasks.

\section{Discussion}

We found that changing from "one size fits all" perioperative care to tailored care using functional goals for patients undergoing TKR accelerated the recovery of physical functioning on average by 0.5 day and shortened the LoS. The shortened LoS was not achieved at the expense of significantly more referrals to inpatient rehabilitation facilities, significantly more readmissions, or patient satisfaction. In addition, healthcare professionals were positive about the tailored care pathway, feeling that it improved patient care.

This study is performed in regular practice, which means that there is no selection of patients. This is an important strength of this study which means that one can implement such innovative pathway developments in regular practice. Another strength of this study is that the data used in the analyses, with the exception of the interviews with the health professionals, came from data collected as part of routine care. The availability of preoperative baseline information, prospectively collected with validated instruments according to scientific standards at the preoperative functional screening, and availability of well-monitored outcome information made it possible to apply a valid epidemiological study design. This shows that well-kept, up-to-date patient records that include relevant baseline data can form a source of information to monitor the effectiveness of changes in routine medical care and management. 
Our study had several limitations:

- Postoperative complications that did not result in hospital readmission and outcomes after hospital discharge (in particular functioning and quality of life) were not monitored, although this information is important for assessing the longer-term effectiveness of the new tailored care pathway. ${ }^{28}$

- We formally monitored compliance with two of the key elements of the care pathway, i.e. preoperative screening and postoperative milestones and monitored the last key element (i.e. team mission) qualitatively. Unfortunately, we did not extract data from the medical file on time elapsed between completion of surgery and start of mobilisation (key element 3 ), nor did we have sufficient data on compliance with key element 4, i.e. enhancement of selfefficacy.

- We evaluated patient satisfaction using the standard patient evaluation questionnaire that is routinely administered on the orthopaedic ward on the day of discharge, but the response rate was low because not all patients received the questionnaire. Patient satisfaction should be re-evaluated in a future study.

- Although we were able to adjust the differences in outcome between the two patient groups for the most important confounders, we cannot exclude some residual confounding by unmeasured factors.

Because of the increased awareness that a successful functional outcome of TKR and a shorter LoS are achievable, health care professionals are interested in clinical pathways with fast track approaches. Our new care pathway for TKR patients focused only on the early and more intensive mobilisation approach.

A challenge for the near future is to investigate if and how patients at risk for a prolonged functional recovery would benefit, with faster recovery, from state of the art perioperative physiotherapy, anaesthesiology and nutritional interventions. ${ }^{8,25,29}$ As effect of these interventions, we expect that a larger number of patients could be mobilized according to the fast track rehabilitation protocol. 8,9,10,29 This might be particularly relevant to the older and fragile patients, as long hospitalisation is especially harmful to them. ${ }^{6}$

In conclusion, we demonstrated that the introduction of a new TKR care pathway, focused more systematically on functional recovery of patients, speeded recovery of physical functioning and shortened the hospital stay. The shortened LoS was not achieved at the expense of significantly more referrals to inpatient rehabilitation facilities, significantly more readmissions, or patient satisfaction. In addition, the staff found working in an interdisciplinary team with shared goals, commitment, and insight into healthcare processes to be fulfilling. Furthermore we showed that evaluation of innovations in health care are feasible in a routine care setting and should be encouraged. 


\section{References}

1. Hawker GA: Who, when, and why total joint replacement surgery? The patient's perspective. Curr Opin Rheumatol 2006, 18(5):526-530.

2. Stevens M, van den Akker-Scheek I, Spriensma A, Boss NA, Diercks RL, van Horn JR: The Groningen Orthopedic Exit Strategy (GOES): a home-based support program for total hip and knee arthroplasty patients after shortened hospital stay. Patient Educ Couns 2004, 54(1):95-99.

3. Wylde V, Dieppe P, Hewlett S, Learmonth ID: Total knee replacement: is it really an effective procedure for all? Knee 2007, 14(6):417-423.

4. Kirksey M, Chiu YL, Ma Y, Della Valle AG, Poultsides L, Gerner P, Memtsoudis SG: Trends in in-hospital major morbidity and mortality after total joint arthroplasty: United States 1998-2008. Anesth Analg 2012, 115(2):321-327.

5. Beswick AD, Wylde V, Gooberman-Hill R, Blom A, Dieppe P: What proportion of patients report long-term pain after total hip or knee replacement for osteoarthritis? A systematic review of prospective studies in unselected patients. BMJ Open 2012, 2(1):e000435.

6. Kortebein P, Ferrando A, Lombeida J, Wolfe R, Evans WJ: Effect of 10 days of bed rest on skeletal muscle in healthy older adults. JAMA 2007, 297(16):1772-1774.

7. Brown CJ, Redden DT, Flood KL, Allman RM: The underrecognized epidemic of low mobility during hospitalization of older adults. J Am Geriatr Soc 2009, 57(9):1660-1665.

8. Kehlet H: Fast track hip and knee surgery. Lancet 2013 May 11, 381(9878):1600-1602

9. Kehlet H: Multimodal approach to postoperative recovery. Curr Opin Crit Care 2009, 15(4):355-358.

10. Husted H, Lunn TH, Troelsen A, Gaarn-Larsen L, Kristensen BB, Kehlet H: Why still in hospital after fast-track hip and knee arthroplasty? Acta Orthop 2011, 82(6):679-684.

11. Malani PN. Functional status assessment in the preoperative evaluation of older adults. JAMA. 2009;302:1582-1583

12. Barbieri A, Vanhaecht K, Van Herck P, Sermeus W, Faggiano F, Marchisio S, Panella M: Effects of clinical pathways in the joint replacement: a meta analysis. BMC Medicine 2009, 7:32

13. Huber M, Knottnerus JA, Green L, Van der Horst H, Jadad AR, Kromhout D, Leonard B, Lorig K, Loureiro MI, Van der Meer JWM, Schnabbel P, Smith R, Van Weel C, Smid H: How should we define health? BMJ 2011, 343:d4163

14. Beard JR, Bloom DE: Towards a comprehensive public health response to population ageing. Lancet 2014, pii: S0140-6736(14)61461-6.

15. Enright PL, Sherrill DL: Reference equations for the six-minute walk in healthy adults. Am J Respir Crit Care Med 1998, 158(5 Pt 1):1384-1387.

16. Podsiadlo D, Richardson S: The timed "Up \& Go": a test of basic functional mobility for frail elderly persons. J Am Geriatr Soc 1991, 39(2):142-148.

17. Jans MP, Slootweg VC, Boot CR, de Morton NA, van der Sluis G, van Meeteren NL: Reproducibility and validity of the Dutch translation of the de Morton Mobility Index (DEMMI) used by physiotherapists in older patients with knee or hip osteoarthritis. Arch Phys Med Rehabil 2011, 92(11):1892-1899.

18. Roorda LD, Jones CA, Waltz M, Lankhorst GJ, Bouter LM, van der Eijken JW, Willems WJ, Heyligers IC, Voaklander DC, Kelly KD, Suarez-Almazor ME: Satisfactory cross cultural equivalence of the Dutch WOMAC in patients with hip osteoarthritis waiting for arthroplasty. Ann Rheum Dis 2004, 63(1):36-42.

19. Gallagher EJ, Bijur PE, Latimer C, Silver W: Reliability and validity of a visual analog scale for acute abdominal pain in the ED. Am J Emerg Med 2002, 20(4):287-290.

20. Jesudason C, Stiller K: Are bed exercises necessary following hip arthroplasty? Aust J Physiother 2002, 48(2):73-81.

21. Shields RK, Enloe LJ, Evans RE, Smith KB, Steckel SD: Reliability, validity, and responsiveness of functional tests in patients with total joint replacement. Phys Ther 1995, 75(3):169-76; discussion 176-9.

22. Wainwright $T$, Middleton $R$, An orthopaedic enhanced recovery pathway. Current anaesthesia \& critical care 2010, 21: 114-120

23. Grol R, Grimshaw J: From best evidence to best practice: effective implementation of change in patient care. Lancet 2003, 362(9391): 1225-1230).

24. Perera R, Heneghan C, Yudkin P: Graphical method for depicting randomised trials of complex interventions. BMJ 2007, 334(7585):127-129. 
25. Oosting E, Jans MP, Dronkers JJ, Naber RH, Dronkers-Landman CM, Appelman-de Vries SM, van Meeteren NL: Preoperative home-based physical therapy versus usual care to improve functional health of frail older adults scheduled for elective total hip arthroplasty: a pilot randomized controlled trial. Arch Phys Med Rehabil 2012, 93(4):610-616.

26. Baarda DB, de Goede MPM, Teunissen J; Qualitative research, practical guideline for the design and performance of qualitative research (kwalitatief onderzoek, praktische handleiding voor het opzetten en uitvoeren van kwalitatief onderzoek) Groningen / Houten: Wolters-Noordhoff: 2005

27. antaguida PL, Hawker GA, Hudak PL, Glazier R, Mahomed NN, Kreder HJ, Coyte PC, Wright JG. Patient characteristics affecting the prognosis of total hip and knee joint arthroplasty: a systematic review. Can J Surg. 2008 Dec;51(6):428-36.

28. Marang-van de Mheen PJ, van Duijn-Bakker N, Kievit J: Adverse outcomes after discharge: occurrence, treatment and determinants. Qual Saf Health Care 2008, 17(1):47-52.

29. Hoogeboom TJ, Oosting E, Vriezekolk JE, Veenhof C, Siemonsma PC, de Bie RA, van den Ende CH, van Meeteren NL: Therapeutic validity and effectiveness of preoperative exercise on functional recovery after joint replacement: a systematic review and meta-analysis. PLoS One 2012, 7(5):e38031. 


\section{Abstract}

\section{Objective}

To gain insight into the current state-of-the-art of shared decision making (SDM) during decisions related to care process surrounding primary total knee replacement (TKR).

\section{methods}

A systematic scoping review was performed to gain insight into (1) the needs and preferences of patients in SDM (qualitative studies), (2) interventions that are being employed to support SDM (quantitative studies), and (3) Are relevant factors related to the patients' needs and preferences to make healthcare decisions taken into account in SDM (qualitative vs. quantitative).

\section{results}

From qualitative studies ( $n=7$ ), we identified four themes regarding the decision of patients to have TKR or not: 1) personal factors, 2) external factors, 3) utilized information sources, and 4) preferences towards outcome prediction. The quantitative studies $(n=6)$ showed heterogeneous effects of how decision aids impact patients' ideas about TKR. Patients' needs and preferences were hardly taken into account in SDM processes.

\section{Conclusion}

The limited scope in which SDM is being employed in TKR patients and the lack of accounting for patients' needs and preferences might explain the conflicting study results among the available effect studies.

\section{Practical implication}

The merit of SDM in real world practice is currently unknown as the literature fails to properly study this. 


\section{Introduction}

We constantly make decisions, either implicitly or explicitly, not just about daily health and (physical) functioning. However, if we make decisions in a healthcare setting, shared decision making (SDM) is typically considered to be the norm. ${ }^{1}$ Several definitions for SDM exist. They all have in common that patients and healthcare professionals collaborate in making decisions regarding health and healthcare by incorporating patient values, expectations and preferences, $^{2-5}$ as well as using the best available evidence in their decisions. ${ }^{6}$ SDM is considered most valuable if more than one reasonable path forward exists (including "doing nothing"). ${ }^{1}$ A clear example is the decision to have total knee replacement surgery (TKR). Despite the fact that this procedure is frequently performed, long-term outcomes are not always favourable. Hawker et al. (2013) demonstrated, in a frail and older cohort, that half of the individuals who underwent TKR did not experience a clinically meaningful improvement. ${ }^{7}$ Moreover, Beswick et al. (2012) showed that 10-34\% of people who underwent TKR still report moderate to severe chronic pain at a time when recovery should have been achieved. ${ }^{8}$ Furthermore, alternative interventions to TKR are emerging, like exercise interventions, ${ }^{9}$ or joint distraction. ${ }^{10}$ Thus, choosing whether or not to have a TKR is complex.

Interestingly, orthopaedic surgeons are typically the ones making these difficult decisions, while some suggest that the introduction of SDM will most likely improve the decision making process and perhaps the experienced outcomes of this decision ${ }^{11-13}$ However, when introducing SDM into the practice of TKR, a broader conceptualization and measurement of SDM - instead of solely the decision to have TKR or not - seems necessary. ${ }^{4}$ SDM is a continuum of collaboration and deliberation regarding important health, functioning and healthcare decisions and not just an intervention that takes place at a certain time point. ${ }^{3}$ In 2012, Elwyn et al. proposed a three-stage model to support the application of SDM in clinical practice, covering the entire process of collaboration and deliberation, namely: (1) choice talk, (2) option talk and (3) decision talk. ${ }^{3}$ Choice talk refers to the step of making sure that patients know that several reasonable options are available. Option talk refers to providing more detailed information about specific options and their consequences and decision talk refers to supporting the work of considering preferences and deciding what seems to be best. ${ }^{3}$

To date, little is known about which elements from the SDM model are utilized in the patient care before, during and after TKR and to what extent SDM in TKR matches patients' decisional preferences and needs. Therefore, we aim to gather broad insight in the state-ofthe-art of SDM in patient considering, choosing, preparing for and/or recovering from TKR surgery. 
To do so, we performed a scoping review and formulated the following three research questions:

- Which themes can be identified regarding the needs and preferences of patients going through SDM when they are considering, preparing and/or recovering from TKR surgery?

- How are patients and healthcare providers supported during the SDM processes, regarding the three key decision moments before and after TKR? Which steps of Elwyn's SDM model (2012) ${ }^{3}$ can be identified? What is the rationale for SDM and what are the effects of SDM?

- Are the needs and preferences of patients (research question 1), taken into account in the process and content of SDM as found in the studied articles included in research question 2 ?

\section{Methods}

Our scoping review followed the five methodological steps described by Arksey et al. ${ }^{14}$ In this review we will focus on three key moments where SDM could be used during the care process for TKR: 1) the decision to undergo surgery or not, 2) the decision regarding how to prepare for surgery, 3) the decision regarding how/where to recover after surgery.

\section{Search strategy, identifying of relevant studies}

To include relevant studies, we used a broad search strategy consisting of a search string that identified all studies related to TKR. Then a separate search string was built related to SDM. This SDM search string was adopted from a Cochrane review of Légaré et al. ${ }^{15}$ As a last step in our search strategy, we combined search terms related to TKR and terms related to SDM (see Appendix 1). We included published, unpublished and in-progress studies through February 8th 2017 in the electronic databases MEDLINE, Embase, CINAHL, PsychINFO and the Cochrane library. Additionally, reference tracking was performed in all included articles. There were no language or geographical restrictions. We included all studies that aimed to study or describe SDM processes in adults who are considering, preparing for, or recovering from elective primary TKR. Records were managed using Endnote X8. 


\section{Study selection}

Studies that described SDM before and after TKR surgery and contained original data were included in the final analysis. Due to the nature of the first research question, we only included studies with a qualitative study design and due to the nature of the second research question, we only included clinical trials or cohort studies. Systematic reviews were excluded, as they could contain information from original studies that were already included. Moreover, studies that investigated SDM in orthopaedics wherein patients undergoing TKR were not treated or analysed as a separated group were excluded.

First, two reviewers (GS and JJ) independently conducted the eligibility screening of the articles. Initially, articles were screened for eligibility on their title and abstract. If the title and abstract implied that an article was potentially eligible for inclusion, a full paper copy of the report was obtained. Second, the same reviewers independently assessed the full text articles to determine their eligibility.

\section{Data extraction and analysis}

Both reviewers (GS and $\mathrm{JJ}$ ) independently charted the data from eligible studies using a standardized data charting form.

To gain insight into the study characteristics, the following data were extracted from all studies: 1) General: author(s), type of publication and country of origin; 2) Study characteristics: aims/objectives of the study, study design (including control groups, if any), in- and exclusion criteria; 3) Participants: population type and setting, eligibility criteria, number of participants, and baseline characteristics (i.e., age, gender, and ethnicity); 4) Features of SDM and underlying rationale; and 5) Main findings and outcome variables of the study.

Research question 1: What are the needs and preferences of potential patients undergoing TKR?

To answer our first research question -we used principles of meta-ethnography to synthesize data from the qualitative studies that we selected for answering this question. ${ }^{16}$ First, GS developed the framework of concepts and themes, based on study data and pertinent discussion points. Subsequently, JJ independently reviewed the studies and further developed the framework. We used NVivo version 11 software to synthesize the research themes. Finally with TH, MF and MNvdS (experienced in qualitative research and scientific and practical application of SDM processes) we checked, discussed and adjusted the derived concepts and themes for clinical meaningfulness and face validity in an iterative process of several rounds until we reached consensus. GS and JJ independently assessed the methodological quality of the qualitative studies using the Critical Appraisal Skills Programme (CASP) score criteria [CASP Checklists (URL Used) Oxford (2014)]. 


\section{Research question 2: How is SDM supported before and after surgery?}

To extract relevant information from the quantitative studies regarding our second research question, we initially organized the eligible literature according to the three steps of the model of Elwyn et al. ${ }^{3}$ and extracted relevant study information (e.g., rationale of study, content of the SDM process, at what time point provided, purpose of SDM, outcome of study). Moreover, for the quantitative studies, GS and JJ independently assessed the methodological quality by using Hoy's risk of bias tool. ${ }^{17}$ Any discrepancies between the two reviewers were resolved in a consensus meeting. Furthermore, we narratively described the findings and effects of the interventions to support SDM.

\section{Research question 3: To what extent are patient needs and preferences considered in SDM?}

To determine to what extent the quantitative studies (RQ2) are informed by the qualitative data (RQ1), GS and JJ independently extracted relevant information regarding the content of the SDM methods and concepts used in the quantitative studies. Each of the studies that described content of SDM was rated (yes, partly or no) on how well it covered the main themes that were derived from the meta-synthesis from research question 1. This rating is presented in a table. Any discrepancies between the two reviewers were resolved in a consensus meeting.

\section{Results}

Our initial search yielded 3,780 titles and after removing the duplicates $(n=468)$ we screened the titles and abstracts of 3,312 articles. All disagreements $(n=61)$ were resolved by a consensus meeting between the two reviewers. After reading of 57 potentially relevant studies, finally 13 studies met the inclusion criteria and were included in the scoping review. From these 13 studies, we found seven studies for answering our first research question and six studies for answering our second research question (see Figure 1). 


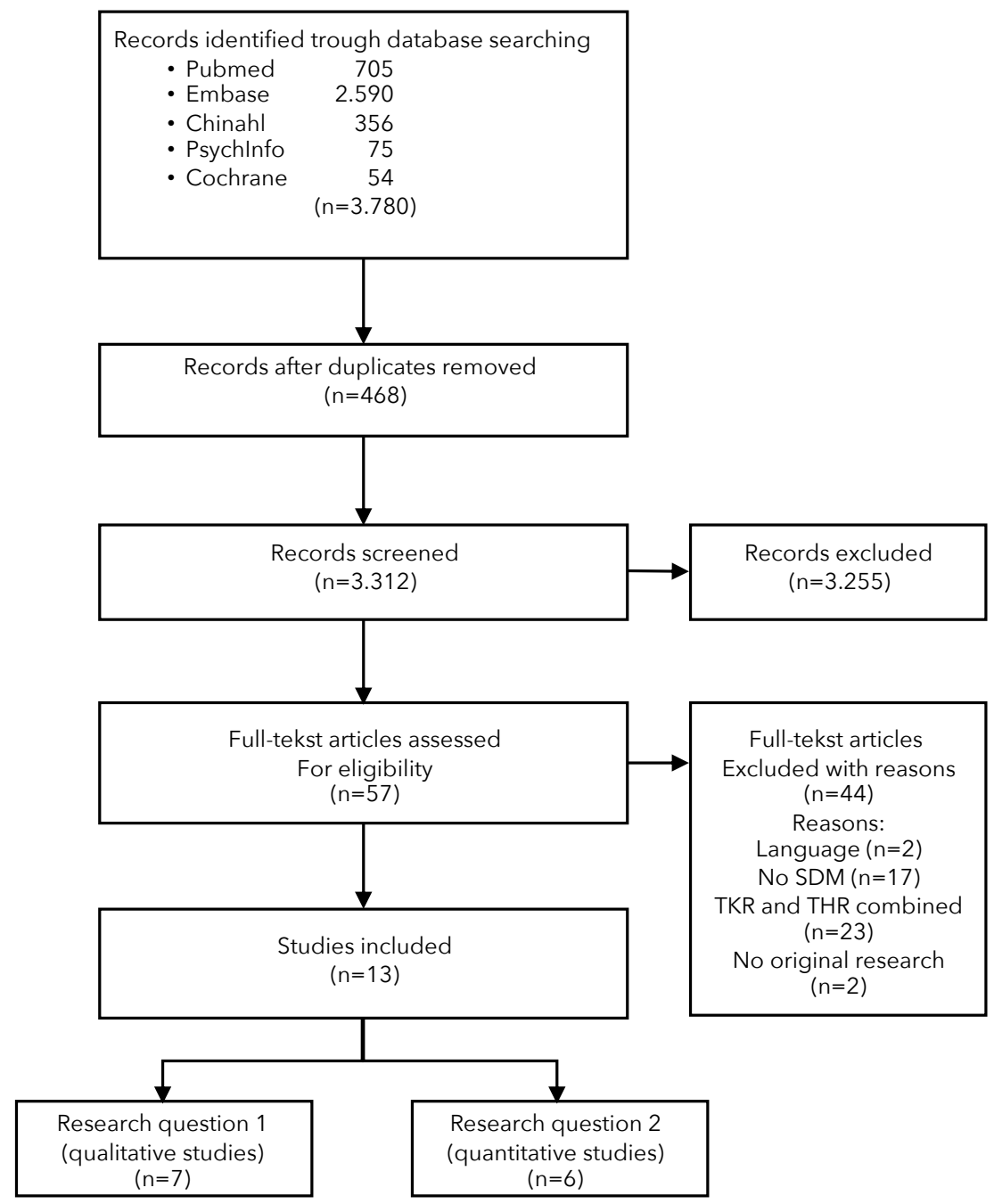

Figure 1. PRISMA flowchart diagram for study selection

\section{Study characteristics}

Our search yielded seven qualitative studies, ${ }^{18-24}$ three observational studies, ${ }^{25-27}$ and three randomized controlled trials (RCTs). ${ }^{28-30}$ The seven qualitative studies involved a total of 152 participants, the three observational studies a total of 3,797 participants, and the three RCTs a total of 654 participants. All studies focussed on the decision to have TKR or not. No studies were found on the decisions regarding how to prepare for surgery, whether to go home after surgery or whether to partake in rehabilitation after surgery. 
Seven of the 13 studies explored patient capacity, needs or preferences regarding the participation in an SDM process for TKR surgery. ${ }^{18-24}$ Six studies analysed the effect of a decision aid regarding whether or not to undergo TKR surgery. ${ }^{25-30}$ More detailed information about inclusion of patients and study aims and rationales of the included studies are described in Table 1.

Table 1a. Characteristics of the included manuscript to answer question 1; Which factors support the decisional skills and / or capacity of patients considering, choosing, preparing and/or recovering from TKR surgery?

\begin{tabular}{|c|c|c|c|c|}
\hline $\begin{array}{l}\text { Authors, } \\
\text { year of } \\
\text { publication }\end{array}$ & $\begin{array}{l}\text { Population, inclusion } \\
\text { criteria participants; } \\
\text { Age (SD, range); } \\
\text { gender (\%); Ethnicity }\end{array}$ & Aim of study & $\begin{array}{l}\text { Study } \\
\text { design }\end{array}$ & authors conclusions \\
\hline
\end{tabular}

Al

Taiar,2013

Female patients on the waiting list for TKA in Kuwait; 39; 62 (7.9); female (100\%); Arabic.
Study of pain experience, and mobility limitations as well as the patient decision among woman on the waiting list for TKR surgery.
Barlow, 2016 Focus groups with patients after TKR and in depth interviews with patients considering TKR; 12 in focus group and 10 in in-depth interviews; 65,5; female (45\%); British, Asian.

Ho, 2015
An elderly patient with cognitive limitations with a symptomatic right knee; 1 ; 77; one female; American.
Examination how individual predictions of outcome could affect patients decision making by providing fictions predictions to patients at different stages of treatment.

Establishing the decisional capacity of elderly patients and providing a capacity adjusted approach to SDM.
Qualitative Both verbal and written study information about TKA In depth should be provided as part interviews. of preoperative rehabilitation. This is critical to improve doctor-patient interactions and facilitate informed decision about the procedure and thus achieve patient-centered healthcare.

Qualitative An outcome prediction tool study has the most effect targeted In depth towards people at the start interviews. of their treatment pathway, with a "bottom line" prediction of outcome.

$\begin{array}{ll}\text { Case } & \text { Whit respect for autonomy } \\ \text { report. } & \text { demands support for } \\ & \text { patient participation and } \\ \text { decision making in their } & \text { own care, many elderly } \\ & \text { patients demonstrate } \\ & \text { questionable } \\ \text { understanding and/ or } \\ \text { desire in making healthcare } \\ \text { decisions. }\end{array}$




\begin{tabular}{|c|c|c|c|c|}
\hline $\begin{array}{l}\text { Authors, } \\
\text { year of } \\
\text { publication }\end{array}$ & $\begin{array}{l}\text { Population, inclusion } \\
\text { criteria participants; } \\
\text { Age (SD, range); } \\
\text { gender (\%); Ethnicity }\end{array}$ & Aim of study & $\begin{array}{l}\text { Study } \\
\text { design }\end{array}$ & authors conclusions \\
\hline
\end{tabular}

Kesternich, Hypothetical patients 2016 diagnosed with knee OA; n/a; n/a; n/a.

Yeh, 2016

Older adults (1) diagnosed with knee OA and recommended by their physicians to undergo TKA, (2) in decision about the surgery, (3) 60 years old, and (4) able to communicate; 26; 73.6 years old (SD 1/4 6.9, range $1 / 461-86)$; female $(76,9 \%)$;

Taiwanese.
To analyze the effect of personalized outcome probabilities on treatment decisions.

To explore factors related to the indecision of older adults with knee osteoarthritis (OA) about receiving physicianrecommended total knee arthroplasty (TKA) and their needs during the decision-making process.
Suarez- Physician diagnosis of Almazor, 2010 knee osteoarthritis; no previous knee replacement; race (African-American and non-Hispanic,

Hispanic, or white and non-Hispanic); age (55 to 80 years); 37 ; $\mathrm{n} / \mathrm{a}$; female $(62,1 \%)$; 13 white, 15 AfricanAmerican, 9 Hispanic.

Qualitative Patient specific outcome study forecasts significantly Internet influenced decisions with survey. effect sizes comparable to those of physicians opinion and patient testimonials.

Qualitative Subjects were undecided study about whether to undergo In depth physician-recommended interviews. TKA due to treatmentrelated, physical conditionrelated, surgery-related, and postsurgical care concerns.

When a TKA is recommended, physicians must also educate patients about preparations for surgery, postsurgical care, rehabilitation, and medicines while they are deciding whether to undergo knee-replacement surgery.

To conduct a qualitative analysis of decisionmaking factors influencing preferences for TKA in patients with knee osteoarthritis.
Qualitative study In depth interviews.
Patient experiences, fears, and expectations, and physician trust are prominent factors influencing decision making. An open doctorpatient is important to achieve satisfactory shared decision-making for TKA. Doctor-patient interactions and subsequent patient decision-making could be improved by developing and using decision aids for patients, and educating physicians about patient concerns and expectations. 


\begin{tabular}{|c|c|c|c|c|}
\hline $\begin{array}{l}\text { Authors, } \\
\text { year of } \\
\text { publication }\end{array}$ & $\begin{array}{l}\text { Population, inclusion } \\
\text { criteria participants; } \\
\text { Age (SD, range); } \\
\text { gender (\%); Ethnicity }\end{array}$ & Aim of study & $\begin{array}{l}\text { Study } \\
\text { design }\end{array}$ & authors conclusions \\
\hline Kroll, 2007 & $\begin{array}{l}\text { Inclusion: physician } \\
\text { diagnosis of knee OA, } \\
\text { no previous knee } \\
\text { replacement, } \\
\text { selfreported etnic } \\
\text { backgound african } \\
\text { american non- } \\
\text { hispanic, hispanic, } \\
\text { white non-hispanic, } \\
\text { age 55-80, english } \\
\text { language proficiency; } \\
37 ; 64 \text { (no SD); female } \\
\text { (62,1\%); African- } \\
\text { American non- } \\
\text { Hispanic, Hispanic, } \\
\text { white non-Hispanic. }\end{array}$ & $\begin{array}{l}\text { To identify decision } \\
\text { making factors } \\
\text { influencing ethnic } \\
\text { preferences for TKA in } \\
\text { patients with knee OA. }\end{array}$ & $\begin{array}{l}\text { Qualitative } \\
\text { study }\end{array}$ & $\begin{array}{l}\text { Patient attitudes and beliefs } \\
\text { vary among ethnic groups. } \\
\text { There is a need for open } \\
\text { patient-doctor } \\
\text { communication around } \\
\text { individual experiences and } \\
\text { beliefs in an effort to } \\
\text { enhance decision making } \\
\text { for TKA. }\end{array}$ \\
\hline
\end{tabular}


Table 1b. Characteristics of the included manuscript for research question 2: How are SDM processes supported among patients, regarding the three key decision moments before and after TKR

\begin{tabular}{|c|c|c|c|}
\hline $\begin{array}{l}\text { Authors, } \\
\text { year of } \\
\text { publication }\end{array}$ & $\begin{array}{l}\text { Population, inclusion } \\
\text { criteria; Number of } \\
\text { participants; Age (SD, } \\
\text { range); gender } \\
\text { (\%);gender; Ethnicity }\end{array}$ & Aim of study & Study design \\
\hline
\end{tabular}

$\begin{array}{ll}\text { Arterburn, } & \text { Patients with knee or hip } \\ 2012 & \text { osteoartitis (cf ICD-9), } \\ & \text { over } 45 \text { years of age; } \\ & 3510 ; 65.0(11.1) ; \text { female } \\ & (62 \%) ; n / a .\end{array}$

Filardo, Patients who underwent 2017

de Achaval, Patients medically 2012 appropriate for a TKR; 208; 62.8 (9.0); female (68\%); 66\% white, $24 \%$ black, 7\% Hispanic and $3 \%$ other. TKA between 2011 and 2015 in one hospital in Italy; 176; 66 (9); female $(68,2 \%) ; n / a$.

\section{To examine the} associations between introducing decision aids for elective hip and knee replacement and changes in rates of surgery and costs of care.

To evaluate if a more active role in the patient decision making preference may be correlated with a more successful outcome in patients undergoing TKR.

To evaluate the impact of different decision aids, on patients decisional conflict associated with TKA surgery.
Observation al study.

Observation al study.

Randomized controlled trial.

Randomized controlled trial. decision aid improve access to total knee replacement surgery for black patients with OA of the knee.
The introduction of decision aids was associated with 38\% fewer knee replacements and $12-21 \%$ lower costs over 6 months.

The control preference of patients undergoing TKA is correlated with the final outcome.

Audiovisual patient decision aid decreased decisional conflict more than printed material alone, or than the addition of a more complex Adaptive Conjoint Analysis (ACA) tool.

The use of a knee decision aid increased the receipt of TKR within 12 months by $85 \%$, compared to the control group. 


\begin{tabular}{|c|c|c|c|c|}
\hline $\begin{array}{l}\text { Authors, } \\
\text { year of } \\
\text { publication }\end{array}$ & $\begin{array}{l}\text { Population, inclusion } \\
\text { criteria; Number of } \\
\text { participants; Age (SD, } \\
\text { range); gender } \\
\text { (\%);gender; Ethnicity }\end{array}$ & Aim of study & Study design & Main findings \\
\hline
\end{tabular}

Volkmann, Eligible participants

$2015 \quad$ were between 55-85 years of age, able to speak and read English, and had moderate to severe knee OA, (score of $>39$ on the WOMAC). Exclusion criteria: included: $\geq 3$ Charlson comorbidity index, or a single specific comorbidity (dementia, stroke with residual plegia or paresis, cancer (other than skin) and/or end-stage liver disease. Patients reporting a history of inflammatory arthritis, recent significant knee trauma, residence in a nursing home or prior hip or knee replacement surgery were also excluded; 111; Female 72 (8.2), male 70 (9.6); female $(63,1 \%) ; n / a$.

\section{Stacey, Eligible knee OA} patients were those with access to a television with a VCR or DVD player. Exclusion: inflammatory arthritis, previous TJA, uncorrected hearing or visual impairment, or unable to read or understand English; 142; Intervention 76,1 $(10,85)$ control $67,3(12,16)$; female $(67,7 \%)$; n/a.
To examine the impact of exposure to a decision aid on changes in expectations of health outcomes following

TKA and to evaluate decision-making parameters of the decision aid among men and women with knee OA.

To evaluate feasibility and to provide preliminary data on the effectiveness of a decision aid with a preference report for surgeons on wait times and decision quality in patients with $O A$ considering TKR.
Observation al study.

A decision aid has the potential to improve postTKA expectations. It may be beneficial reducing gender disparities in TKA patients.
Pilot

Randomized controlled trial.
It was feasible to recruit patients with knee osteoarthritis, administer the decision support interventions, and collect outcome measures.

Preliminary effectiveness outcomes demonstrated that the used decisional aid improved decision quality and knowledge. 
Research question 1: What are the needs and preferences of potential patients undergoing TKR?

\section{Risk of bias}

One study had a low risk of bias 20 and six studies had a high risk of bias (Table 2) 18,19,21-24 The bias that could occur through the interaction between researchers and patients was not mentioned in six studies. ${ }^{18,19,21-24}$ It was also unclear in these same six studies whether ethical approval was obtained.

Table 2. Methodological quality assessment outcome of qualitative studies

\begin{tabular}{|c|c|c|c|c|c|c|c|c|c|c|}
\hline Study & CASP 1 & CASP 2 & CASP 3 & CASP 4 & CASP 5 & CASP 6 & CASP 7 & CASP 8 & CASP 9 & CASP 10 \\
\hline Al Taiar 2013 & yes & yes & yes & no & yes & no & ? & yes & no & no \\
\hline Barlow 2016 & yes & yes & yes & yes & yes & no & no & yes & yes & yes \\
\hline Kesternich 2016 & yes & yes & yes & yes & no & no & ? & no & yes & yes \\
\hline Kroll 2007 & yes & yes & yes & yes & yes & no & no & yes & yes & yes \\
\hline Suarez 2010 & yes & yes & yes & yes & yes & no & no & no & yes & no \\
\hline Yeh 2016 & yes & yes & yes & yes & yes & yes & yes & yes & yes & yes \\
\hline Ho 2015 & no & No & no & no & no & no & no & no & no & no \\
\hline
\end{tabular}

CASP: Critical Appraisal Skills Programme

CASP criteria:

1. Was there a clear statement of the aims of the research?

2. Is a qualitative methodology appropriate?

3. Was the research design appropriate to address the aims of the research?

4. Was the recruitment strategy appropriate to the aims of the research?

5. Was the data collected in a way that addressed the research issue?

6. Has the relationship between researcher and participants been adequately considered?

7. Have ethical issues been taken into consideration?

8. Was the data analysis sufficiently rigorous?

9. Is there a clear statement of findings?

10. How valuable is the research?

Identified themes regarding patients' needs and preferences

The identified needs and preferences related to the SDM process of patients considering TKR were categorized into four different themes as described below (Table 3 ). 
Table 3. Themes and categories relevant to patients for participating in a SDM process around total knee replacement surgery.

\section{Personal factors related to shared decision making}

Factors related to fear and concerns regarding the surgical treatment

- Interestingly, and quite unexpected were the positive aspects of providing a report that was predominantly negative. Patients felt that it was easier to cope with a poor result $[\ldots]^{18}$.

- Twenty-six participants [...] have mentioned fear of the operation which was either related to fear of the operation itself, the anaesthesia, pain after surgery or fear that the operation may not produce the hoped outcome ${ }^{19}$.

- Participants' fear of the operation was a strong reason for delaying the operation even after they received the clinical advice for the operation ${ }^{19}$.

- A number of fears were also identified: fear of lengthy recovery, fear from complications and form of anaesthesia, concerns about longevity of prosthesis and worries about how surgery affect their other health problems ${ }^{37}$.

- Some were general concerns about surgery, e.g. fear of surgery, worries about pain, anaesthesia, infection, and complications. But other concerns were specifically related to their knee OA ${ }^{20}$.

Factors related to the communication with the health care professional related to concerns and other preferences

- Some orthopaedic patients are also reluctant to voice their concerns about their capacity to meet the demands of surgery ${ }^{24}$.

- Several participants mentioned the issue of their physical condition One aspect of this concern was related to their age [...]. Many participants felt they were too old to undergo surgery ${ }^{20}$.

- The majority of patients mentioned that surgery was not the first treatment choice. Even though the physician recommended TKA, they wanted to keep trying rehabilitation or/and taking medicine ${ }^{20}$.

- $\quad[. .$.$] participants who mentioned their needs, mostly wanted more information about preparing for$ surgery and post-surgical care ${ }^{20}$.

Ethnical variability

- Hispanic and Caucasian participants were less willing to base their explanations of illness or disability on the natural process of ageing or deterioration. Instead, they were more likely to attribute the cause of their knee OA to an accident or injury from the past ${ }^{22}$.

- Caucasians were the only ethnic group to express frustration with a current lack of knowledge regarding knee osteoarthritis ${ }^{22}$.

- African American subjects described their arthritis as a condition where personals freedom become limited, described by one person as "being in a vacuum"22.

- Knee OA was described by African American and Hispanic participants as being more debilitating compared to the perception of Caucasian respondents ${ }^{22}$.

- $\quad[\ldots]$ there may also concerns among Hispanic patients that members of health care teams have loyalties to the system when errors occurs 22 .

- $\quad[\ldots]$ African American and Caucasian patients were more likely to have trust based on the reputation of the physician or the reputation of the facility where the physician is affiliated ${ }^{22}$.

- Scepticism from African American participants was most likely to be associated with the prosthetic device 22

- White patients are more likely to undergo TKA than African American and Hispanic patients ${ }^{37}$. 


\section{External factors related to shared decision making}

Factors regarding health care professional interaction

- $\quad[. .$.$] clinicians may overestimate elderly patients decisional capacity { }^{24}$.

- Teach back methods which verify understanding by asking patients to restate the information provided [...], have been shown to improve health outcomes ${ }^{24}$.

- $\quad[. .$.$] decisional capacity is not an all or nothing phenomenon, making it challenging for surgeons to$ determine how much decisional support patients may need ${ }^{24}$.

- An elderly patient may have the capacity to make simple medication decisions, but no more complex surgical decisions ${ }^{24}$.

- Mental capacity varies along a continuum and depends in part on the complexity of the decision ${ }^{24}$.

- $\quad[. .$.$] participants expressed full trust in their surgeons, but at the same time expressed a strong sense of$ dissatisfaction with the insufficient amount of information provided by their surgeons ${ }^{19}$.

- The relationship between patients and their physicians was often discussed and included issues of communication, informativeness and trust ${ }^{37}$.

Issues that could delay or hinder decision making

- Financial issues are often discussed, and most participants expressed concerns about the costs of surgery, although in general they stated that financial difficulties would not affect their final decision to undergo knee surgery ${ }^{37}$.

- $\quad[\ldots]$ further and even longer delay was caused by the participants deliberation on whether to undergo the surgery ${ }^{19}$.

- The concepts of readiness for surgery and surgery at last resort as perceived by the patient or the physician was also important and often brought up as the threshold for decision making ${ }^{37}$.

- Like many older people, many participants suffered from chronic diseases. These other diseases were severe and had to be resolved before surgery is the opinion of some patients ${ }^{20}$.

\section{Sources of information to enhance shared decision making}

Personal experiences

- $\quad[. .$.$] attitudes and beliefs of patients with knee osteoarthritis about TKA are largely based on personal$ experiences-both positive and negative ${ }^{37}$.

- Previous personal experience with surgery, including non-orthopedic procedures also played a role in patients preferences about knee surgery ${ }^{37}$.

- Regarding specific concerns about knee-replacement surgery, some participants were undecided due to past bad experiences with $\mathrm{TKA}^{20}$.

Experiences of relevant others

- $\quad$ All participants cited positive experiences of people who had undergo the surgery ${ }^{19}$.

- People who had had the surgery were mentioned as a source of information and their experiences were brought up several times ${ }^{19}$.

- Some participants shared their relatives or friends negative knee replacement surgery experiences, which hindered participants from deciding to have the surgery ${ }^{20}$.

- $\quad$ Both positive and negative personal experiences played a major role in decision making, and included TKA experienced by relatives, friends or acquaintances ${ }^{37}$.

- Patients social network functioned as an information source related to the social network's experience of surgery ${ }^{18}$.

- $\quad$ patients obtained information about TKA from different sources which often included nonprofessional contacts, such as $[\ldots]$, the media or internet ${ }^{37}$

- $\quad[\ldots] 64 \%$ of the respondents were very interested in second opinions before decision ${ }^{38}$.

- Participants had received the advice to undertake TKA at least once locally and once abroad but this was very late and different advices are given by physicians. This caused long and unnecessary suffering ${ }^{19}$. 
Theme /nodes

Result

- Part of the delay in medical advice to have TKR came from the fact that patients sought second, third and probably fourth opinions ${ }^{19}$.

- $\quad$ Primary care physicians were the most common source of professional medical information ${ }^{37}$.

Decision tools

- Outcome probabilities significantly influenced surgery recommendations ${ }^{38}$.

- Participants were universally positive about the principles behind an outcome prediction tool, feeling that such information would be helpful ${ }^{18}$.

\section{Prediction tools and presentation of relevant information to enhance shared decision making}

Instruments or interventions to obtain relevant information

- Information from capacity assessments and exploration of patient perspectives helps to determine whether patients would be able to recall and adhere to preoperative and postoperative instructions ${ }^{24}$.

- Having standard tools, questions and procedures to investigate the patients cognitive status and available support network can help Dr. Z or other designated members of the team to efficiently identify Mrs. A's decisional and care management context ${ }^{24}$.

- Patients who had already an operation [...] were asked how the decision tool would have affected their deliberation process [...] all patients thought that the information would have had the ability to change their expectations ${ }^{18}$.

- Decision aids that explain various orthopedic treatment choices as well as their risks and benefits can be helpful in shared decision making ${ }^{24}$.

Presentation of information

- There is a general preference for graphical displays with a bottom line prediction to present, along with the opportunity to discuss it with a medical professional ${ }^{18}$.

- Take home decision aids with visual or auditive information on pre and postoperative regimes may help elderly patients with cognitive limitations to grasp and recall critical information ${ }^{24}$.

- Respondents most often reported outcome probabilities as most influential regarding their decision ${ }^{38}$.

- There was also the belief that having information in a written format that could be taken away was a worthwhile aim, especially for people who are socially isolated and not may have contacts [...] to discuss the outcome ${ }^{18}$

\section{Theme 1: Important factors and arguments for patients to make decisions}

This theme is built upon three different categories. The first category is related to fears and concerns regarding surgical treatment, which comprise fear of TKR surgery, fear of the anaesthesia, concerns regarding postoperative pain or complications, and concerns regarding the long-term outcomes of TKR. ${ }^{19,20,23}$ From a patients' perspective, fear of the operation was found to be an important reason for postponing surgery, even for patients who received the clinical advice to undertake the operation. ${ }^{19}$

The second category is related to concerns and other preferences. Many older patients are likely to postpone or refuse TKR. Factors for this preference were that patients felt too old, that they suffered from unresolved severe comorbidity, and that they have preferences towards other treatment modalities like medication or physical therapy. ${ }^{20}$ 
The third category is related to ethnic variability. In a study group of Arabic women, preferences regarding TKR are influenced by ambivalence caused by fear and lack of information regarding harms and benefits of the $T K R$, and the advice about the best treatment option of the clinician (and second opinion from abroad). ${ }^{19}$ One author found that Caucasian patients report willingness to undergo TKR surgery than African American and Hispanic patients. $^{23}$

\section{Theme 2: External factors related to SDM}

This theme is built upon two categories. The first category is related to factors regarding interaction between the patient and the orthopaedic surgeon. One of the most mentioned factors by. patients was the patient-doctor relationship, which was universally seen as a major factor in decision making. 19,20,23,24 Important patients issues in the discussion about the patientdoctor relationship were communication, information and trust. ${ }^{19,23}$ Moreover, orthopaedic surgeons mention that over- and underestimating elderly patients' decision making capacity is an issue of concern. ${ }^{24}$ They perceive a difference in the capacity of patients to interpret information and to make healthcare decisions. ${ }^{24}$ They mention that patients often have the capability to make simple decisions about medication, but not complex decisions like whether or not to have TKR. ${ }^{24}$ To create an adequate and effective SDM process, even with cognitively impaired patients, orthopaedic surgeons mention that they find it challenging to establish the patient's decisional capacity and engagement of the context, which they feel is necessary to determine the appropriate decisional support and to create an adequate and effective SDM process. $^{24}$

The second category was related to issues that could delay or hinder decision making. The timing of decision making is affected by several factors, such has the ambivalence of patients, concepts of readiness for surgery and surgery perceived as a last resort by patients and doctors. ${ }^{19,23}$ Financial issues are often discussed by patients in a decision making process; however, these issues would not affect their final decision to undergo TKR. ${ }^{23}$

\section{Theme 3: Sources of information to enhance SDM}

This theme is built upon three categories. The first category was related to personal experiences. Both positive or negative personal experiences of patients with knee OA play a major role in patients' attitudes and beliefs about TKR surgery and have therefore a substantial influence on the decision making process of patients who are considering TKR. ${ }^{23}$

The second category was related to the experiences of relevant others. Patients use different sources to obtain information, such as second opinions and general practitioners, ${ }^{19,21,23}$ but also non-professional contacts such as relatives and the media. ${ }^{23}$ Experiences of relatives or friends with TKR surgery played a major role in thoughts about 
outcome and decision making. ${ }^{18-20,23}$ Patients see their social network as an important source of information about a major surgery like TKR. ${ }^{18}$

The final category was related to the use of decision tools in an SDM process. Patients were positive about the principles behind an outcome prediction tool and felt that such information can enhance adequate SDM. ${ }^{18}$

\section{Theme 4: Prediction tools and presentation of relevant information to enhance SDM}

This theme is built upon two categories. The first category was related to methods to obtain relevant information. Decision aids that explain various orthopaedic treatment choices with their risks and benefits would be helpful for patients in a decision making process. ${ }^{24}$ Patients wanted a bottom-line outcome prediction, presented by a prediction tool. ${ }^{18}$

The second category was related to the presentation of relevant information. Regarding the presentation of outcome probabilities patients mentioned that they need a bottom-line prediction, with visual presentations. ${ }^{18,21}$ Patients mentioned regarding that the presentation of the risk and benefits of the surgical procedure needs to be personalized, based on their individual characteristics. ${ }^{21}$

\section{Research question 2: How is SDM supported before and after TKR surgery?}

Six studies were eligible for this research question: three observational studies ${ }^{25-27}$ and three RCTs. ${ }^{28-30}$ In five studies, the effect of a decision aid was assessed. ${ }^{25,27-30}$ Primary outcomes were the number of TKR operations and costs, ${ }^{25}$ effect of different decision aids on decision conflicts between patients and doctors about the surgical procedure, ${ }^{30}$ receipt of a TKR (within 12 months), ${ }^{28}$ effect on the quality of SDM (how did the intervention or method affect the process of SDM) ${ }^{29}$ and effect on gender disparities in patients considering TKR. ${ }^{27}$ Furthermore, Filardo et al. $^{26}$ focussed on the importance of control preferences (the degree of control a patient wants to assume when important health care decisions are being made) ${ }^{26}$ of patients choosing to have TKR.

\section{Risk of bias}

Except for the study of De Achaval et al, ${ }^{30}$ all studies demonstrated a moderate $(n=3)^{27-29}$ or a high $(n=2)^{25,26}$ risk of bias. In none of the studies was it clear whether the researched population in the study was a close representation of the (inter)national TKR population. There was only one study that had a minimal likelihood of non-response bias. ${ }^{29}$ In two studies ${ }^{28,30}$ it became clear that the sampling frame was a true or close representation of the target population. Further details of the scores are shown in Table 4. 
Table 4. Risk of bias of quantitative studies

\begin{tabular}{lrrrrrrrrrrrr}
\hline & 1 & 2 & 3 & 4 & 5 & 6 & 7 & 8 & 9 & 10 & total yes \\
\hline Arteburn & & & & & & & & & & & & \\
ne Archeval & no & Yes & yes & no & yes & yes & yes & yes & yes & yes & 8 \\
Filardo & no & No & no & no & no & yes & yes & no & yes & yes & 5 \\
lbrahim & no & Yes & yes & no & yes & yes & yes & yes & no & yes & 7 \\
Stacey & no & No & yes & yes & yes & yes & yes & yes & no & yes & 7 \\
Volkmann & no & No & no & no & yes & yes & yes & yes & yes & yes & & 6
\end{tabular}

Risk of bias criteria:

1. Was the study target population a close representation of the national population in relation to relevant variables?

2. Was the sampling frame a true or close representation of the target population?

3. Was some form of random selection used to select the sample OR was a census undertaken?

4. Was the likelihood of nonresponse bias minimal?

5. Were data collected directly from the subjects (as opposed to a proxy)?

6. Was an acceptable case definition used in the study?

7. Was the study instrument that measured the parameters of interest shown to have validity and reliability?

8. Was the same mode of data collection used for all subjects?

9. Was the length of the shortest prevalence period for the parameter of interest appropriate?

10. Were the numerator(s) and denominator(s) for the parameter of interest appropriate?

\section{Methods and interventions to support SDM}

\section{Choice Talk}

Choice Talk refers to the step of making sure that patients know that reasonable options are available. This step is described in four articles. ${ }^{27-30} \mathrm{De}$ Achaval et al. ${ }^{30}$ studied the usefulness of several decision aids. One of these decision aids aimed to visually describe the different treatment options available for a patient. ${ }^{30}$ The three other studies used decision tools to provide patients with insight into different options of treating knee OA. ${ }^{27-29}$ Stacey et al. ${ }^{29}$ described the content and goal of the decision tool they provided to patients. The tool was used to explore different treatment options available.

\section{Option talk}

Option talk refers to providing more detailed information about options and was (partially) recognized in four studies. ${ }^{27-30}$ De Achaval et al. ${ }^{30}$ used several decision aids. Only one of them, a tool which uses Adaptive Conjoint Analysis (ACA), is described in detail. This method uses an individual respondent's answers to update and refine the questions for the respondent. The other tools were not reproducibly described. ${ }^{30}$ Stacey et al. ${ }^{29}$ provided comprehensive insight into the content of the decision tool that was used and its influence on this step. The decision tools used by Ibrahim et al. ${ }^{28}$ and Volkmann et al. ${ }^{27}$ were not described in terms of their content. 
However, the authors explained that they aimed to enhance the patients' insight into the different treatment options and their risks ${ }^{28}$ and gave explanations about pathogenesis and different treatment options. ${ }^{27}$

\section{Decision talk}

Decision talk refers to supporting the work of considering preferences and deciding what is best for the patient. This step is only described in the study of Stacey et al. ${ }^{29}$ They stated that patients need to discuss their values and preferences with the orthopaedic surgeon, prior to feeling certain about the best treatment choice for them.

Research question 3: To what extent are patient needs and preferences taken into account in SDM?

The extent to which patient needs and preferences were taken into account in the actual content of the applied SDM processes was very low (Table 6). From the qualitative studies, we elicited that personal factors, external factors, important sources of information and preferences towards outcome prediction were related to the decision to undergo TKR or not. "Personal factors" or "external factors" relevant to the patient were virtually never taken into account. There was one study that investigated the "personal factor" control preference, but this was not integrated into a SDM intervention. ${ }^{26}$ Five out of six studies did take a number of factors related to the theme "sources of information" into account to enhance the SDM process, ${ }^{25,27-30}$ as they studied the impact of using a decision aid. One study did take some issues regarding prediction tools and presentation of relevant information into account, as they described the way they visually described relevant information to patients. ${ }^{30}$ Details are shown in Table 5.

Table 5. Are the factors that support the decisional skills and / or capacity of patients, as found as results of research question 1 , been covered in the process and content of SDM as found in the studied articles included in research question 2 ?

\begin{tabular}{|c|c|c|c|c|c|c|}
\hline & Arterburn & DeAchaval & Filardo & Ibrahim & Stacey & Volkmann \\
\hline \multicolumn{7}{|l|}{ patient need / preference } \\
\hline personal factors related to SDM & no & no & partly & no & no & no \\
\hline $\begin{array}{l}\text { external factors related to SDM } \\
\text { Sources of information to enhance }\end{array}$ & no & no & no & no & no & no \\
\hline $\begin{array}{l}\text { SDM } \\
\text { prediction tools and presentation of }\end{array}$ & partly & partly & no & partly & partly & partly \\
\hline relevant information & no & partly & no & no & no & no \\
\hline
\end{tabular}

SDM: Shared decision making 


\section{Discussion}

Our aim was to explore the state-of-the-art of SDM when patients and their healthcare providers consider, prepare for and recover from TKR. With regard to the three different key decision moments, we found that only the decision to undergo TKR or not has been studied. Moreover, in the studies that assessed the impact of SDM, we found that interventions did utilize the SDM steps "choice talk" and "option talk"; however, "decision talk" was typically overlooked. We identified four themes that are important for patients for participation in SDM when considering TKR. Moreover, we found a serious discrepancy between the SDM interventions and the patient needs and preferences regarding decision making, potentially resulting in suboptimal SDM processes.

When reflecting on the needs and preferences of patients, our findings are in line with two previous systematic reviews. Barlow et al. ${ }^{31}$ performed a systematic review on qualitative studies regarding decision making in TKR surgery procedures. Their main objective was to identify factors that influence patient decisions when considering $T K R$, which is in line with our first research question. However, Barlow et al. ${ }^{31}$ had a broader search strategy, which focussed on decision making in general and not just on SDM. They identified ten themes relevant for patients in making a decision whether to undergo TKR surgery or not. The following themes overlap with the themes in our study: expectations of surgery, fear, patient-doctor relationship, social network, previous experiences with surgery, pain and functioning. They also found that psychological implications, conflict in opinions and coping mechanisms were important issues for patients in making this decision. ${ }^{31}$ Another review of $\mathrm{O}^{\prime}$ Neill et al. ${ }^{32}$ concluded that unmet needs for TKR and influencing factors on decision making are complex. Patients must consider many factors before deciding to undergo TKR. They point out the importance of the patienthealthcare professional relationship in this process. ${ }^{32}$ This is also in line with our findings and strengthens the importance of inquiring about the needs, preferences and capacity of patients before they can and are willing to participate in an SDM process. Furthermore, health care professionals should provide patients with adequate information regarding all possible treatment options with their potential harms and benefits. ${ }^{1,2,4}$ In an optimal process of SDM, a well-informed patient is essential to reach the right personalized decision considering health and (physical) function fitting the patient's needs and preferences. This process of giving relevant information was not reproducibly described in most of the reviewed studies.

We revealed that in the available literature, the use of SDM is limited to choice talk and option talk regarding the decision to undergo TKR surgery. Moreover, authors have mainly researched the usefulness of decision aids. It is evident that well-designed decision aids are helpful in increasing patient knowledge, decreasing decisional conflict and improving the involvement of patients in the process of decision making. ${ }^{1,33}$ However, we were surprised to find that none of the SDM interventions addressed patients' individual needs and preferences related to personal and external factors. The question therefore arises as to whether the 
literature on SDM in TKR, really studies SDM. After all, SDM should happen within the encounter between patients and healthcare professionals, ${ }^{34}$ while the studied decision aids were often times provided to patients before the encounter with the orthopaedic surgeon and it remained unclear how they impacted the interaction between patient and professional within the clinical encounter. As Hargraves et al ${ }^{34}$ stated: "A decision aid, patient power, medical skills and scientific evidence do not simply result in good decisions by being in a room together. Each may potentially contribute, but their potential is drawn out and realized in conversation". Unfortunately, this last step remains largely unclear in the available studies, perhaps explaining to some extent their conflicting study results.

Moreover, we found that_in the majority of studies an open perspective of intervention options was not always used. Instead, patients were already funnelled towards TKR. When a patient visits an orthopaedic surgeon, this is a logical consequence. However, this does not fit well with SDM, as patients and healthcare professionals should collaborate towards an adequate intervention regarding the patient's knee complaints. Therefore, SDM should perhaps take place between a patient and a health care professional who has insight into all possible treatment options and can address patients' needs and preferences towards health and (physical) functioning to find an optimal solution.

This scoping review has several strengths. The comprehensive and systematic search strategy was iterative and used preliminary search strings to skim the literature. This was performed independently by two reviewers. Moreover, the study selection and data extraction was done by two reviewers. By using an iterative review process, we were able to justify the search strategy and research questions based on the available literature and information regarding SDM in patients considering TKR surgery.

The conclusions of our review are limited by the following: (1) The small number of included studies, which varied widely in design, patient inclusion and primary aims. (2) The focus of these studies which was solely on the decision whether to undergo surgery or not. Therefore a large part of our inquiry remained unanswered. (3) A lot of information regarding SDM in TKR surgery is part of studies that consider total hip replacement (THR) and TKR as one surgical intervention. However, we know that patient characteristics, needs and outcomes between THR and TKR are different. ${ }^{35,36}$ This is one of the main reasons that we finally had a small number of studies, because we only included studies in which we could identify patients with chronic knee problems and the option of having a TKR as a unique population. 


\section{Conclusion}

By use of a scoping review design, we have gained insight into the current state of SDM in the domain of patients with chronic knee health and functioning problems and the option of having a TKR. We found that SDM processes mainly focus on the decision to undergo TKR or not and that these processes are typically carried out by use of decision tools in the option talk phase of SDM. Moreover, there appears to be a mismatch between the factors that support patients' preferences and needs to make adequate healthcare treatment decisions and the actually applied and studied SDM processes for patients that chose to undergo TKR. Thus, this research might represent the funnelling approach towards TKR that could prevail in clinic. The limited degree to which SDM processes are being employed in the care surrounding these patients as well as the lack of accounting for patients' needs and preferences might explain to some extent the conflicting study results among the available effect studies. Future research and development of SDM in patients suffering from chronic knee health conditions needs to treat SDM as a constant process of collaboration and deliberation within clinical encounters between the patient and healthcare professional. Furthermore, this process should entail the complete patient journey, i.e. from choosing whether or not to undergo treatment, deciding which treatment option best fits the patient's needs and preferences regarding his chronic knee health condition, to the decisions regarding how to optimally recover from TKR surgery.

\section{Practical implications}

We recommend that the focus of SDM for persons with chronic knee conditions should be broader than just the decision to have a TKR or not. We should provide this person with information about all possible options of treatment (with doing nothing as a possible option as well) and not only funnelling the patient towards having a TKR. However, when the decision to undergo surgery has been made, the focus of decision making should also be broader. For instance, the decision regarding how to prepare for surgery and how to recover after surgery, i.e., home or elsewhere and to partake in rehabilitation, should also be part of the SDM process. Another recommendation is that the currently available SDM interventions should take the patient's personal and external factors regarding the healthcare decisions into account. Finally, future studies on the impact of SDM should be based on the available SDM models, for instance that of Elwyn et al. ${ }^{3}$ which distinguishes (1) choice talk, (2) option talk and (3) decision talk. Ideally SDM processes used in the decisions surrounding TKR should incorporate each of these three steps. 


\section{References}

1. Barry MJ, Edgman-Levitan S. Shared Decision Making - The Pinnacle of Patient-Centered Care. N Engl J Med. 2012;(366):780-781. doi:10.1056/NEJMp1109283.

2. Hoffmann TC, Légaré F, Simmons MB, et al. Shared decision making: what do clinicians need to know and why should they bother? Med J Aust. 2014;201(1):35-39. doi:10.5694/mja14.00002.

3. Elwyn G, Frosch D, Thomson R, et al. Shared decision making: A model for clinical practice. J Gen Intern Med. 2012;27(10):1361-1367. doi:10.1007/s11606-012-2077-6.

4. Elwyn G, Frosch DL, Kobrin S. Implementing shared decision-making: consider all the consequences. Implement Sci. 2015;11(1):114. doi:10.1186/s13012-016-0480-9.

5. Clayman ML, Bylund $\mathrm{CL}$, Chewning B, Makoul G. The impact of patient participation in health decisions within medical encounters: A systematic review. Med Decis Mak. 2016;36(4):427-452. doi:10.1177/0272989X15613530.

6. Dawes M, Summerskill W, Glasziou P, et al. Sicily statement on evidence-based practice. BMC Med Educ. 2005;5(1):1. doi:10.1186/1472-6920-5-1.

7. Hawker GA, Badley EM, Borkhoff $\mathrm{CM}$, et al. Which patients are most likely to benefit from total joint arthroplasty? Arthritis Rheum. 2013;65(5):1243-1252. doi:10.1002/art.37901.

8. Beswick AD, Wylde V, Gooberman-Hill R, Blom A, Dieppe P. What proportion of patients report long-term pain after total hip or knee replacement for osteoarthritis? A systematic review of prospective studies in unselected patients. BMJ Open. 2012;2(1):e000435. doi:10.1186/s12891-015-0469-6.

9. Skou ST, Roos EM, Laursen MB, Rathleff MS, Arendt-Nielsen L, Simonsen O. A Randomized, Controlled Trial of Total Knee Replacement. N Engl J Med. 2015;373(17):1597-1606. doi:10.1056/NEJMoa1505467.

10. Woude JAD Van Der, Wiegant K, Roermund PM Van, et al. Five-Year Follow-up of Knee Joint Distraction : Clinical Benefit and Cartilaginous Tissue Repair in an Open Uncontrolled Prospective Study. 2017. doi:10.1177/1947603516665442.

11. Bozic KJ, Chiu V. Emerging ideas: Shared decision making in patients with osteoarthritis of the hip and knee. Clin Orthop Relat Res. 2011;469(7):2081-2085. doi:10.1007/s11999-010-1740-7.

12. Gioe TJ. Shared decision making in orthopaedic surgery: More than two to tango? J Bone Jt Surg - Ser A. 2013;95(18):e1361-e1362. doi:10.2106/JBJS.M.00723.

13. Youm J, Chenok K, Belkora J, Chan V, Bozic KJ. The emerging case for shared decision making in orthopaedics. J Bone Jt Surg - Ser A. 2012;94(20):1907-1912.

http://www.embase.com/search/results?subaction=viewrecord\&from=export\&id=L365922082.

14. Arksey H, Malley LO. Scoping Studies: Towards a Methodological Framework. Int J Soc Res Methodol. 2005;8(1):19-32. doi:10.1080/1364557032000119616.

15. Légaré F, Stacey D, Turcotte $S$, et al. Interventions for improving the adoption of shared decision making by healthcare professionals ( Review ) SUMMARY OF FINDINGS FOR THE MAIN COMPARISON. 2014;(9). doi:10.1002/14651858.CD006732.pub3.www.cochranelibrary.com.

16. Walsh D, Downe S. Meta-synthesis method for qualitative research: A literature review. J Adv Nurs. 2005;50(2). doi:10.1111/j.1365-2648.2005.03380.x.

17. Hoy D, Brooks P, Woolf A, et al. Assessing risk of bias in prevalence studies: Modification of an existing tool and evidence of interrater agreement. J Clin Epidemiol. 2012;65(9):934-939. doi:10.1016/j.jclinepi.2011.11.014.

18. Barlow T, Scott P, Griffin D, Realpe A. How outcome prediction could affect patient decision making in knee replacements: a qualitative study. BMC Musculoskelet Disord. 2016;17:304. doi:10.1186/s12891-0161165-x.

19. Al-Taiar A, Al-Sabah R, Elsalawy E, Shehab D, Al-Mahmoud S. Attitudes to knee osteoarthritis and total knee replacement in Arab women: a qualitative study. BMC Res Notes. 2013;6:406. http://www.embase.com/search/results?subaction=viewrecord\&from=export\&id=L563085055.

20. Yeh W-L, Tsai Y-F, Hsu K-Y, Chen DW, Chen C-Y. Factors related to the indecision of older adults with knee osteoarthritis about receiving physician-recommended total knee arthroplasty. Disabil Rehabil. September 2016:1-6. doi:10.1080/09638288.2016.1226407.

21. Kesternich I, Caro FG, Gottlieb AS, Hoffmann S, Winter JK. The Role of Outcome Forecasts in Patients' Treatment Decisions--Evidence from a Survey Experiment on Knee Replacement Surgery. Health Serv Res. 2016;51(1):302-313.

http://search.ebscohost.com/login.aspx?direct=true\&db=cin20\&AN=112404147\&site=ehost-live. 
22. Kroll TL, Richardson M, Sharf BF, Suarez-Almazor ME. "Keep on truckin"' or "It"s got you in this little vacuum': race-based perceptions in decision-making for total knee arthroplasty. J Rheumatol. 2007;34(5):1069-1075. http://search.ebscohost.com/login.aspx?direct=true\&db=cin20\&AN=106151541\&site=ehost-live.

23. Suarez-Almazor ME, Richardson M, Kroll TL, Sharf BF. A qualitative analysis of decision-making for total knee replacement in patients with osteoarthritis. J Clin Rheumatol. 2010;16(4):158-163. doi:10.1097/RHU.0b013e3181df4de4.

24. Ho A, Pinney SJ, Bozic K. Ethical concerns in caring for elderly patients with cognitive limitations: a capacityadjusted shared decision-making approach. J Bone Jt Surgery, Am Vol. 2015;97(3):e16-e16. http://search.ebscohost.com/login.aspx?direct=true\&db=cin20\&AN=103748222\&site=ehost-live.

25. Arterburn D, Wellman R, Westbrook E, et al. Introducing decision aids at group health was linked to sharply lower hip and knee surgery rates and costs. Health Aff. 2012;31(9):2094-2104. doi:10.1377/hlthaff.2011.0686.

26. Filardo G, Roffi A, Merli G, et al. Patients control preferences and results in knee arthroplasty. Knee Surgery, Sport Traumatol Arthrosc. 2017. doi:10.1007/s00167-016-4405-6.

27. Volkmann ER, FitzGerald JD. Reducing gender disparities in post-total knee arthroplasty expectations through a decision aid. BMC Musculoskelet Disord. 2015;16:16. doi:10.1186/s12891-015-0473-x.

28. Ibrahim SA, Blum M, Lee G-C, et al. Effect of a Decision Aid on Access to Total Knee Replacement for Black Patients With Osteoarthritis of the Knee. JAMA Surg. 2017;152(1):e164225. doi:10.1001/jamasurg.2016.4225.

29. Stacey D, Hawker G, Dervin G, et al. Decision aid for patients considering total knee arthroplasty with preference report for surgeons: a pilot randomized controlled trial. BMC Musculoskelet Disord. 2014;15:54. doi:10.1186/1471-2474-15-54.

30. Sofia de Achaval, Liana Fraenkel, Robert J. Volk, Vanessa Cox MES-A. Impact of educational and patient decision aids on decisional conflict associated with total knee arthroplasty. Arthiritis Care Res. 2013;64(2):229-237. doi:10.1002/acr.20646.Impact.

31. Barlow T, Griffin D, Barlow D, Realpe A. Patients' decision making in total knee arthroplasty: a systematic review of qualitative research. Bone Joint Res. 2015;4(10):163-169. doi:10.1302/2046-3758.410.2000420.

32. O'Neill T, Jinks C, Ong BN. Decision-making regarding total knee replacement surgery: a qualitative metasynthesis. BMC Health Serv Res. 2007;7:52. doi:10.1186/1472-6963-7-52.

33. Sepucha KR, Borkhoff CM, Lally J, et al. Establishing the effectiveness of patient decision aids: key constructs and measurement instruments. BMC Med Inf Decis Mak. 2013;13 Suppl 2(Suppl 2):S12. doi:10.1186/14726947-13-S2-S12.

34. Hargraves I, Montori VM. Decision aids, empowerment, and shared decision making. Bmj. 2014;349(sep25 6): g5811-g5811. doi:10.1136/bmj.g5811.

35. Wright JG, Hawker GA, Hudak PL, et al. Variability in physician opinions about the indications for knee arthroplasty. J Arthroplasty. 2011;26(4):569-575.e1. doi:10.1016/j.arth.2010.04.028.

36. Hawker GA. Who, when, and why total joint replacement surgery? The patient's perspective. Curr Opin Rheumatol. 2006;18(5):526-530. doi:10.1097/01.bor.0000240367.62583.51.

37. Suarez-Almazor ME, Richardson M, Kroll TL, Sharf BF. A qualitative analysis of decision-making for total knee replacement in patients with osteoarthritis. J Clin Rheumatol. 2010;16(4):158-163. doi:10.1097/RHU.0b013e3181df4de4.

38. Kesternich I, Caro FG, Gottlieb AS, Hoffmann S, Winter JK. The role of outcome forecasts in patients' treatment decisions - Evidence from a survey experiment on knee replacement surgery. Health Serv Res. 2016;51(1):302-313. doi:10.1111/1475-6773.12311. 


\section{Abstract}

Study design

Prospective cohort design using data derived from usual care.

\section{Background}

It is important that patients are able to function independently as soon as possible after total hip replacement. However, the speed of regaining activities divers significantly.

\section{Objectives}

To develop a risk stratification model (RSM) to predict delayed inpatient recovery of physical activities in people who underwent total hip replacement surgery.

\section{Methods}

This study was performed in 2 routine orthopaedic settings: Diakonessenhuis Hospital (setting A) and Nij Smellinghe Hospital (setting B). Preoperative screening was performed for all consecutive patients. In-hospital recovery of activities was assessed with the Modified lowa Level of Assistance Scale. Delayed inpatient recovery of activities was defined as greater than 5 days. The RSM, developed using logistic regression analysis and bootstrapping, was based on data from setting $A(n=154)$. External validation was performed on the data set from setting $B(n=271)$.

\section{Results}

Twenty-one percent of the patients in setting A had a delayed recovery of activities during their hospital stay. Multivariable logistic regression modeling yielded a preliminary RSM that included the following factors: male sex (odds ratio $[\mathrm{OR}]=0.8 ; 95 \%$ confidence interval [Cl]: $0.2,2.6)$, 70 or more years of age (OR $=1.2 ; 95 \% \mathrm{Cl}: 0.4,3.4)$, body mass index of $25 \mathrm{~kg} / \mathrm{m}^{2}$ or greater $(\mathrm{OR}=2.2 ; 95 \% \mathrm{Cl}: 0.7,7.4)$, an American Society of Anesthesiologists score of $3(\mathrm{OR}=$ 1.2; $95 \% \mathrm{Cl}: 0.3,4.4)$, a Charnley score of $\mathrm{B}$ or $\mathrm{C}(\mathrm{OR}=6.1 ; 95 \% \mathrm{Cl}: 2.2,17.4)$, and a timed upand-go score of 12.5 seconds or greater $(\mathrm{OR}=3.1 ; 95 \% \mathrm{Cl}: 1.1,9.0)$. The area under the receiver operating characteristic $(\mathrm{ROC})$ curve was $0.82(95 \% \mathrm{Cl}: 0.74,0.90)$ and the HosmerLemeshow test score was 3.57 ( $P>.05)$. External validation yielded an area under the ROC curve of $0.71(95 \% \mathrm{Cl}: 0.61,0.81)$.

\section{Conclusion}

We demonstrated that the risk for delayed recovery of activities during the hospital stay can be predicted by using preoperative data. 


\section{Introduction}

In the next 2 decades, the number of total hip replacements (THRs) will rise considerably. ${ }^{17}$ Efficient use of resources is the key to cope with this rise. A straightforward way to save costs is to reduce the length of hospital stay and increase the number of people discharged home after THR. To do so, it is important that people can function independently as soon as possible, as the inability to do so is associated with prolonged length of hospital stay and an increased rate of discharge to chronic care facilities. ${ }^{18}$

Through preoperative identification of patients at risk for delayed inpatient recovery of activities, health care professionals may be able to adjust and optimize functional recovery and discharge planning for these vulnerable individuals. To our knowledge, there is no available preoperative screening instrument to predict delayed inpatient recovery of activities after THR. The current literature mainly comprises studies that assess the predictive value of individual variables in the International Classification of Functioning, Disability and Health (ICF) domain "personal factors." ${ }^{3}$ Ideally, one would combine these individual predictors into a single model, augmented with relevant self-reported and performance-based variables from each ICF domain, ${ }^{3,7,18}$ to serve as a risk stratification model (RSM). ${ }^{19}$

Therefore, the aim of our study was to develop a clinically feasible RSM that identifies people with a low or high risk for delayed inpatient recovery of activities after $\mathrm{THR}^{3}$ by combining literature based variables with relevant indices from each domain of the ICF.

\section{Methods}

This prospective, observational study consisted of 2 parts: (1) development of a preliminary RSM with data from Diakonessenhuis Hospital in Utrecht, the Netherlands (data set A), and (2) external validation of the RSM with data from Nij Smellinghe Hospital in Drachten, the Netherlands (data set B). Data collection at both sites was performed in the routine care setting for people undergoing THR. An anesthesiologist, a physical therapist, and a nurse assessed the surgical risk and preoperative functional status of each patient placed on the waiting list for a primary THR. During their hospital stays, we monitored recovery of activities, length of hospital stay, and complications.

We only used data from regular patient files. According to Dutch law, research with anonymized regular care data does not require approval from a medical ethical committee (confirmed by the local ethical committee, reference 131211) and is subject to a general optout procedure by the hospital. This study is reported in accordance with the STROBE statement. $^{35}$ 


\section{Outcome Variable}

The duration (days) of inpatient recovery of activities was assessed with the Modified lowa Level of Assistance Scale (MILAS). The MILAS assesses the assistance necessary to safely perform 5 activities of daily living (ie, supine-to-sit, sit-to-supine, sit-to-stand, walking, and stair climbing). Each of these activities was scored daily on an ordinal scale ranging from 0 to 6 with the following response categories: 0 (independent; 1, standby/supervision; 2, 1 point of contact; 3, 2 points of contact; 4, 3 or more points of contact; 5, failed with maximal assistance; 6 , not tested due to medical reasons or for reasons of safety). ${ }^{15}$

Stair climbing was not a standard assessment for all patients, but only for those who were required to climb stairs at their discharge destination. To avoid loss of statistical power due to separating groups of stair climbers and non-stair climbers, we excluded stair climbing from our outcome measure.

This exclusion resulted in a sum score range for the MILAS of 0 to 24 points. A sum score of 1 or less on the MILAS suggests that a patient may be able to function safely at home. We recorded the number of postoperative days necessary to achieve this sum score, then divided the patients into 2 groups: patients who reached functional independence within 5 days (timely recovery) and those who reached functional independence in more than 5 days (delayed recovery). Five days was chosen as the cut-off because it is the typical period for clinical pathways like rapid recovery. ${ }^{1}$

All physical therapists $(n=11)$ had relevant work experience in a hospital setting. They had worked in this setting for 2 to 33 years (median, 10 years) and, prior to the introduction of functional screening into the care pathway, were trained to assess the MILAS in a standardized and uniform way. Further details about the MILAS can be found in the appendix

\section{Predictor Variables}

We collected the following preoperative predictor variables: age (less than 70 years or 70 years or greater) ${ }^{12}$; body mass index (BMI) (less than $25 \mathrm{~kg} / \mathrm{m}^{2}, 25-30 \mathrm{~kg} / \mathrm{m}^{2}$, or $30 \mathrm{~kg} / \mathrm{m}^{2}$ or greater); American Society of Anesthesiologists (ASA) score (1 to 2 or 3 and higher, with a higher score indicating less fitness for surgery) ${ }^{21}$; Charnley score (a score of $A$ or $B$ or $C$ to indicate the function of the hip with regard to the ability to walk, with A being more favorable than C)2; the Western Ontario and McMaster Universities Osteoarthritis Index (WOMAC) score (to assess pain, stiffness, and activities of daily living, with ranges of 0-20, 0-6, and 0-68, respectively, a higher score indicating more perceived discomfort or dysfunction $)^{25}$; the numeric rating scale for pain ( 0 to 10 , with a higher score indicating more pain $)^{6}$; and estimated walking capacity (minutes). ${ }^{24}$

We also collected performance-based functional activities. These included the sixminute walk test ([distance in meters] to assesses walking capacity, with a higher score indicating a better walking capacity), ${ }^{16}$ chair-rise time ([in seconds] to assess functional lower- 
leg power, with a lower score indicating better muscle power), ${ }^{32}$ a handheld dynamometer ([in Newton-meters] to assess quadriceps muscle strength, with a higher score indicating better muscle strength), ${ }^{26}$ and the timed up-and-go (TUG) test ([in seconds] to assess functional mobility, with a lower score indicating better functional mobility). ${ }^{27}$

\section{Clinical Care Pathway}

The surgical approach was similar for all patients (straight lateral or posterolateral). In the majority of cases, hip replacement surgery was performed without the use of cement; however, the postoperative clinical pathway was identical regardless of the procedure.

Physical therapy started 1 day after surgery. The patients received one 20 to 30 -minute therapy session per day that consisted of (1) bed exercises to regain muscle power and strength, avoid inactivity, and prevent deep vein thrombosis; (2) muscle exercises in sitting and standing positions to regain muscle power and strength; and (3) practicing transfers (into and out of bed, walking indoors) to achieve functional independence. ${ }^{10}$ Patients were discharged from the hospital when (1) there was no further need for medical treatment, (2) their MILAS score was 1 or less, and (3) necessary care was arranged at the discharge destination.

\section{Statistical Analysis}

We used data set A to develop the RSM. We first tested all individual variables for multicollinearity (variance inflation factor, less than 10). ${ }^{31}$ Consequently, we used receiver operating characteristic (ROC) curves to dichotomize each of the performance-based variables at the visually optimal sensitivity and specificity cut-offs related to inpatient recovery of activities. ${ }^{11}$

Logistic regression modelling was used to compose the preliminary prediction model. First, we included age, sex, BMI, and ASA score in the logistic regression analysis (enter method), as these variables were established predictors based on the literature. ${ }^{3}$ We then used backward deletion (stepwise multivariable backward method) of the remaining variables in 2 blocks, under the premise that their univariate correlation with inpatient recovery of activities was $\rho<0.20$. Block 1 consisted of conventional medical indices and block 2 consisted of performance-based measures. The final model, therefore, consisted of the base model plus (conventional indices plus performance tests).

The remaining, independent predictors were then weighted by their regression coefficients relative to the weakest predictor. The cut-off point for the RSM was set at a point where both sensitivity and specificity were relatively high. Moreover, we determined the area under the ROC curve (AUC) and the HosmerLemeshow statistic. The AUC represents the sensitivity and specificity of the test, with higher values representing more sensitivity and specificity on each part of the RSM. 
Finally, we used bootstrap validation to account for possible data over fitting produced by generating and testing a logistic regression model with the same data set. Five hundred bootstrap samples generated through replacement were used to estimate the model performance if the selected model was applied to a different sample from the same data set.

When the AUC of the RSM was high (greater than $0.80^{4}$ ), we conducted an external validation, using the data collected at the Nij Smellinghe Hospital (setting B) to fit the original RSM. We recalculated the AUC statistic for these data to determine the predictive value of the RSM. All statistics were performed using STATA Version 12 (StataCorp LP, College Station, TX).

\section{Results}

\section{Development of the Prediction Rule (Data Set A)}

The medical files of 224 consecutive patients were included in the study. Each patient attended a preoperative assessment by the physical therapist. Of the 224 patients, 70 were lost to followup, as their medical files could not be retrieved due to the transition from a paper-based to a digital filing system. In general, the patients lost to follow-up were not clinically different from those included in the study (Table 1). 
Table 1. Characteristics of patients with total hip replacement at intake before surgery.

\begin{tabular}{|c|c|c|c|c|c|c|}
\hline \multirow[b]{2}{*}{ Characteristic } & \multicolumn{2}{|c|}{$\begin{array}{l}\text { Diakonessenhuis } \\
\text { Hospital }(n=154)\end{array}$} & \multicolumn{2}{|c|}{ Nij Smellinghe $(n=271)$} & \multicolumn{2}{|c|}{ lost to follow-up $(n=70)$} \\
\hline & $\mathrm{n}$ & value* $^{\star}$ & $\mathrm{n}$ & value* $^{*}$ & $\mathrm{n}$ & value* \\
\hline age, y & 154 & $70.8 \pm 9.2$ & 271 & $70.4 \pm 8.9$ & 70 & $72.6 \pm 8.9$ \\
\hline \multicolumn{7}{|l|}{$\operatorname{sex}^{\dagger}$} \\
\hline male & 46 & 29.9 & 85 & 31.4 & 19 & 28.0 \\
\hline female & 108 & 70.1 & 186 & 68.6 & 49 & 72.0 \\
\hline $\mathrm{BMI}, \mathrm{kg} / \mathrm{m}^{2}$ & 151 & $27.1 \pm 4.4$ & 268 & $27.7 \pm 4.3$ & 55 & $26.9 \pm 4.6$ \\
\hline Hip flexion, deg & 136 & $85.6 \pm 22.9$ & $\ldots$ & & 45 & $84.3 \pm 17.7$ \\
\hline Pain (0-100) & 147 & $51.7 \pm 20.4$ & $\ldots$ & & 70 & $45.1 \pm 20.8$ \\
\hline Walking time, min & 147 & $18.7 \pm 16.6$ & $\ldots$ & & 70 & $21.2 \pm 21.2$ \\
\hline MILAS (0-30) & 136 & $0.9 \pm 2.1$ & $\ldots$ & & 70 & $0.4 \pm 1.6$ \\
\hline WOMAC pain (0-20) & 95 & $12.8 \pm 4.4$ & 255 & $11.9 \pm 4.3$ & 43 & $12.1 \pm 4.0$ \\
\hline WOMAC stiffness (0-8) & 95 & $4.9 \pm 1.6$ & 254 & $4.3 \pm 1.7$ & 43 & $4.2 \pm 1.7$ \\
\hline $\begin{array}{l}\text { WOMAC physical function } \\
(0-68)\end{array}$ & 94 & $48.6 \pm 14.2$ & 246 & $42.9 \pm 13.4$ & 43 & $46.1 \pm 13.7$ \\
\hline Chair-rise time, s & 137 & $40.4 \pm 33.7$ & 239 & $38.2 \pm 18.2$ & 67 & $31.8 \pm 15.9$ \\
\hline Quadriceps strength, Nm & 126 & $185.0 \pm 73.2$ & $\ldots$ & $\ldots$ & 66 & $188.9 \pm 67.3$ \\
\hline Timed up-and-go test, s & 143 & $12.1 \pm 8.2$ & 259 & $11.7 \pm 6.3$ & 70 & $11.8 \pm 9.2$ \\
\hline Six-minute walk test, $\mathrm{m}$ & 140 & $315.8 \pm 116.6$ & 259 & $336.0 \pm 129.0$ & 70 & $302.0 \pm 128.6$ \\
\hline \multicolumn{7}{|l|}{ ASA score $^{\dagger}$} \\
\hline 1 & 30 & 19.7 & 42 & 18.0 & 38 & 62.3 \\
\hline 2 & 101 & 66.5 & 168 & 72.1 & 8 & 13.1 \\
\hline 3 & 21 & 13.8 & 23 & 9.9 & 15 & 24.6 \\
\hline \multicolumn{7}{|l|}{ Bilateral problems ${ }^{\dagger}$} \\
\hline Yes & 38 & 24.7 & 141 & 52.6 & 15 & 50.0 \\
\hline No & 116 & 75.3 & 127 & 47.4 & 15 & 50.0 \\
\hline \multicolumn{7}{|l|}{ Charnley score $^{\dagger}$} \\
\hline$A$ & 96 & 62.3 & 144 & 53.7 & 14 & 25.9 \\
\hline B & 30 & 19.5 & 70 & 26.1 & 36 & 66.7 \\
\hline $\mathrm{C}$ & 28 & 18.2 & 54 & 20.2 & 4 & 7.4 \\
\hline \multicolumn{7}{|l|}{ Use of preoperative care ${ }^{\dagger}$} \\
\hline Yes & 51 & 33.1 & & & 23 & 32.9 \\
\hline No & 103 & 66.9 & & & 47 & 67.1 \\
\hline \multicolumn{7}{|l|}{ House with stairs ${ }^{\dagger}$} \\
\hline Yes & 96 & 62.3 & & & 44 & 62.9 \\
\hline No & 58 & 37.7 & & & 26 & 37.1 \\
\hline
\end{tabular}

Abbreviations: ASA, American Society of Anasthesiologists; BMI, body mass index; MILAS, modified lowa Level of Assistance Scale; WOMAC, Western Ontario and McMaster Universities Osteoarthritis Index. *Values are mean \pm SD unless otherwise indicated. + Values are percent. 
Table 2. Complications reported by orthopaedic surgeons in 16 out of 154 patients

\begin{tabular}{lr}
\hline complication & $\mathrm{n}(\%)$ \\
\hline & \\
fissure of the femur & $6(4.0)$ \\
pulmonary embolism & $1(0.6)$ \\
cerebrospinal fluid leakage & $1(0.6)$ \\
delirium & $2(1.3)$ \\
peroneus nerve neurapraxia & $1(0.6)$ \\
ileus & $2(1.3)$ \\
low blood pressure interfering with mobilization & $1(0.6)$ \\
pneumonia & $1(0.6)$ \\
wound dehiscence & $1(0.6)$ \\
hip dislocation & $1(0.6)$
\end{tabular}

Table 3. Predictors of delayed functional recovery ( $>5$ days) after total hip replacement (logistic regression)*

\begin{tabular}{|c|c|c|c|c|}
\hline independent variables & $\mathrm{n}$ & odds ratio ${ }^{\dagger}$ & AUC & $\begin{array}{c}\text { AUC change } \\
\text { from base model }\end{array}$ \\
\hline base model & 150 & & .68 & $\ldots$ \\
\hline sex (female vs. male) & & $0.61(0.21-1.74)$ & & \\
\hline age ( $\geq 70$ vs. $<70$ years) & & $1.74(0.71-4.27)$ & & \\
\hline BMI $\left(\geq 25 \mathrm{~kg} / \mathrm{m}^{2} \mathrm{vs} .<25 \mathrm{~kg} / \mathrm{m}^{2}\right)$ & & $2.56(0.88-7.45)$ & & \\
\hline ASA (1/2 vs. 3$)$ & & $2.71(0.96-7.69)$ & & \\
\hline base model plus & 140 & & .82 & $.15^{\ddagger}$ \\
\hline Charnley score (B or $C$ versus $A)^{\S}$ & & $6.12(2.15-17.4)$ & & \\
\hline timed up and go $(\geq 12.5 \text { versus }<12.5 \mathrm{~s})^{\S}$ & & $3.15(1.10-8.96)$ & & \\
\hline
\end{tabular}

Abbreviations: ASA, American Society of Anasthesiologists; AUC, area under the curve; BMI, body mass index. *Patients were dropped from the analyses if no data were present for the item included in the regression analyses. †Values in parentheses are $95 \%$ confidence interval.

$\ddagger \mathrm{P}<.05$.

§Each individual functional test was added together with the Charnley score to the base model, with list wise deletion of subjects with missing tests. 
Table 4. Factor point distribution for the final model for prediction of clinical postoperative recovery.

\begin{tabular}{lr}
\hline risk factor & points $^{\star}$ \\
\hline Sex $($ male $)$ & 1.0 \\
Age $(\geq 70 \mathrm{y})$ & 1.0 \\
BMI $\left(\geq 25 \mathrm{~kg} / \mathrm{m}^{2}\right)$ & 4.5 \\
ASA score (3) & 1.0 \\
Charnley score (B or C) & 10.0 \\
Timed up-and-go test $(\geq 12.5 \mathrm{~s})$ & 6.5 \\
\end{tabular}

Abbreviations: ASA, American Society of Anasthesiologists; BMI, body mass index.

*14.5 points or higher, high risk; less than 14.5 points, low risk.

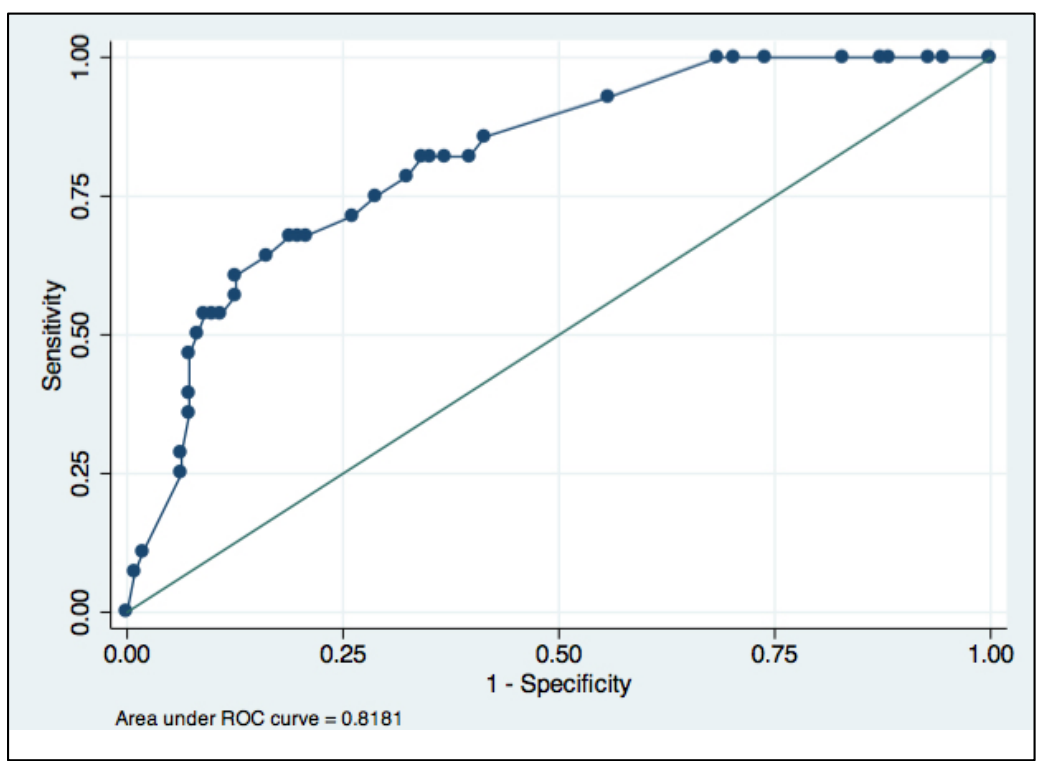

Figure 1. Receiver operating characteristic curve of the final model. Area under the curve was 0.82 . 
Table 5. Classification of predicted functional recovery time by actual recovery time*

\begin{tabular}{|c|c|c|c|}
\hline \multirow[b]{2}{*}{ predicted by CPR } & \multicolumn{3}{|c|}{ actual } \\
\hline & $>5$ days & $\leq 5$ days & total \\
\hline$>5$ days & 19 & 21 & 40 \\
\hline$\leq 5$ days & 9 & 90 & 99 \\
\hline total & 28 & 111 & 139 \\
\hline
\end{tabular}

Abbreviations: $\mathrm{Cl}$, confidence interval; CPR, clinical prediction rule.

*Sensitivity, 68\% (95\% Cl: 47.6\%, 84.1\%). Specificity, 81\% (95\% Cl: 72.5\%, 87.9\%). Positive predictive value, $48 \%$ (95\% Cl: 31.5\%, 63.9\%). Negative predictive value, 91\% (95\% Cl: 83.4\%, 95.8\%). Positive likelihood ratio = 3.6 (95\% Cl: 2.26, 5.69). Negative likelihood ratio $=0.4$ (95\% Cl: $0.23,0.68)$.

Table 6. Classification of predicted functional recovery time by actual recovery time (external validation data set)*

\begin{tabular}{lrrr}
\hline & & \multicolumn{2}{c}{ actual } \\
predicted by CPR & $>4$ days & & \\
& & & \\
$>4$ days & 23 & 48 & 71 \\
$\leq 4$ days & 13 & 101 & 114 \\
total & 36 & 149 & 185
\end{tabular}

Abbreviations: $\mathrm{Cl}$, confidence interval; $\mathrm{CPR}$, clinical prediction rule.

*Sensitivity, 64\% (95\% Cl: 46.2\%, 79.2\%). Specificity, 68\% (95\% Cl: 59.6\%, 75.2\%). Positive predictive value, 32\% (95\% Cl: $21.8 \%, 44.5 \%)$. Negative predictive value, $89 \%$ (95\% Cl: $81.3 \%, 93.8 \%)$. Positive likelihood ratio $=2.0$ (95\% Cl: $1.41,2.78)$. Negative likelihood ratio $=0.5$ (95\% Cl: $0.34,0.83)$.

Data from 154 patients were analysed. The majority of patients were female (70\%), with a mean SD age of 70.89 .2 years and a BMI of $27.14 .4 \mathrm{~kg} / \mathrm{m}^{2}$. More detailed information about the study population is presented in Table 1. Seventeen postoperative complications that might have affected the inpatient recovery of activities were reported, fissure of the femur $(n=6,3.9 \%)$ being the most commonly reported (Table 2 ).

Univariate association with delayed inpatient recovery of activities demonstrated that the WOMAC stiffness score, Charnley score, chair-rise time, handheld dynamometer, TUG, and six-minute walk test were all associated with delayed functional recovery. Variables such as hip flexion, estimated walking time, pain, WOMAC pain score, and WOMAC physical function score were not related to delayed inpatient recovery of activities $(\rho>0.20)$.

Multivariable logistic regression with the forced literature-based variables (ie, sex, age, $\mathrm{BMI}$, and ASA score) yielded a base model with an AUC of 0.68 ( $95 \% \mathrm{Cl}: 0.58,0.78)$. Adding the dichotomized TUG and the Charnley score to the base model increased the AUC to 0.82 (95\% Cl: 0.74, 0.90) (Table 3), with a HosmerLemeshow goodness-of-fit test score of 3.57 $(P=.89)$. 
The final prediction model consisted of 6 dichotomous variables: sex (odds ratio $[O R]=$ $0.8 ; 95 \%$ confidence interval $[\mathrm{Cl}]: 0.2,2.6)$, age (OR $=1.2 ; 95 \% \mathrm{Cl}: 0.4,3.4), \mathrm{BMI}(\mathrm{OR}=2.2 ; 95 \%$ $\mathrm{Cl}: 0.7,7.4)$, ASA score (OR $=1.2 ; 95 \% \mathrm{Cl}: 0.3,4.4)$, Charnley score $(\mathrm{OR}=6.1 ; 95 \% \mathrm{Cl}: 2.2$, $17.4)$, and TUG (OR $=3.1 ; 95 \% \mathrm{Cl}: 1.1,9.0)$. The bootstrap yielded an adjusted AUC that was 0.04 lower than the original $\mathrm{AUC}(0.78 ; 95 \% \mathrm{Cl}: 0.67,0.88$ and $0.82 ; 95 \% \mathrm{Cl}: 0.74,0.90$, respectively).

To create a simple scoring system, points were assigned to the high-risk category of each predictor and summed (Table 4). The curve based on the sum scores of the 6 predictors completely overlapped the curve based on the original regression coefficients. We chose a sum score of 14.5 , with $68 \%$ sensitivity and $81 \%$ specificity, as the optimal cut-off for distinguishing patients at high risk for delayed inpatient recovery of activities from those with normal recovery (Figure 1).

Nineteen of the 40 patients (48\%) with a predicted high risk of delayed inpatient recovery of activities experienced a postoperative inpatient recovery-of-activities time of more than 5 days, in contrast to 9 of 99 patients (9\%) with a predicted normal inpatient recovery-of- activities time (Table 5).

\section{External Validation of Prediction Rule (Data Set B)}

In the second part of the study, the study population used to validate the prediction rule (data set $B$ ) was comparable to that of the initial study population (data set $A$ ) in terms of age and BMI, but was slightly faster on the chair-rise time and TUG, and walked a little farther on the six minute walk test (Table 1). Twenty-three of 71 patients (32\%) with a predicted high risk of delayed inpatient recovery of activities experienced a postoperative inpatient recovery-ofactivities time of more than 4 days, compared to less than or equal to 4 days in 13 of 114 patients $(11 \%)$ with a predicted normal inpatient recovery-of-activities time (Table 6). For the 7 patients who could not perform the TUG, the TUG was classified as 12.5 seconds or longer. A ROC curve was assessed with the scores derived from the prediction model developed in the index data. The AUC of the prediction rule applied to the external data set was 0.71 (95\% Cl: $0.61,0.81$ ). Exclusion of patients with a missing TUG (as applied in the index set) did not change the AUC.

\section{Post Hoc Analysis}

In contrast to the model for predicting prolonged inpatient recovery of activities, the same procedure was conducted to investigate which patients needed 3 days or fewer after THR to reach a MILAS score of 1 or less. Those patients were more often younger men (less than 70 years old) with normal BMI (less than $25 \mathrm{~kg} / \mathrm{m}^{2}$ ), low ASA scores (less than 3), and high walking capacities (greater than $337 \mathrm{~m}$ on the six-minute walk test). The AUC of this model was 0.81 (95\% Cl: 0.72, 0.90). 


\section{Discussion}

In this study, we developed an RSM for inpatient recovery of activities by combining literaturebased indices with additional variables (mostly performance tests) within all ICF domains except participation. The literature-based indices represent an AUC of 0.68 ( $95 \% \mathrm{Cl}: 0.58$, 0.78 ); when they were combined with 2 additional variables, the AUC increased to $0.82(95 \%$ $\mathrm{Cl}: 0.74,0.90$ ). The best prediction model (with a sensitivity of $68 \%$ and specificity of $81 \%$ ) for identifying patients at high risk for delayed inpatient recovery of activities combined the 4 literature-based indices (sex, age, BMI, and ASA score) with the Charnley score and the TUG test. Because the replication of our findings in the validation study was acceptable, the RSM was not altered.

The length of hospital stay is the most frequently studied main outcome variable in studies evaluating the association between preoperative patient-related factors and the recovery of patients undergoing $\mathrm{THR}^{3}$ despite the fact that length of hospital stay depends on more than functional recovery alone. Other contributing factors are (1) medical (preoperative and postoperative protocols, etc.) and (2) discharge variables (availability of nursing home beds, etc.). Therefore, this study identified risk factors for delayed inpatient recovery of activities measured with MILAS instead of length of hospital stay. Wang et al ${ }^{36}$ used a clinical instrument to assess inpatient recovery of activities (modified Barthel index) instead of length of hospital stay. The modified Barthel index overlaps with the MILAS, as they both measure transfers, walking, and stair climbing. Two of the 3 factors reported by Wang et al ${ }^{36}$ (age and comorbidity) were also included in our RSM. Charnley score is the most predictive variable in our RSM. This confirms the conclusions of Röder et $\mathrm{al}^{24}{ }^{24}$ who reported that patients with a preoperative Charnley score of $\mathrm{B}$ or $\mathrm{C}$ were less likely to functionally recover and experience pain relief than were patients with a Charnley score of $A$.

There are some considerations about 2 of the performance tests in this study. First, muscle strength was measured with the handheld dynamometer, but most patients were forced to give up due to pain before reaching their maximum muscle strength. This could explain why muscle strength did not increase the AUC in the logistic regression. Second, the refinement of the lowa Level of Assistance Scale into the MILAS by adding a fifth activity (transfer from sit to supine), which in our clinical experience is crucial for the functional independence of a THR patient, could have affected its clinimetric properties.

The strengths of the study are its pragmatic design (all data collected from regular care) and the acceptable generalizability of the RSM after validation. However, there are also some limitations. First, the analyses for the RSM were conducted with a relatively small sample size, which might have erroneously eliminated slightly weaker predictors from the model. However, the results of our validation show that the RSM outcome may be considered relatively robust. Second, patients in the validation study were mobilized on the day of surgery. Therefore, the cutoff for delayed inpatient recovery of activities was set at 4 days for the validation data set 
instead of 5 days in the index data set. This should be kept in mind when interpreting the external validation analysis. Third, the data in this study were collected between 2007 and 2009. The reader should consider that the clinical pathway in use at that time is different from the currently accepted fast-track regime. ${ }^{14}$ Fourth, the mean age of the study population was 70 years, whereas the current mean age for patients undergoing THR is around 65 years. ${ }^{3}$ This might impact the generalizability of the model.

The RSM provides a preoperative prediction of the postoperative inpatient recovery of activities of individual patients. For instance, patients at high risk for delayed inpatient recovery of activities may benefit from a preoperative physical program. ${ }^{33}$ There is some evidence that a preoperative, individualized, high intensity physical exercise program may increase preoperative function ${ }^{20}$ and decrease inpatient recovery-of-activities time ${ }^{33,34}$ in high-risk individuals.

The study results have implications for future research. First, future studies should include performance-based measurements to properly identify patients at risk for delayed inpatient recovery of activities. ${ }^{13}$ Patient-reported measures, like the WOMAC score, are more influenced by patients' experience and confidence in their own abilities. ${ }^{7,30}$ Furthermore, the inpatient recovery of activities measures the postoperative basic mobility of patients (eg, transfers and walking), whereas the WOMAC items reflect more complex activities (eg, shopping, putting on socks, and domestic duties). Second, this study was focused on literature based classical patient-related variables and preoperative physical function as risk factors for postoperative inpatient recovery of activities; however, the RSM explained only $22 \%$ of the variance in recovery. It would be interesting to assess whether other characteristics (eg, cognitive function, ${ }^{29}$ mental health [eg, anxiety and depression] ${ }^{28}{ }^{28}$ coping styles, ${ }^{9}$ social support, $^{22}$ and patient expectations ${ }^{8}$ ) also contribute to the prediction of delayed inpatient recovery of activities.

\section{Conclusion}

This RSM can determine the risk of delayed inpatient recovery of activities in people undergoing THR. Interestingly, physical performance is a strong predictor of risk for delayed inpatient recovery of activities. Considering that these data are easily acquired, health care professionals should augment their classical preoperative risk evaluation with performancebased indices for predicting the short-term outcome of THR. 


\section{Key points}

\section{Findings}

Twenty percent to $30 \%$ of the patients demonstrated delayed inpatient recovery of physical activities after a THR. Preoperative performance-based tests are strong predictors for delayed inpatient recovery of physical activities.

\section{Implications}

Health care professionals should augment their classical preoperative risk evaluation with performance-based indices for predicting the short-term outcome of THR.

\section{Caution}

The RSM was developed in a specific clinical care setting without fast-track or rapid-recovery interventions (e.g., mobilizing 4 hours postoperatively and avoiding the use of opiates). 


\section{Reference list}

1. Brunenberg DE, van Steyn MJ, Sluimer JC, Beke- brede LL, Bulstra SK, Joore MA. Joint recovery programme versus usual care: an economic evaluation of a clinical pathway for joint replace- ment surgery. Med Care. 2005;43:1018-1026.

2. Charnley J. The long-term results of low-friction arthroplasty of the hip performed as a pri- mary intervention. 1972. Clin Orthop Relat Res. 1995:4-15.

3. Elings J, Hoogeboom TJ, van der Sluis G, van Meeteren NL. What preoperative patient- related factors predict inpatient recovery of physical functioning and length of stay after total hip arthroplasty? A systematic review. Clin Rehabil. 2015;29:477-492. http://dx.doi. org/10.1177/0269215514545349

4. El Khouli RH, Macura KJ, Barker PB, Habba MR, Jacobs MA, Bluemke DA. Relationship of tem- poral resolution to diagnostic performance for dynamic contrast enhanced MRI of the breast. J Magn Reson Imaging. 2009;30:999-1004. http://dx.doi.org/10.1002/jmri.21947

5. Enright PL, Sherrill DL. Reference equations for the six-minute walk in healthy adults. Am J Respir Crit Care Med. 1998;158:1384-1387. http://dx.doi.org/10.1164/ajrccm.158.5.9710086

6. Gallagher EJ, Bijur PE, Latimer C, Silver W. Reli- ability and validity of a visual analog scale for acute abdominal pain in the ED. Am J Emerg Med. 2002;20:287-290.

7. Gandhi R, Tsvetkov D, Davey JR, Syed KA, Ma- homed NN. Relationship between self-reported and performance-based tests in a hip and knee joint replacement population. Clin Rheumatol. 2009;28:253257. http://dx.doi.org/10.1007/ s10067-008-1021-y

8. Gonzalez Saenz de Tejada M, Escobar A, Bilbao A, et al. A prospective study of the as- sociation of patient expectations with changes in health-related quality of life outcomes, following total joint replacement. BMC Mus- culoskelet Disord. 2014;15:248. http://dx.doi. org/10.1186/1471-2474-15-248

9. Greenglass ER, Marques S, deRidder M, Behl S. Positive coping and mastery in a rehabilitation setting. Int J Rehabil Res. 2005;28:331-339.

10. Guccione AA, Fagerson TL, Anderson JJ. Re- gaining functional independence in the acute care setting following hip fracture. Phys Ther. 1996;76:818-826.

11. Hanley JA, McNeil BJ. The meaning and use of the area under a receiver operat- ing characteristic (ROC) curve. Radiology. 1982;143:29-36. http://dx.doi.org/10.1148/ radiology.143.1.7063747

12. Hardy SE, Concato J, Gill TM. Stressful life events among community-living older persons. J Gen Intern Med. 2002;17:832-838.

13. Hoogeboom TJ, van den Ende $\mathrm{CH}$, van der Sluis $\mathrm{G}$, et al. The impact of waiting for total joint replacement on pain and functional status: a systematic review. Osteoarthritis Cartilage. 2009;17:1420-1427. http://dx.doi.org/10.1016/j. joca.2009.05.008

14. Jans $\mathrm{O}$, Bundgaard-Nielsen M, Solgaard S, Johansson PI, Kehlet H. Orthostatic intolerance during early mobilization after fast-track hip arthroplasty. $\mathrm{Br} J$ Anaesth. 2012;108:436-443. http://dx.doi.org/10.1093/bja/aer403

15. Jesudason C, Stiller K. Are bed exercises neces- sary following hip arthroplasty? Aust J Physio- ther. 2002;48:73-81.

16. Kennedy DM, Stratford PW, Wessel J, Goll- ish JD, Penney D. Assessing stability and change of four performance measures: a longitudinal study evaluating outcome fol- lowing total hip and knee arthroplasty. BMC Musculoskelet Disord. 2005;6:3. http://dx.doi. org/10.1186/1471-2474-6-3

17. Kurtz S, Ong K, Lau E, Mowat F, Halpern M. Projections of primary and revision hip and knee arthroplasty in the United States from 2005 to 2030. J Bone Joint Surg Am. 2007;89:780-785. http://dx.doi.org/10.2106/JBJS.F.00222

18. Malani PN. Functional status assessment in the preoperative evaluation of older adults. JAMA. 2009;302:1582-1583. http://dx.doi.org/10.1001/ jama.2009.1453

19. McGinn TG, Guyatt GH, Wyer PC, Naylor CD, Stiell IG, Richardson WS. Users' guides to the medical literature: XXII: how to use articles about clinical decision rules. Evidence-Based Medicine Working Group. JAMA. 2000;284:79- 84. http://dx.doi.org/10.1001/jama.284.1.79

20. Oosting E, Jans MP, Dronkers JJ, et al. Preopera- tive home-based physical therapy versus usual care to improve functional health of frail older adults scheduled for elective total hip arthro- plasty: a pilot randomized controlled trial. Arch Phys Med Rehabil. 2012;93:610-616. http:// dx.doi.org/10.1016/j.apmr.2011.11.006

21. Owens WD, Felts JA, Spitznagel EL, Jr. ASA phys- ical status classifications: a study of consistency of ratings. Anesthesiology. 1978;49:239-243. 
22. Perry MA, Hudson S, Ardis K. "If I didn't have anybody, what would I have done?": Experiences of older adults and their discharge home after lower limb orthopaedic surgery. J Rehabil Med. 2011;43:916-922.

23. Podsiadlo D, Richardson S. The timed "Up \& Go": a test of basic functional mobility for frail elderly persons. J Am Geriatr Soc. 1991;39:142- 148. http://dx.doi.org/10.1111/j.1532-5415.1991. tb01616.x

24. Röder C, Staub LP, Eggli S, Dietrich D, Busato A, Müller U. Influence of preoperative functional status on outcome after total hip arthroplasty. J Bone Joint Surg Am. 2007;89:11-17. http:// dx.doi.org/10.2106/JBJS.E.00012

25. Roorda LD, Jones CA, Waltz M, et al. Satisfacto- ry cross cultural equivalence of the Dutch WOM- AC in patients with hip osteoarthritis waiting for arthroplasty. Ann Rheum Dis. 2004;63:36-42. http://dx.doi.org/10.1136/ard.2002.001784

26. Roy MA, Doherty TJ. Reliability of hand-held dynamometry in assessment of knee extensor strength after hip fracture. Am J Phys Med Re- habil. 2004;83:813-818.

27. Shumway-Cook A, Brauer S, Woollacott M. Predicting the probability for falls in community- dwelling older adults using the Timed Up \& Go Test. Phys Ther. 2000;80:896-903.

28. Singh JA, O'Byrne MM, Colligan RC, Lewallen DG. Pessimistic explanatory style: a psycho- logical risk factor for poor pain and functional outcomes two years after knee replacement. J Bone Joint Surg Br. 2010;92:799806. http:// dx.doi.org/10.1302/0301-620X.92B6.23114

29. Söderqvist A, Miedel R, Ponzer S, Tidermark J. The influence of cognitive function on outcome after a hip fracture. J Bone Joint Surg Am. 2006;88:2115-2123. http://dx.doi.org/10.2106/ JBJS.E.01409

30. Stevens-Lapsley JE, Schenkman ML, Dayton MR. Comparison of self-reported knee injury and osteoarthritis outcome score to perfor- mance measures in patients after total knee arthroplasty. PM R. 2011;3:541-549; quiz 549. http://dx.doi.org/10.1016/j.pmrj.2011.03.002

31. Steyerberg EW. Clinical Prediction Models: A Practical Approach to Development, Validation, and Updating. New York, NY: Springer; 2009.

32. Suzuki T, Bean JF, Fielding RA. Muscle power of the ankle flexors predicts functional perfor- mance in community-dwelling older women. J Am Geriatr Soc. 2001;49:1161-1167.

33. Topp R, Ditmyer M, King K, Doherty K, Hornyak J, 3rd. The e ect of bed rest and potential of prehabilitation on patients in the intensive care unit. AACN Clin Issues. 2002;13:263-276.

34. Villadsen A, Overgaard S, Holsgaard-Larsen A, Christensen R, Roos EM. Postoperative e ects of neuromuscular exercise prior to hip or knee arthroplasty: a randomised controlled trial. Ann Rheum Dis. 2014;73:1130-1137. http://dx.doi. org/10.1136/annrheumdis-2012-203135

35. von Elm E, Altman DG, Egger M, Pocock SJ, Gøtzsche PC, Vandenbroucke JP. The Strength- ening the Reporting of Observational Studies in Epidemiology (STROBE) statement: guidelines for reporting observational studies. Lancet. 2007;370:1453-1457. http://dx.doi.org/10.1016/ S0140-6736(07)61602-X

36. Wang A, Hall S, Gilbey $H$, Ackland T. Patient vari- ability and the design of clinical pathways after primary total hip replacement surgery. J Qual Clin Pract. 1997;17:123-129. 


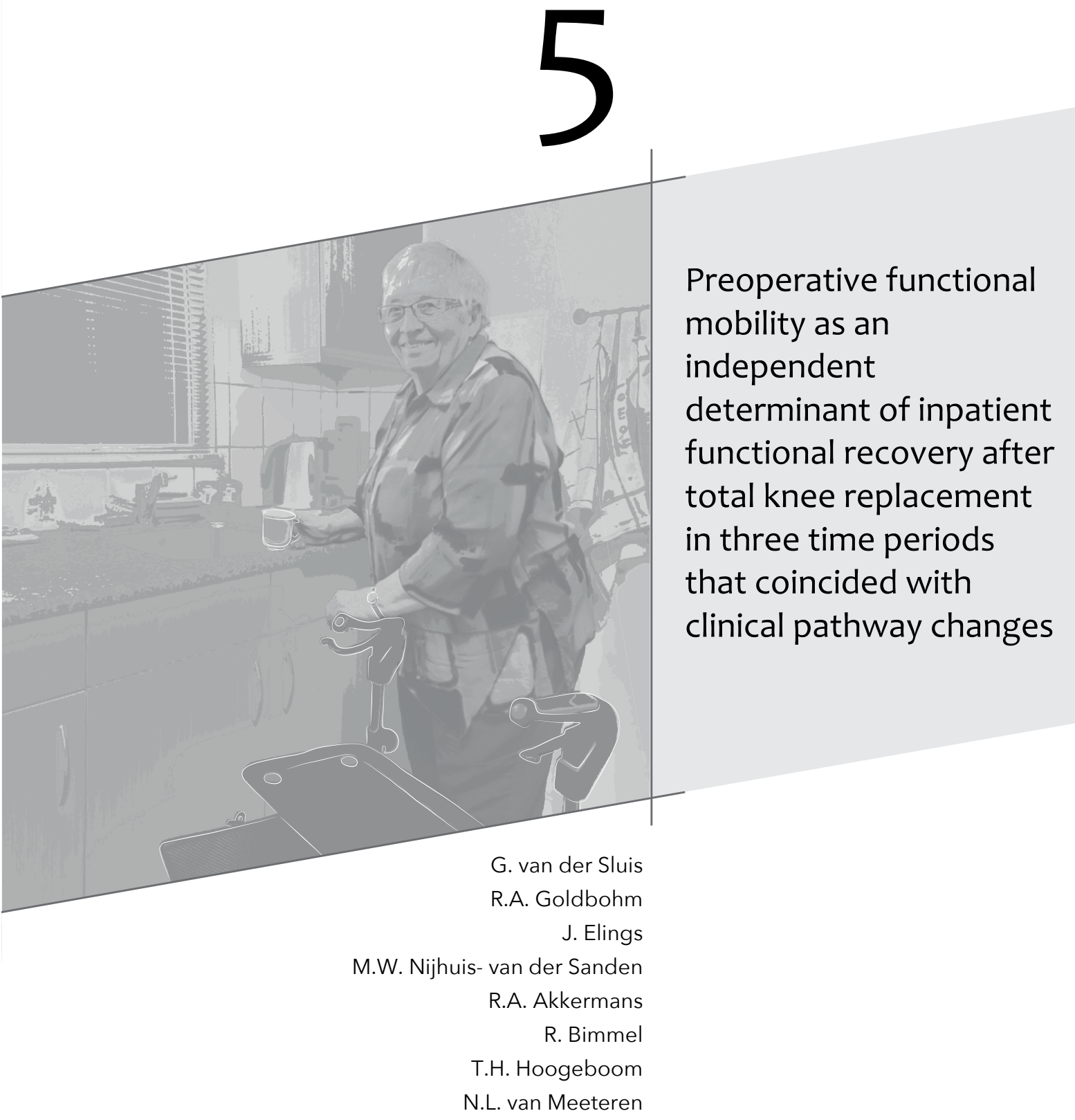

Bone and Joint Journal (2017);

2: $211-217$ 


\section{Abstract}

\section{Aim}

Investigate whether preoperative functional mobility is a determinant of delayed inpatient recovery of activities (IRoA) after total knee replacement (TKR) in three time periods that coincided with clinical pathway changes.

\section{Methods}

All patients ( $n=682$ ) scheduled for TKR between 2009 and 2015, were preoperatively screened for functional mobility by the Timed-up-and-Go test (TUG) and De Morton mobility index (DEMMI). The cut-off point for delayed IRoA was set on the day that $70 \%$ of the patients were recovered, according to the Modified lowa Levels of Assistance Scale (mILAS) (a 5-item activity scale). In a multivariable logistic regression analysis, we added either the TUG or the DEMMI to a reference model including established determinants.

\section{Results}

Both the TUG (OR 1.10 per second, 95\% Cl: 1.06-1.15) and the DEMMI (OR 0.96 per point on the 100-point scale, 95\% Cl: 0.95-0.98) were statistically significant determinants of delayed IRoA in a model that also included age, BMI, ASA score and ISAR score. These associations did not depend on the time period during which the TKR took place, as assessed by tests for interaction.

\section{Conclusion}

Functional mobility, as assessed preoperatively by the TUG and DEMMI, is an independent and stable determinant of delayed IRoA after TKR. 


\section{Introduction}

Disability and poor recovery of activities during hospital stay are common complications after major surgery, especially in the frail elderly. ${ }^{1,2}$ This could be an issue in patients undergoing Total Knee Replacement (TKR), which is an effective high volume treatment in patients suffering from end stage osteoarthritis. It is therefore often performed in the elderly. ${ }^{3}$ Slow functional recovery during hospitalization occurs generally in $30 \%$ of patients over 70 years undergoing major surgery; regardless of the success of the surgical procedure. 4,5,6 These slow recovering patients have an increased risk of being discharged to a skilled nursing facility or rehabilitation centre. Keswani et al. demonstrated that prolonged hospitalization in these post-acute facilities increases the risk of adverse events after TKR. ${ }^{7}$ Therefore, swift recovery of relevant activities (i.e. transferring from bed to a chair, ambulation and climbing stairs), in order to function independently at discharge ${ }^{8}$, is important to prevent a prolonged length of hospital stay and/or discharge to rehabilitation facilities. Ideally, preventive measures (e.g. preoperative physiotherapy) should be initiated as soon as possible after the patient is indicated for surgery. To do so, we need insight in preoperative factors that a) are associated with delayed inpatient recovery of activities and $b$ ) can be improved preoperatively. ${ }^{2,9}$

From other fields of surgery we know that preoperative functional mobility is an important modifiable factor for postoperative recovery. ${ }^{2,9}$ Some authors advocate a routine preoperative functional mobility assessment besides the standard preoperative medical screening of patients scheduled for surgery. They provide objective information which could help during patient and family counselling regarding risks of surgery as well as anticipatory perioperative care planning. ${ }^{1}$ However, evidence on preoperative risk factors predicting inpatient recovery of activities after TKR is scarce. ${ }^{10,11}$ Hoogeboom et al. studied the predictive value of patient characteristics and surgery related variables for delayed inpatient functional recovery. They have found that higher age, female gender and higher BMI were independent risk factors for delayed inpatient functional recovery. ${ }^{10}$ However, these authors did not assess functional mobility as a determinant of delayed inpatient recovery of activities. ${ }^{10} \mathrm{Holm}$ et al. studied the role of preoperative functional mobility as a determinant of hospital discharge based on recovery of activities. ${ }^{11}$ These authors, however, did not find any preoperative factors (except age) that predicted discharge readiness, as most of their patients undergoing fasttrack TKR were discharged within two postoperative days.

It remains to be established whether functional mobility is a determinant of inpatient recovery of activities in a more heterogeneous population and whether such prediction depends on the postoperative circumstances and provided care. The latter is relevant, as clinical pathways for TKR have undergone major changes over the last years. For instance, the start of rehabilitation shifted from two days to two hours after surgery or/and general anaesthesia shifted to use of spinal anesthesia. ${ }^{12,13}$ 
Rather than focusing on who a patient appears to be, clinical care pathways are now increasingly focusing on what a patient actually can do. ${ }^{14}$

Therefore, in this study, we aim to investigate whether preoperative functional mobility - as measured through the TUG or DEMMI (a more extensive measure of functional mobility) ${ }^{15}$ is an independent determinant of delayed inpatient recovery of activities in patients undergoing TKR during three consecutive time periods that are characterized by a change in care pathway. We also aim to investigate whether the association between preoperative functional mobility and inpatient recovery of activities is modified by the time period during which the TKR took place.

\section{Patients and methods}

\section{Setting}

This prospective cohort study is performed in the routine orthopaedic setting in Nij Smellinghe hospital, Drachten, the Netherlands. From May 2009 till March 2015, all patients undergoing primary TKR were routinely screened before and monitored after surgery on their functional mobility. During this 6 year period, the clinical care pathway was updated twice. First, from a Joint Care ${ }^{\circledR}$ pathway $^{16}$ (May 2009 - Dec 2010) towards a Function-Tailored pathway ${ }^{12}$ (Jan 2011 - Oct 2013). Second, from the Function-Tailored pathway towards a Fast-Track pathway ${ }^{17}$ (Nov 2013 - Mar 2015). Table 1 shows the main elements of the three specific care pathways, as applied in the Nij Smellinghe hospital.

According to Dutch law, research with anonymized care data does not require approval from a medical ethical committee and is subject to a general opt-out procedure by the hospital. This standpoint was reconfirmed by the ethical committee of the Nij Smellinghe hospital with respect to this particular study. 
Table 1. Differences between the three clinical care pathways

\begin{tabular}{|c|c|c|c|}
\hline & Joint Care & Function-Tailored & Fast-Track \\
\hline Period & April 2009-august 2010 & $\begin{array}{l}\text { September } 2010 \text { - } \\
\text { October } 2013\end{array}$ & $\begin{array}{l}\text { November } 2013 \text { - May } \\
2015\end{array}$ \\
\hline Preoperative & $\begin{array}{l}\text { Screening of parameters } \\
\text { of human functioning } \\
\text { Medical screening } \\
\text { Information meeting }\end{array}$ & $\begin{array}{l}\text { Screening of parameters } \\
\text { of human functioning } \\
\text { Medical screening } \\
\text { Information module }\end{array}$ & $\begin{array}{l}\text { Screening of parameters } \\
\text { of human functioning } \\
\text { Medical screening } \\
\text { Information module }\end{array}$ \\
\hline Anaesthesia & $\begin{array}{l}\text { Spinal } \\
\text { (bupivacaine } 0.5 \% \text { ) }\end{array}$ & $\begin{array}{l}\text { Spinal } \\
\text { (bupivacaine } 0.5 \% \text { ) }\end{array}$ & $\begin{array}{l}\text { Spinal } \\
\text { (bupivacaine } 0.5 \% \text { ) }\end{array}$ \\
\hline Surgical technique & Medial approach & Medial approach & Medial approach \\
\hline $\begin{array}{l}\text { Preoperative nutritional } \\
\text { management }\end{array}$ & $\begin{array}{l}\text { Starved } 12 \text { hours before } \\
\text { operation }\end{array}$ & $\begin{array}{l}\text { Starved } 12 \text { hours before } \\
\text { operation }\end{array}$ & $\begin{array}{l}400 \mathrm{ml} \text { preop }{ }^{\circledR} 2 \text { hours } \\
\text { before operation }\end{array}$ \\
\hline $\begin{array}{l}\text { Preloading of pain } \\
\text { medication }\end{array}$ & None & None & $\begin{array}{l}3 \text { days before operation } \\
\text { start with Gabapentin }\end{array}$ \\
\hline $\begin{array}{l}\text { Postoperative pain } \\
\text { medication }\end{array}$ & $\begin{array}{l}\text { Patient controlled } \\
\text { analgesia, paracetamol } \\
\text { (acetaminophen), } \\
\text { NSAID's }\end{array}$ & $\begin{array}{l}\text { Patient controlled } \\
\text { analgesia, paracetamol } \\
\text { (acetaminophen), } \\
\text { NSAID's }\end{array}$ & $\begin{array}{l}\text { Gabapentin, local } \\
\text { infiltration analgesia, } \\
\text { paracetamol } \\
\text { (acetaminophen), } \\
\text { NSAID's, } \\
\text { Patient controlled } \\
\text { analgesia as rescue }\end{array}$ \\
\hline Drain / Catheter & $\begin{array}{l}\text { Until } 2 \text { days } \\
\text { postoperative }\end{array}$ & $\begin{array}{l}\text { Removed a.s.a.p. } \\
\text { (<24 hours) }\end{array}$ & $\begin{array}{l}\text { Removed a.s.a.p. } \\
(<24 \text { hours })\end{array}$ \\
\hline Start mobilization & After 24 hours & Within 4 hours & Within 4 hours \\
\hline Discharge planning & $\begin{array}{l}\text { Time table and medical } \\
\text { conditions }\end{array}$ & $\begin{array}{l}\text { Functional and medical } \\
\text { goal setting based on } \\
\text { preoperative screening } \\
\text { outcomes }\end{array}$ & $\begin{array}{l}\text { Functional and medical } \\
\text { goal setting } \\
\text { based on preoperative } \\
\text { screening outcomes }\end{array}$ \\
\hline $\begin{array}{l}\text { Projected discharge from } \\
\text { hospital }\end{array}$ & $\begin{array}{l}5 \text { days, starting from the } \\
\text { day of surgery }\end{array}$ & mILAS score 0 achieved & mILAS score 0 achieved \\
\hline
\end{tabular}

Bold denotes a change from the previous care pathway

\section{Data collection}

All patients placed on the waiting list for a primary TKR were routinely screened by an anaesthetist for surgical risk, by an orthopaedic physiotherapist for functional status and risk for delayed inpatient recovery of activities and by a nurse practitioner for social and environmental issues. 
After surgery, an orthopaedic physiotherapist daily assessed a patient's recovery of activities. The healthcare team in charge of the treatment of patients scheduled for elective TKR consists of four orthopaedic surgeons, four nurse practitioners, four orthopaedic physiotherapists, and thirty-five nurses. To ensure that all patients were assessed in the same manner, we standardized the pre- and postoperative functional assessment by using a measurement protocol and implementing a training programme for the physiotherapists.

\section{Inpatient recovery of activities}

We measured inpatient recovery of activities using the modified lowa Levels of Assistance Scale (mILAS). ${ }^{18}$ The mILAS scores patients' ability to safely perform five activities of daily life (i.e., supine to sit, sit to supine, sit to stand, walking (with walking aids), and stair climbing) and the degree of assistance needed to safely perform these tasks. Scores range from 30 to 0; (the lower the score, the better the activity level of the patient) with a total mILAS score of zero reflecting sufficient inpatient recovery of physical function to be safely discharged home. Stair climbing was only assessed if the patient needed to climb stairs at their discharge destination. Therefore we excluded stair climbing from our outcome measure in those patients who did not require stair climbing. The time (in days) for a patient to achieve a mILAS score of 0/6 was used to compute the outcome variable in this study, i.e. timely versus delayed recovery.

Each update of the care pathway aimed to further improve the quality and speed of inpatient recovery of activities without increasing the risk of readmissions and long term inpatient rehabilitation stay. Therefore, we had to define timely recovery for each specific time period. After exploring cumulative frequency distribution tables and plots, from our data, we decided to set the cut off point for delay in inpatient recovery of activities on the day that $70 \%$ of the patients were recovered, according to the mILAS, for each time period. Patients who did not achieve a mILAS score of 0 before discharge from the hospital were coded as delayed recovered as they all went to inpatient rehabilitation facilities or nursing homes.

\section{Preoperative patient characteristics}

The following potential predictors of recovery were assessed directly after the patient was indicated for TKR: Age (years), gender, BMI $\left(\mathrm{kg} / \mathrm{m}^{2}\right)$, comorbidities assessed by (1) the American Society of Anesthesiologists (ASA) score (ASA score 1-2 or $\geq 3$; a higher score indicates less fit for surgery) and (2) the Charnley score (A/B/C; indicates the function of the knee with regard to the ability to walk; $A$ is more favourable than $C)^{14}$, and self-reported information about frailty included the Identification of Seniors at Risk score (ISAR). ${ }^{19}$ In addition we included the element "stairs at home", because this is an additional activity according the mILAS that could possibly delay the recovery time of the patient. 


\section{Preoperative functional mobility}

This included the Timed Up and Go test (TUG in seconds; assesses functional mobility; a lower score indicates a better functional mobility) ${ }^{20}$ and the DeMorton Mobility Index (DEMMI in points; assesses functional mobility by monitoring 15 functional activities; a higher score indicates a better functional mobility). ${ }^{15}$

\section{Data analysis}

Preoperative patient characteristics were described using counts and percentages for categorical variables, and means and standard deviations (SD) for continuous variables.

We used multivariate logistic regression to determine whether performance-based functional mobility indicators are determinants of inpatient recovery of activities after TKR, independent of other patient characteristics. We first made a model including other potential determinants of recovery as independent variables, i.e. age, gender, ASA, Charnley, ISAR, BMI, and the question "stairs at home?" Subsequently, variables with a non-significant or small contribution were excluded from this model, resulting in the final reference model. The TUG or the DEMMI were each separately added as independent variables to the reference model. To investigate whether time period modified the relationship between functional mobility and inpatient recovery of activities, we added the periods (two indicator variables) and their interaction with preoperative TUG or DEMMI data, respectively, as terms to the model. To avoid multicollinearity between the interaction variables and period variables, we first subtracted the mean from each of the functional mobility measurements (TUG and DEMMI). Finally, we added the DEMMI to the model including the TUG to investigate whether the DEMMI contributes more to the inpatient recovery of activities than the TUG alone. To compare the predictive value of the DEMMI and the TUG we calculated Nagelkerke's pseudo R ${ }^{2}$. All analyses were performed using STATA version 12. Statistical tests were performed two-sided $(p<0.05)$.

\section{Results}

Between May 2009 and March 2015, a total of 682 people undergoing primary TKR (73\% women and a mean age of 70 [SD, 9] years) were screened preoperatively (Table 2). Characteristics of patients who were included during the joint care $(n=171)$, function-tailored $(n=360)$ or fast-track $(n=151)$ period are presented in table 2. Despite inclusion of all patients undergoing TKR in our hospital, we missed $2 \%$ of the values of preoperative characteristics in total. The item with the largest number of missing data was the DEMMI (6\%). 
Table 2. Baseline characteristics by period

\begin{tabular}{|c|c|c|c|c|c|c|c|c|c|c|c|c|}
\hline & \multicolumn{3}{|c|}{ Total population } & \multicolumn{3}{|c|}{$\begin{array}{c}\text { Joint care } \\
\text { (Apr. 2009-Sept. 2010) }\end{array}$} & \multicolumn{3}{|c|}{$\begin{array}{c}\text { Function-tailored care } \\
\text { (Oct. 2010-Oct. 2013) }\end{array}$} & \multicolumn{3}{|c|}{$\begin{array}{c}\text { Fast-track } \\
\text { (Nov. 2013-Mar. 2015) }\end{array}$} \\
\hline & $n$ & mean/\% & SD & $\mathrm{n}$ & mean/\% & SD & $\mathrm{n}$ & mean/\% & $\mathrm{SD}$ & $\mathrm{n}$ & mean/\% & SD \\
\hline $\begin{array}{l}\text { Gender } \\
\text { (\% female) }\end{array}$ & 682 & 73.2 & & 171 & 73.1 & & 360 & 71.4 & & 151 & 78.1 & \\
\hline Age (years) & 682 & 70.0 & 9.1 & 171 & 71.0 & 8.4 & 360 & 69.2 & 9.8 & 151 & 70.9 & 8.0 \\
\hline $\mathrm{BMI}\left(\mathrm{kg} / \mathrm{m}^{2}\right)$ & 682 & 30.0 & 4.9 & 171 & 29.8 & 5.3 & 360 & 30.1 & 5.0 & 151 & 29.9 & 4.1 \\
\hline ISAR (0-6 points) & 660 & 1.0 & 1.1 & 156 & 1.2 & 1.2 & 353 & 0.9 & 1.0 & 151 & 0.9 & 0.9 \\
\hline $\begin{array}{l}\text { ASA (1-5 points) } \\
\text { Charnley score }\end{array}$ & 667 & 1.9 & 0.5 & 156 & 2.0 & 0.4 & 360 & 1.9 & 0.5 & 151 & 2.0 & 0.4 \\
\hline $\begin{array}{l}(\% \mathrm{~B} / \mathrm{C}) \\
\text { Stairs at home }\end{array}$ & 680 & 57.7 & & 171 & 59.1 & & 358 & 55.9 & & 151 & 60.3 & \\
\hline (\% yes) & 678 & 72.1 & & 169 & 59.1 & & 359 & 73.3 & & 150 & 84.0 & \\
\hline $\begin{array}{l}\text { TUG (s) } \\
\text { DEMMI }\end{array}$ & 667 & 11.4 & 6.3 & 170 & 12.1 & 7.1 & 353 & 11.4 & 5.8 & 144 & 10.6 & 10.6 \\
\hline (0-100 points) & 641 & 76.7 & 16.3 & 155 & 77.1 & 17.1 & 344 & 76.2 & 16.6 & 142 & 77.7 & 14.7 \\
\hline
\end{tabular}

Abbreviations: ASA: American Society of Anasthesiologists; BMI: Body Mass Index; DEMMI: De Morton Mobility index; ISAR: Identification of Seniors At Risk; TUG: Timed Up and Go

\section{Cut off point for timely or delayed inpatient recovery of activities}

Using cumulative frequency tables, the cut-off points for timely recovery were set on six (70\%), four $(74 \%)$ and three (70\%) days for the joint care, function-tailored care, and fast-track pathways, respectively (data not shown).

\section{Reference model}

In the logistic regression model including all selected patient characteristics as independent variables, only age (OR 1.06, 95\% Cl: 1.04-1.09), ASA (OR 2.45, 95\% Cl: 1.49-4.02) and ISAR (OR 1.61, 95\% Cl: 1.36-1.97) were significant determinants of delayed inpatient recovery of activities (Table 3). Despite the non-significant, but not negligible contribution of the BMI ( $p$ value 0.06 , OR $1.03,95 \% \mathrm{Cl}: 0.99-1.08$ ) in this model, we decided to include $\mathrm{BMI}$ in the final reference model to avoid possible confounding by BMI of the association between TUG (or DEMMI) and inpatient recovery of activities. The resulting reference model with age, ASA, ISAR and $\mathrm{BMI}$ predicted $15 \%$ of the variance in delayed inpatient recovery of activities (Pseudo $\mathrm{R}^{2}$ ).

\section{TUG as independent determinant}

To investigate whether the TUG added to the prediction of delayed inpatient recovery of activities, we added the TUG to the reference model. The TUG score (OR 1.10,95\% CI: 1.061.15) was a significant determinant of delayed inpatient recovery of activities (Table 3 ). The resulting model predicted $19 \%$ of the variance in delayed inpatient recovery of activities 
(Pseudo $\mathrm{R}^{2}$ ). We further investigated whether the different time period that coincided with clinical pathway changes modified the relationship between TUG and inpatient recovery of activities. The overall interaction between TUG and the time period to the model was not statistically significant $(p=0.41)$.

\section{DEMMI as independent determinant}

To investigate whether the DEMMI added to the prediction of timely inpatient recovery of activities, we added the DEMMI to the reference model. The DEMMI score (OR 0.96, 95\% $\mathrm{Cl}$ : 0.95-0.98) was a significant determinant of delayed inpatient recovery of activities (Table 3). The resulting model predicted $20 \%$ of the variance in delayed inpatient recovery of activities (Pseudo $\mathrm{R}^{2}$ ). The overall interaction between DEMMI and the time period had a non-statistically significant contribution to the model $(p=0.74)$.

To investigate whether the more extensive DEMMI added to the prediction of inpatient recovery of activities over the TUG, we added the DEMMI variable to the model including TUG (Table 3). Both functional mobility measures were statistically significant in this model, while each of the ORs were somewhat attenuated towards 1. The OR for the TUG decreased from 1.10 (95\% Cl: $1.06-1.15)$ to 1.06 (95\% Cl: 1.01-1.11), while the OR for the DEMMI increased from 0.96 (95\% Cl: $0.95-0.98$ ) to 0.97 (95\% Cl: $0.96-0.99$ ). The resulting model predicted $22 \%$ of the variance in delayed inpatient recovery of activities (Pseudo $\mathrm{R}^{2}$ ). 
Table 3: Logistic regression models of determinants of inpatient recovery of activities

\begin{tabular}{|c|c|c|c|c|c|}
\hline model & & Odds Ratio & \multicolumn{2}{|c|}{$95 \% \mathrm{Cl}$} & $\mathrm{p}$-value \\
\hline \multirow{4}{*}{ Reference model } & age (years) & 1.06 & 1.04 & 1.09 & $<0.01$ \\
\hline & $\mathrm{BMI}\left(\mathrm{kg} / \mathrm{m}^{2}\right)$ & 1.04 & 1.00 & 1.08 & 0.06 \\
\hline & ISAR (0-6 points) & 1.64 & 1.36 & 1.97 & $<0.01$ \\
\hline & ASA (1-5 points) & 2.45 & 1.49 & 4.02 & $<0.01$ \\
\hline \multirow{5}{*}{ Model with TUG } & age (years) & 1.03 & 1.01 & 1.06 & 0.01 \\
\hline & $\operatorname{BMI}\left(\mathrm{kg} / \mathrm{m}^{2}\right)$ & 1.03 & 0.99 & 1.07 & 0.19 \\
\hline & ISAR (0-6 points) & 1.37 & 1.12 & 1.67 & $<0.01$ \\
\hline & ASA (1-5 points) & 1.96 & 1.19 & 3.25 & $<0.01$ \\
\hline & TUG (s) & 1.10 & 1.06 & 1.15 & $<0.01$ \\
\hline \multirow{5}{*}{ Model with DEMMI } & age (years) & 1.04 & 1.01 & 1.07 & $<0.01$ \\
\hline & $\mathrm{BMI}\left(\mathrm{kg} / \mathrm{m}^{2}\right)$ & 1.02 & 0.98 & 1.07 & 0.29 \\
\hline & ISAR (0-6 points) & 1.34 & 1.09 & 1.65 & $<0.01$ \\
\hline & ASA (1-5 points) & 2.19 & 1.30 & 3.67 & $<0.01$ \\
\hline & DEMMI (0-100 points) & 0.96 & 0.95 & 0.98 & $<0.01$ \\
\hline \multirow{6}{*}{ Model with TUG and DEMMI } & age (years) & 1.03 & 1.00 & 1.06 & $<0.01$ \\
\hline & $\mathrm{BMI}\left(\mathrm{kg} / \mathrm{m}^{2}\right)$ & 1.02 & 0.98 & 1.07 & 0.31 \\
\hline & ISAR (0-6 points) & 1.29 & 1.05 & 1.60 & 0.02 \\
\hline & ASA (1-5 points) & 2.07 & 1.23 & 3.49 & $<0.01$ \\
\hline & TUG (s) & 1.06 & 1.01 & 1.11 & 0.02 \\
\hline & DEMMI (0-100 points) & 0.97 & 0.96 & 0.99 & $<0.01$ \\
\hline
\end{tabular}

Abbreviations: ASA: American Society of Anasthesiologists; BMI: Body Mass Index; DEMMI: De Morton Mobility index; ISAR: Identification of Seniors At Risk; TUG: Timed Up and Go

\section{Discussion}

The aim of this study was to investigate the role of functional mobility as determinant of inpatient recovery of activities after TKR. We added two measurements of functional mobility, the TUG and the DEMMI, separately to a reference model including the well-established determinants age, ASA, ISAR, and BMI. Both the TUG in seconds (OR 1.10, 95\% Cl: 1.06-1.15) and the DEMMI, in points (0-100) (OR 0.96, 95\% Cl: $0.95-0.98)$ proved independent determinants of inpatient recovery of activities.

For example, a patient who is one second slower on the TUG is $10 \%$ more likely to experience a delayed inpatient recovery of activities, compared to a patient with the same preoperative characteristics, but a TUG time 1 second faster. Time period, representing TKR 
care pathways, which changed twice during the period of observation, did not modify the associations between TUG or DEMMI on one hand and inpatient recovery of activities on the other hand.

Our results seem in contrast to the work of Holm et al. ${ }^{11}$, who did not find any added value of functional mobility as an independent determinant of inpatient recovery of activities in patients undergoing fast-track total joint replacement surgery. ${ }^{11}$ These conflicting results might be explained by the relative low mean age of the population (mean 65 years), as compared to our patients (mean 70 years), and the low score of the preoperative TUG (mean $9.3 \mathrm{~s}$ ), indicating that Holm's patients were functionally more mobile/fit than our patients (11.4 s). Also the spread in the TUG was much lower in Holm's patients than in our patients (SD, 2.3 versus 6.3 s). ${ }^{21}$ We conclude from this comparison that our patient population was more heterogeneous with respect to functional mobility and included a substantial percentage of frail patients ( $25.5 \%$ in our population according the ISAR).

Our study outcomes are in line with the outcomes of Elings et al. in a risk stratification model for delayed inpatient recovery of activities in patients undergoing total hip replacement. ${ }^{22}$ In a multivariate logistic regression model with gender, age, ASA, Charnley score, and $\mathrm{BMI}$, the TUG ( $\geq 12.5$ vs $<12.5 \mathrm{~s}$ ) was a significant determinant of delayed recovery (OR 3.1, 95\% Cl 1.2-9.0) as measured with the mILAS. Application of the same cut-off for the TUG in our data, showed an OR of $3.2(95 \% \mathrm{Cl} 2.1-5.0)$ comparing patients having a TUG $\geq$ $12.5 \mathrm{~s}$ (mean TUG $19.3 \mathrm{~s}$ ) with those having a TUG <12.5 s (mean TUG $8.3 \mathrm{~s}$ ). If patients experience a delayed inpatient recovery of activities, there is a serious risk of important (medical) complications or iatrogenic disability. 4,5 Besides this, inpatient recovery of activities and the length of hospital stay predict functional recovery on the long term. ${ }^{10,23}$ As preoperative functional mobility is a factor that can be positively influenced, our research provides a starting point in looking at how to accelerate inpatient recovery of activities in patients with a high risk for delayed recovery. To our knowledge there is inconclusive evidence for the merit of prehabilitation in people undergoing TKR. ${ }^{9,24-27}$ However, patients at high risk for delayed recovery of activities may benefit from prehabilitation interventions ${ }^{9,28}$ whereas low risk patients may not. ${ }^{24}$ With our work we have shown that poor preoperative functional mobility does hamper inpatient recovery of activities in TKR patients. Any prehabilitation interventions should therefore include functional screening to establish a baseline functional mobility level and to identify patients at risk for prolonged inpatient recovery of activities after the surgery. A preoperative exercise program tailored to optimize the functional mobility of the high risk patient is one of the promising interventions to accomplish his return to the highest level of functioning possible as quickly as possible after surgery. ${ }^{2,9}$

Our study has strengths and weaknesses. An important strength of this study is that the data used in the analyses were collected as part of routine care and relate to all patients undergoing TKR in our hospital. Also, preoperative functional mobility appeared to be a strong 
and stable predictor of inpatient recovery of activities, independent of time period and type of care. Therefore, the findings are applicable not only to the patient population undergoing TKR in our hospital, but probably also to patient populations in other hospitals, provided that this population has similar preoperative characteristics. In the Netherlands, the majority of TKR patients is between 65 and $85^{3}$. We have also shown that the concept of functional mobility was captured consistently by using two measurements, the TUG and the DEMMI. A priori, we expected the DEMMI to be a more comprehensive and therefore better test of functional mobility than the TUG. Together, they appeared to predict slightly better than either test alone, whereas the DEMMI alone indeed performed slightly better than the TUG alone. The availability of baseline information, prospectively collected with validated instruments according to scientific standards at the preoperative functional screening, and availability of well-monitored outcome information made it possible to apply a valid study design. This shows that well-kept, up-to-date patient records that include relevant baseline data are a source of information to monitor the quality of routine medical care in TKR. There are also limitations to our study. First, there were missing data on several study parameters. Missing data were mainly attributed to incomplete patient records. The predictor with the largest number of missing data was the DEMMI (6\%), which can still be considered fairly small. Second, even though we think that delayed inpatient recovery of activities is an important determinant of long term recovery of functional mobility, we were not able to investigate this among our patient population.

Our study has a number of important implications for daily practice and future research. First, we showed that functional mobility, measured by the TUG and the DEMMI, is an important and independent determinant of inpatient recovery of activities after TKR. Therefore, the next step is to develop a risk model in order to select high risk patients and to investigate the effectiveness of prehabilitation interventions in selected TKR patients at risk for delayed inpatient recovery of activities. Oosting et al. showed in a pilot study, that supervised homebased prehabilitation interventions in patients at risk, are feasible and effective on preoperative functional mobility. ${ }^{29}$

\section{Conclusion}

Functional mobility performance of patients undergoing TKR, as assessed by the TUG and DEMMI before surgery, is an independent and stable determinant of delayed inpatient recovery of activities after surgery. Through the addition of functional mobility to preoperative risk assessment, clinicians have the possibility to offer prehabilitation interventions to patients at high risk for delayed recovery. The effectiveness of such prehabilitation interventions on recovery of activities after TKR in high risk patients should be subject of future research. 


\section{Reference list}

1. Malani PN. Functional status assessment in the preoperative evaluation of older adults. JAMA. 2009;302(14):1582-1583. doi:10.1001/jama.2009.1453.

2. Hulzebos EHJ, van Meeteren NLU. Making the elderly fit for surgery. Br J Surg. 2015:n/a - n/a. doi:10.1002/bjs.10033.

3. Otten R, van Roermund PM, Picavet HSJ. [Trends in the number of knee and hip arthroplasties: considerably more knee and hip prostheses due to osteoarthritis in 2030]. Ned Tijdschr Geneeskd. 2010;154:A1534.

4. Covinsky KE, Pierluissi E, Story THEPS. Hospitalization-Associated Disability " She Was Probably Able to Ambulate, but I' m Not Sure." J Am Med Assoc A. 2011;306(16):1782-1793.

5. Ettinger WH. Can Hospitalization-Associated Disability. 2011;01655.

6. Sourdet S, Lafont C, Rolland Y, Nourhashemi F, Andrieu S, Vellas B. Preventable latrogenic Disability in Elderly Patients During Hospitalization. J Am Med Dir Assoc. 2015;16(8):674-681. doi:10.1016/j.jamda.2015.03.011.

7. Keswani A, Tasi MC, Fields A, Lovy AJ, Moucha CS, Bozic KJ. Discharge Destination After Total Joint Arthroplasty: An analysis of Postdischarge Outcomes, Placement Risk Factors, and Recent Trends. J Arthroplasty. 2016:1-8. doi:10.1016/j.arth.2015.11.044.

8. Guccione AA, Fagerson TL, Anderson JJ. Regaining functional independence in the acute care setting following hip fracture. Phys Ther. 1996;76(8):818-826.

9. Hoogeboom TJ, Dronkers JJ, Hulzebos EHJ, van Meeteren NLU. Merits of exercise therapy before and after major surgery. Curr Opin Anaesthesiol. 2014;27(2):161-166. doi:10.1097/ACO.0000000000000062.

10. Hoogeboom TJ, Van Meeteren NLU, Schank K, Kim RH, Miner T, Stevens-Lapsley JE. Risk factors for delayed inpatient functional recovery after total knee arthroplasty. Biomed Res Int. 2015;2015:5-9. doi:10.1155/2015/167643.

11. Holm B, Bandholm T, Lunn TH, et al. Role of preoperative pain, muscle function, and activity level in discharge readiness after fast-track hip and knee arthroplasty. Acta Orthop. 2014;85(5):488-492. doi:10.3109/17453674.2014.934186.

12. van der Sluis G, Goldbohm RA, Bimmel R, et al. What augmented physical activity and empowerment can bring to patients receiving total knee replacement: content, implementation, and comparative effectiveness of a new function-tailored care pathway in a routine care setting. Biomed Res Int. 2015;2015:745864. doi:10.1155/2015/745864.

13. Segal O, Bellemans J, Van Gerven E, et al. Important variations in the content of care pathway documents for total knee arthroplasty may lead to quality and patient safety problems. J Eval Clin Pract. 2013;19(1):1115. doi:10.1111/j.1365-2753.2011.01760.x.

14. Elings J, Hoogeboom T, van der Sluis G, van Meeteren N. What preoperative patient-related factors predict inpatient recovery of physical functioning and length of stay after total hip arthroplasty? A systematic review. Clin Rehabil. October 2014. doi:10.1177/0269215514545349.

15. Jans MP, Slootweg VC, Boot CR, de Morton NA, van der Sluis G, van Meeteren NL. Reproducibility and validity of the Dutch translation of the de Morton Mobility Index (DEMMI) used by physiotherapists in older patients with knee or hip osteoarthritis. Arch Phys Med Rehabil. 2011;92(11):1892-1899. doi:10.1016/j.apmr.2011.05.011.

16. Pilot $P$, Bogie $R$, Draijer WF, Verburg $A D$, van $O s J J$, Kuipers $H$. Experience in the first four years of rapid recovery; is it safe? Injury. 2006;37 Suppl 5:S37-S40. doi:10.1016/S0020-1383(07)70010-4.

17. Kehlet H. Fast-track hip and knee arthroplasty. Lancet. 2013;381(9878):1600-1602. doi:10.1016/S01406736(13)61003-X.

18. Hoogeboom TJ, Dronkers JJ, van den Ende CHM, Oosting E, van Meeteren NLU. Preoperative therapeutic exercise in frail elderly scheduled for total hip replacement: a randomized pilot trial. Clin Rehabil. 2010;24(10):901-910. doi:10.1177/0269215510371427.

19. McCusker J, Bellavance F, Cardin S, Trépanier S, Verdon J, Ardman O. Detection of older people at increased risk of adverse health outcomes after an emergency visit: the ISAR screening tool. J Am Geriatr Soc. 1999;47(10):1229-1237. http://www.ncbi.nlm.nih.gov/pubmed/10522957. Accessed July 27, 2015.

20. Podsiadlo D, Richardson S. The timed "Up \& Go": a test of basic functional mobility for frail elderly persons. J Am Geriatr Soc. 1991;39(2):142-148. http://www.ncbi.nlm.nih.gov/pubmed/1991946. Accessed October 28, 2014.

21. Husted H, Lunn TH, Troelsen A, Gaarn-Larsen L, Kristensen BB, Kehlet H. Why still in hospital after fast-track hip and knee arthroplasty? Acta Orthop. 2011;82(6):679-684. doi:10.3109/17453674.2011.636682. 
22. Elings J, van der Sluis G, Goldbohm S, et al. Development of a Risk Stratification Model for Delayed Inpatient Recovery of Physical Activities in Patients Undergoing Total Hip Replacement. J Orthop Sport Phys Ther. 2016;Jan(26):1-34. doi:10.2519/jospt.2016.6124.

23. Kennedy DM, Stratford PW, Hanna SE, Wessel J, Gollish JD. Modeling early recovery of physical function following hip and knee arthroplasty. BMC Musculoskelet Disord. 2006;7:100. doi:10.1186/1471-2474-7100.

24. Hoogeboom TJ, Oosting E, Vriezekolk JE, et al. Therapeutic validity and effectiveness of preoperative exercise on functional recovery after joint replacement: A systematic review and meta-analysis. PLoS One. 2012;7(5). doi:10.1371/journal.pone.0038031.

25. Ackerman IN, Bennell KL. Does pre-operative physiotherapy improve outcomes from lower limb joint replacement surgery? A systematic review. Aust J Physiother. 2004;50(1):25-30. doi:10.1016/S00049514(14)60245-2.

26. Kwok IHY, Paton B, Haddad FS. Does Pre-Operative Physiotherapy Improve Outcomes in Primary Total Knee Arthroplasty? - A Systematic Review. J Arthroplasty. 2015;30(9):1657-1663. doi:10.1016/j.arth.2015.04.013.

27. Jordan RW, Smith NA, Chahal GS, Casson C, Reed MR, Sprowson AP. Enhanced education and physiotherapy before knee replacement; is it worth it? A systematic review. Physiother (United Kingdom). 2014;100(4):305-312. doi:10.1016/j.physio.2014.03.003.

28. Topp R, Ditmyer M, King K, Doherty K, Hornyak J. The effect of bed rest and potential of prehabilitation on patients in the intensive care unit. AACN Clin Issues. 2002;13(2):263-276. doi:10.1097/00044067200205000-00018.

29. Oosting E, Jans MP, Dronkers JJ, et al. Preoperative home-based physical therapy versus usual care to improve functional health of frail older adults scheduled for elective total hip arthroplasty: A pilot randomized controlled trial. Arch Phys Med Rehabil. 2012;93(4):610-616. doi:10.1016/j.apmr.2011.11.006. 


\section{Abstract}

\section{Aim}

To predict and visually present a patient's individual probabilities of fast, regular and slow inpatient recovery of physical activities after total knee replacement (TKR) from preoperative patient characteristics in the context of patient-oriented decision making.

\section{Methods}

All TKR patients $(n=314)$ operated in the Nij Smellinghe hospital, Drachten, the Netherlands, from November 2013 until March 2016, were preoperatively screened for surgical risk, functional mobility, and issues regarding living environment. After surgery, the Modified lowa Levels of Assistance Scale (mILAS, 5-item activity scale) was assessed daily to monitor progress in inpatient recovery of activities. A multivariate, multinomial logistic model including preoperative patient characteristics as predictor variables estimated individual probabilities of fast ( 2 days) and slow (>3 days) recovery of activities with regular (3 days) recovery as reference.

\section{Results}

Age, BMI, ASA grade, Identification Seniors at Risk score, Timed Up and Go time and DeMorton Mobility Index score were significantly associated $(p<0.05$ ) with fast and/or slow recovery of inpatient activities compared to regular recovery and therefore retained in the prediction model. For the 76 patients that actually recovered their activities fast, application of the prediction model before surgery increased the average predicted probability to recover fast after surgery from 24.9 to $37.1 \%$, an increase of $50 \%$. For the 72 patients that actually recovered slowly, the average predicted probability to recover slowly after surgery doubled after application of the prediction model from 23.6 to $47.3 \%$. For both fast and slow recoverees the predicted probabilities to end up in the opposite category were approximately halved.

\section{Conclusion}

Speed of inpatient recovery of activities after TKR surgery can be predicted from preoperative patient characteristics. The prediction of slow recovery performed better than the prediction of fast recovery. Presentation of probabilities of all possible outcomes - in contrast to a yes or no increased risk of one specific outcome - should provide more insight into the uncertainty of the prediction and should be better understandable for patients to support them in making decisions regarding health care interventions. For healthcare providers is the tool helpful regarding their resource planning. 


\section{Introduction}

Total knee replacement (TKR) is a commonly performed procedure to preserve or enhance functional activities (cf. the WHO's ICF) ${ }^{1}$ of people with end stage degenerative knee disease. ${ }^{2}$ However, part of the population undergoing major surgery such as TKR has a serious risk of slow or insufficient recovery of activities directly after surgery, which can lead to irreversible hospital-related disability. ${ }^{3-5}$

To identify patients at increased risk of delayed inpatient recovery, risk stratification models or clinical prediction rules based on preoperative determinants are often used. The aim of these models or rules is to predict whether the risk for a specific patient is increased or not. ${ }^{6}$ However, this black or white presentation does not take into account that the prediction contains uncertainty and might be difficult to understand for most patients. ${ }^{7}$ In a more patientoriented decision making process, it may be more helpful to present individual predictions to patients as probabilities of the possible outcomes. ${ }^{8-10}$ Such a presentation makes clear that predictions are not black or white and it shows - at the same time - the relative probability of one outcome compared to the other, which is the main message. It is also suitable for graphical representation, for example in a pie chart. Understandable graphical presentation of risks can help patients in gaining insight and make consultations more (time) efficient. ${ }^{7,11}$

Speed of recovery of function after TKR differs between patients. ${ }^{12}$ For adequate, personalized organization and application of care, it is therefore useful to know the probability of the speed of inpatient recovery of activities. Thus, ideally the patient should be provided with a preoperative estimate of the probabilities to recover activities after TKR faster and more slowly than normal and, based on these, to consider specific ( $p$ )rehabilitation interventions.

Aim of our study was to develop and visualize a model to predict a patient's probabilities of fast, regular and slow inpatient recovery after TKR based on prospectively assessed preoperative patient characteristics and postoperative outcome.

\section{Methods}

\section{Setting}

This prospective cohort study is performed in the routine orthopaedic setting in Nij Smellinghe hospital, Drachten, the Netherlands, from November 2013 until March 2016. During this 2.5 year period, the Nij Smellinghe hospital applied a fast-track clinical care pathway for TKR patients. ${ }^{13}$ Box 1 shows the main elements of the pathway. 
Our study was performed in accordance with the declaration of Helsinki and Directive 95/46/EG of the European Union regarding data protection. According to Dutch law, research with anonymized care data does not require approval from a medical ethical committee and is subject to a general opt-out procedure for informed consent applied by the hospital. This standpoint was confirmed by the ethical committee of the Nij Smellinghe hospital with respect to this particular study.

Box 1: Care pathway characteristics for patients undergoing TKR in Nij Smellinghe hospital.

\begin{tabular}{|c|c|}
\hline Preoperative & $\begin{array}{l}\text { Screening of parameters of functional mobility } \\
\text { Medical screening } \\
\text { Information module }\end{array}$ \\
\hline Anaesthesia & Spinal (bupivacaine 0.5\%) \\
\hline Surgical technique & Medial approach \\
\hline $\begin{array}{l}\text { Preoperative nutritional } \\
\text { management }\end{array}$ & $400 \mathrm{ml}$ preop ${ }^{\circledR} 2$ hours before operation \\
\hline Preloading of pain medication & 3 days before operation start with Gabapentin \\
\hline Postoperative pain medication & $\begin{array}{l}\text { Gabapentin, local infiltration analgesia, paracetamol (acetaminophen), } \\
\text { NSAIDs, Patient-controlled analgesia as rescue }\end{array}$ \\
\hline Drain / Catheter & Removed a.s.a.p. ( $<24$ hours) \\
\hline Start mobilization & Within 4 hours \\
\hline Discharge planning & $\begin{array}{l}\text { Functional and medical goal setting based on preoperative screening } \\
\text { outcomes }\end{array}$ \\
\hline $\begin{array}{l}\text { Projected discharge from } \\
\text { hospital }\end{array}$ & $\begin{array}{l}\text { mILAS score } 0 \text { achieved or } 6 \text { when no stair climbing is necessary at discharge } \\
\text { destination }\end{array}$ \\
\hline
\end{tabular}

\section{Data collection}

The healthcare team in charge of the treatment of patients scheduled for elective TKR consisted of four orthopaedic surgeons, four nurse practitioners, four physiotherapists, and thirty-five nurses. All these professionals were working according to the total knee replacement guideline of the Dutch Orthopaedic Society. ${ }^{14}$

All patients were routinely screened by an anaesthetist for surgical risk, by a physiotherapist specialized in orthopaedics for functional mobility and (potential) risk factors for delayed inpatient recovery of activities and by a nurse practitioner for issues regarding the living environment of the patient. ${ }^{16}$ 
After surgery, an orthopaedic physiotherapist (not necessarily the same as the physiotherapist who conducted the screening) daily assessed the patient's inpatient recovery of activities, starting on the day of surgery. To ensure that all patients were assessed in the same manner, we standardized the pre- and postoperative functional assessment by using a measurement protocol and implementing a training programme for the physiotherapists in 2012.

\section{Inpatient recovery of activities}

Inpatient recovery of activities was defined as the time elapsed until recovery of relevant activities (in days, the day of surgery counted as day one), based on the five functional milestones of the modified lowa levels of assistance scale (mILAS). The mILAS is a modified version of the lowa Levels of Assistance Scale (ILAS), which assesses the capability of patients to perform safely four activities of daily life (i.e., supine to sit, sit to stand, walking, and stair climbing) and rates the degree of assistance needed ${ }^{17}$. The mILAS adds a fifth activity, namely, the transfer from sit to supine. ${ }^{6,15}$ Scores range from 30 to 0 , with a score of 0 - or 6 if stair climbing was not required at the discharge destination - reflecting complete recovery of physical functioning relevant for hospital discharge. ${ }^{17}$ The number of days (with day of surgery counting as day 1 ) needed to achieve inpatient recovery of activities was classified into three categories: 2 (fast), 3 (regular), and 4 or more days (delayed). This classification corresponds to cut points at approximately the 25th and 75th percentiles of the distribution of time to recovery according to the mILAS in our data, and is also in accordance with the fast track literature. ${ }^{13}$ Patients who did not achieve recovery before discharge from the hospital were coded as delayed recovered as they all went to inpatient rehabilitation facilities or nursing homes.

\section{Preoperative patient characteristics}

The following patient characteristics were assessed: Age (years), gender, BMI $\left(\mathrm{kg} / \mathrm{m}^{2}\right)$, comorbidities assessed by (1) the American Society of Anasthesiologists (ASA) score (ASA score 1-2 or $\geq 3$; a higher score indicates less fit for surgery) and (2) the Charnley-score (A/B/C; indicates the function of the knee with regard to the ability to walk; $A$ is more favourable than $C)^{18}$, and self-reported information about frailty as assessed by the Identification of Seniors at Risk score (ISAR, scores $>2$ points indicate frailty). ${ }^{19}$ The presence of stairs at home was recorded, because stair climbing requires an activity according to the mILAS and may delay the moment that the patient is considered recovered. 


\section{Preoperative functional mobility}

Preoperative functional mobility was assessed through the Timed Up and Go test (TUG, measured in seconds). A faster time on the TUG indicates a better functional mobility. ${ }^{20}$ As second test of functional mobility the more refined de Morton Mobility Index (DEMMI) was administered. The DEMMI scores range from 0-100 points, a higher score indicates a better functional mobility. ${ }^{21}$

\section{Data analysis}

Preoperative patient characteristics were described using counts and percentages for categorical variables, and means and standard deviations for continuous variables.

All the statistical analysis were performed in STATA version 13.0. Patients with a missing value in one of the independent or dependent variables were excluded from the analyses. We developed a multinomial logistic regression model (mlogit command in STATA) to estimate for each patient the probabilities to recover fast, regularly or slowly with respect to their inpatient activities. In contrast to regular logistic regression, multinomial logistic regression has more than two categories of the outcome (dependent) variable. The dependent variable, i.e. the number of days (with day of surgery counting as day 1 ) needed to achieve inpatient recovery of activities was classified into three categories: 2 (fast), 3 (regular), and 4 days or more (delayed).

Preoperative characteristics (age, gender, BMI, ASA, ISAR score, stairs at home and Charnley score) and preoperative functional mobility (measured through the TUG and DEMMI) were used as independent variables in the multivariate multinomial model. Stairs at home (yes/no), gender (man/woman) and Charnley score $(A / B+C)$ were entered into the model as categorical variables and the other as continuous variables. To estimate the probabilities for fast and delayed recovery the regular recovery group was assigned as reference. The predictors included in the final prediction model were all variables with a statistical significant contribution to either fast or slow recovery or to both. From the resulting regression equations, we calculated for each patient the predicted probabilities for each of the three outcome categories., by using the "predict pr" command in STATA. To provide an impression of the fit of the model we calculated the McFadden pseudo $\mathrm{R}^{2}$ and the likelihood ratio chi-square test ${ }^{2}$. Visual representations of statistical information may enhance the understanding of the possible outcomes of the treatment ${ }^{7}$. Therefore, as an information tool for each patient, a pie chart is presented that can be applied to visualize his individual probabilities (in percent) to recover fast, regularly or slowly.

Statistical tests were conducted two sided and we considered a p-value $<0.05$ statistically significant. 


\section{Results}

Between November 2013 and March 2016, a total of 314 people underwent primary TKR in our hospital. Characteristics of the study population are presented in table 1. The majority of this cohort were women (61.5\%), the cohort had a mean age of 70.1 [SD, 8.4] years and a mean BMI of 29.3 [SD 4.2] kg/m². Despite inclusion of all patients undergoing TKR in our hospital, we missed $0.5 \%(n=9)$ of the total number of values of preoperative variables in total. The item with the largest number of missing data was the DEMMI ( $n=9 ; 2.9 \%$ of all DEMMI-scores).

Table 1: Characteristics of the patients scheduled for TKR at preoperative screening, also divided into the three categories of recovery time

\begin{tabular}{|c|c|c|c|c|c|c|c|c|c|c|c|c|}
\hline & \multicolumn{3}{|c|}{ total population } & \multicolumn{3}{|c|}{$\begin{array}{c}\text { fast recovery } \\
\text { ( } \leq 2 \text { days) }\end{array}$} & \multicolumn{3}{|c|}{$\begin{array}{c}\text { regular recovery } \\
\text { (3 days) }\end{array}$} & \multicolumn{3}{|c|}{$\begin{array}{c}\text { slow recovery } \\
\text { (> } 3 \text { days) }\end{array}$} \\
\hline & $\mathrm{n}$ & $\begin{array}{r}\text { mean } \\
/ \%\end{array}$ & SD & $\mathrm{n}$ & $\begin{array}{r}\text { mean / } \\
\%\end{array}$ & SD & $\mathrm{n}$ & $\begin{array}{r}\text { mean/ } \\
\%\end{array}$ & SD & $n$ & $\begin{array}{r}\text { mean/ } \\
\%\end{array}$ & SD \\
\hline $\begin{array}{l}\text { Gender } \\
\text { (\% female) }\end{array}$ & 314 & 61.5 & & 79 & 63.2 & & 160 & 61.2 & & 75 & 60.0 & \\
\hline Age (years) & 314 & 70.1 & 8.4 & 79 & 66.3 & 7.9 & 160 & 69.7 & 7.8 & 75 & 75.4 & 7.8 \\
\hline BMI $\left(\mathrm{kg} / \mathrm{m}^{2}\right)$ & 314 & 29.3 & 4.2 & 79 & 28.3 & 4.1 & 160 & 29.7 & 4.2 & 75 & 29.4 & 4.3 \\
\hline ISAR (0-6 points) & 314 & 0.8 & 0.9 & 79 & 0.6 & 0.8 & 160 & 0.6 & 0.8 & 75 & 1.4 & 1.0 \\
\hline ASA (1-5 points) & 314 & 2.0 & 0.5 & 79 & 1.9 & 0.5 & 160 & 1.9 & 0.5 & 75 & 2.2 & 0.5 \\
\hline $\begin{array}{l}\text { Charnley score } \\
(\% \mathrm{~B}+\mathrm{C})\end{array}$ & 314 & 58.3 & & 79 & 51.9 & & 160 & 58.9 & & 75 & 64.0 & \\
\hline $\begin{array}{l}\text { Stairs at home } \\
\text { (\% yes) }\end{array}$ & 313 & 83.4 & & 79 & 91.1 & & 159 & 86.9 & & 75 & 67.5 & \\
\hline TUG (s) & 307 & 9.4 & 5.6 & 77 & 6.9 & 2.0 & 157 & 8.6 & 4.0 & 73 & 13.5 & 8.3 \\
\hline $\begin{array}{l}\text { DEMMI } \\
\text { (0-100 points) }\end{array}$ & 305 & 81.9 & 15.0 & 76 & 89.8 & 11.2 & 157 & 83.8 & 13.0 & 72 & 69.6 & 15.1 \\
\hline
\end{tabular}

Abbreviations: ASA: American Society of Anasthesiologists; BMI: Body Mass Index ; DEMMI: De Morton Mobility index; ISAR: Identification of Seniors At Risk; SD: Standard Deviation; TUG: Timed Up and Go test

\section{Predicted individual probabilities of fast, regular and slow recovery}

Twenty five percent of the patients $(n=79)$ recovered fast, fifty one percent $(n=160)$ had a regular recovery time and twenty four percent $(n=75)$ experienced slow recovery (Table 1$)$. Nine subjects ( 3 fast, 3 regular and 3 slow recoverees) with one or more missing values were excluded from the regression analyses. The multivariate multinomial regression analysis revealed that age, BMI, ASA grade, ISAR score, TUG time and DEMMI score were significantly associated ( $p<0.05$ ) with fast and/or slow recovery of inpatient activities compared to regular recovery and were therefore included in the final prediction model. Stairs at home, gender and Charnley score were not significantly associated with fast or slow recovery, compared to regular recovery, in the multivariate model and were therefore excluded from the final model. 
Table 2. Determinants of fast, regular and slow recovery after total knee replacement (multivariate multinomial logistic regression)

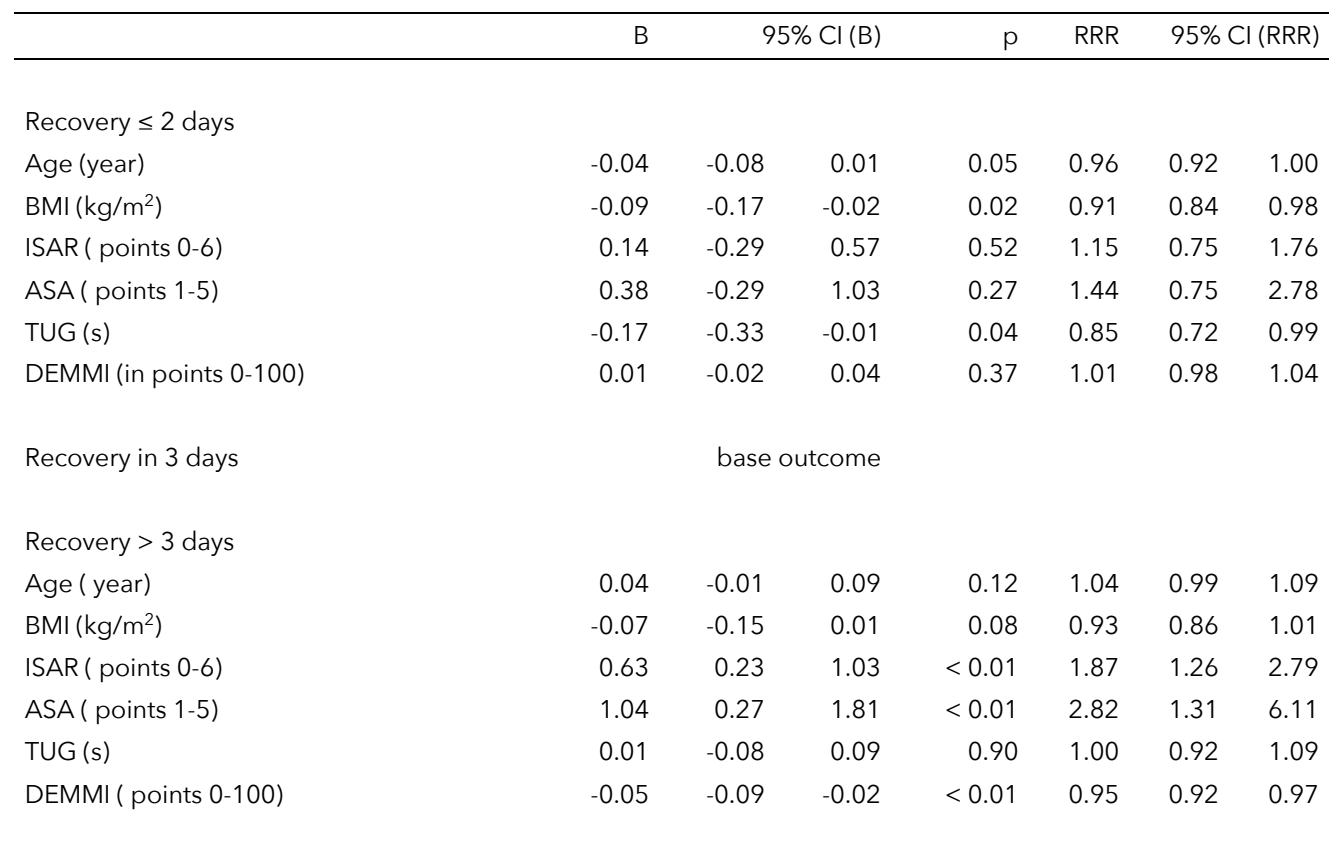

Abbreviations; Cl: Confidence interval; ASA: American Society of Anasthesiologists, BMI: Body mass index, Cl: Confidence interval, DEMMI: De Morton Mobility Index, ISAR: Identification of seniors at risk; RRR: Relative-Risk Ratio

Table 2 shows the results of the final multivariate multinomial logistic model. Age, BMI and TUG time were statistically significant determinants of fast inpatient recovery of activities compared to regular recovery. ISAR score, ASA grade and DEMMI score appeared to be statistically significant determinants of slow recovery of inpatient recovery compared to regular recovery. Thus, younger and leaner patients with a relative short TUG time were more likely to recover fast, whereas frail patients with comorbidities (higher ASA score) and a low DEMMI score were more likely to experience delayed recovery. Regarding the fit of the model, we observed a McFadden Pseudo $R^{2}$ of 0.195 and a likelihood ratio Chi2 of 122.6 ( $p<0.001$ ). 
Table 3. Mean predicted probabilities of fast, regular or slow recovery for actual fast, regular and slow recovered patients without and with application of the prediction model $(n=305)$.

\begin{tabular}{|c|c|c|c|}
\hline & \multicolumn{3}{|c|}{ Actual recovery group } \\
\hline & Fast & Regular & Slow \\
\hline $\mathrm{N}$ & 76 & 157 & 72 \\
\hline \multicolumn{4}{|c|}{ Predicted probabilities (\%) without prediction model } \\
\hline Fast & 24.9 & 24.9 & 24.9 \\
\hline Regular & 51.5 & 51.5 & 51.5 \\
\hline Slow & 23.6 & 23.6 & 23.6 \\
\hline Total & 100 & 100 & 100 \\
\hline \multicolumn{4}{|c|}{ Predicted probabilities (\%) with prediction model } \\
\hline Fast & 37.1 & 24.8 & 12.3 \\
\hline Regular & 51 & 56.8 & 40.4 \\
\hline Slow & 11.9 & 18.4 & 47.3 \\
\hline Total & 100 & 100 & 100 \\
\hline
\end{tabular}

Table 3 shows the mean predicted probabilities of fast, regular and slow recovery for each of the three outcome groups before and after application of the multinomial prediction model. For the 76 patients that actually recovered their activities fast, application of the prediction model before surgery increased the average predicted probability to recover fast after surgery from 24.9 to $37.1 \%$, an increase of $50 \%$. For the 72 patients that actually recovered slowly, the average predicted probability to recover slowly after surgery doubled after application of the prediction model from 23.6 to $47.3 \%$. For both fast and slow recovered patients, the predicted probabilities to end up in the opposite category were approximately halved (Table 3).

As an illustration, table 4 shows the actual and predicted outcomes for the first 20 study subjects. A pie chart (figure 1) displays for one patient his predicted probabilities to recover his activities fast ( $<3$ days), regularly ( 3 days) and slowly ( $>3$ days). 


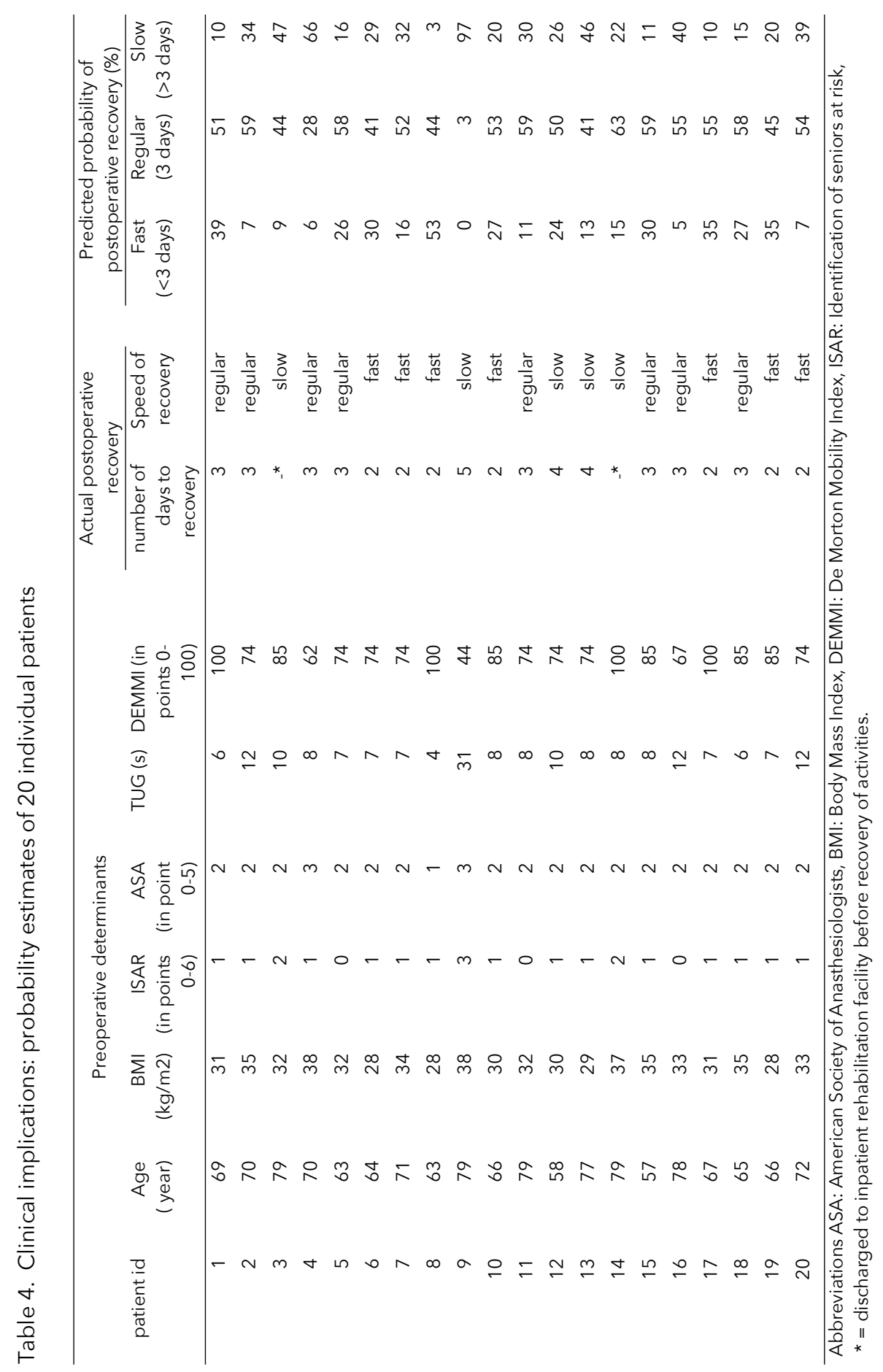




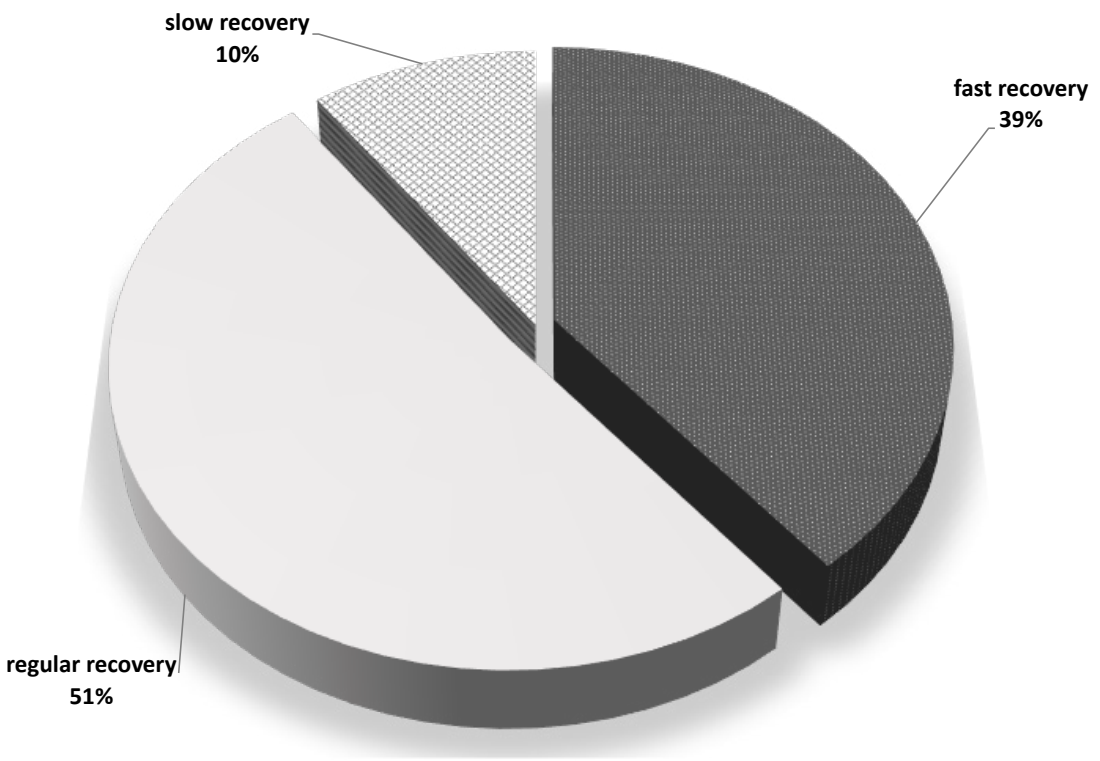

Figure 1. Example of a pie chart of patient \# 1 reflecting his probabilities to recover within 2 days (fast), in 3 days (regular) or $>3$ days (slow)

Information for the patient before surgery:

We have asked you several questions and you have done several tests. Bases on these data we have been able to estimate better how much time you need to function again. That is: to get in and out of bed without help, to sit down in and get up from a chair, to walk with a walking aid and to climb stairs. When you are able to do this, you can be discharged from the hospital. In this pie chart you see your chances to recover functioning in two, three or more than three days. You have a change of $\mathrm{x} \%$ to recover functioning in two days, $y \%$ to recover in three days and $z \%$ to recover in more than three days. We can also say" form 100 persons like you, who are in the same condition as you are before surgery, $x$ will recover in two days, $y$ in three days and $z$ will need more than three days.

\section{Discussion}

In this study we presented a model to predict inpatient recovery of activities after TKR of all possible outcomes by using multinomial logistic regression. This model intended to predict individual probabilities of fast ( 2 days) and slow ( $>3$ days) inpatient recovery of activities with regular ( 3 days) recovery as reference. Model fit statistics revealed that the fit of the model was reasonably good. With application of the prediction model, the average preoperative probability to recover fast increased with $50 \%$ up to $37.1 \%$ among the patients that actually recovered fast. Among the patients that actually recovered slowly, the average preoperatively predicted probability to recover slowly doubled up to $47.3 \%$ with application of the model. 
Although the overall predictive capacity of the multinomial logistic model was reasonably good, the prediction of slow recovery performs substantially better than the prediction of fast recovery of activities. Nevertheless, the prediction of slow recovery is not perfect, as it would have been if the probability of slow recovery among slow recovered patients were $100 \%$. In practice such result is of course never achievable. The multinomial logistic regression analysis also revealed that fast and slow recovery did not share the same determinants. Notable is the difference between the TUG and the DEMMI. Although both are measures of functional mobility, the TUG is more important in the prediction of fast recovery of activities, whereas the DEMMI is a more important predictor of slow recovery. A poor TUG rating in patients with knee osteoarthritis may be explained by a painful knee instead of poor overall functional mobility. The TUG does not distinguish these two different constructs. The DEMMI, on the other hand, gives a poor rating when there are more problems that affect functional mobility than pain alone, such as balance problems, insufficient muscle force, lack of cardio respiratory fitness, other joint damage etc. ${ }^{22}$ Patients at increased risk for loss of functional mobility during and after hospitalization are often frail and elderly individuals, with a hampered premorbid functional mobility. 3,4 Our study supports these findings.

New insights of evidence-based medicine and health (care) have shown the importance of patient involvement in the decisions and organization of care around major surgery. ${ }^{23,24}$ To achieve optimal patient involvement, we developed an information tool - a pie chart reflecting a patient's probabilities to recover in two, three or more days - that offers patients and healthcare professionals adequate and understandable, personalized information with respect to the estimated time to recover their functional mobility while in hospital. A pie chart reflecting the individual probabilities of all possible outcomes is less black and white than e.g. clinical prediction rules, as it incorporates the uncertainty of the prediction. Edwards et al. suggest that communication about probabilities on treatment outcomes should be a two-way process between patients and professionals. They have to exchange understandable information and opinions about the possible outcomes. Several qualitative studies stated that there is a need for individualized probabilities of several outcomes and that numeric or graphical representations of this probabilities influenced decisions more than written representations. ${ }^{25,27}$ Thus, turning statistical data into understandable, visual information is more helpful in these discussions than the data in its raw form. ${ }^{11}$ This is exactly what we have attempted to do. Whether this way of presenting such information to patients is indeed well appreciated and effective, should be subject of future research.

We suggest to use the prediction model to tailor care to patients' capabilities and needs, whether they have a high chance to recover fast or, in contrast, more slowly. For example, patients at high risk of slow recovery may be elected for tailored prehabilitation interventions, which may enhance postoperative recovery of activities. ${ }^{28-30}$ Thienpont et al. stated that organizing TKR surgery on day-case basis is the optimal challenge in enhanced recovery programs. ${ }^{12}$ However, day-case surgery might at the moment not be achievable for all patients. 
Therefore, risk stratification is often used to identify ineligible patients to exclude them from day-case surgery programs. Although day-case surgery for TKR was not yet applied in our hospital, the ability to predict fast, 2-day functional recovery suggests that prediction and selection of eligible patients for day-case surgery may be more effective than prediction and exclusion of ineligible patients. Also, knowledge of the expected individual trajectory of inpatient recovery of activities enables a patient and his informal caregivers to decide -together with the health care professional- about his peri-operative care and rehabilitation process and to plan discharge time and direction (home or elsewhere). Besides, prediction of the speed of inpatient recovery of activities, and the hence prediction of the length of inpatient stay, it is useful information for health care providers to help resource planning, such as bed management.

Our study has strengths and weaknesses. An important strength of this study is its pragmatic nature. The data used in the analyses were collected as part of routine care and relate to all patients undergoing total joint replacement in our hospital. The availability of baseline information, prospectively collected with validated instruments according to scientific standards at the preoperative functional screening, and availability of well-monitored information about inpatient recovery of functional mobility, made it possible to apply a valid study design. Another strength is the use of inpatient recovery of activities as outcome variable instead of length of hospital stay (LoS). Although there is a strong relation between inpatient recovery of activities and LoS, LoS also depends on other factors than recovery alone, such as logistic and administrative factors.

There are also limitations to our study. First, there were missing data on some study parameters. The preoperative determinant with the largest number of missing data was the DEMMI (2.9\% of all DEMMI scores), which can still be considered fairly small. Second, we focussed on short-term, inpatient recovery of functional mobility. Although this appears to be an important determinant of long-term recovery of functional mobility ${ }^{31}$, we did not have data on recovery of functional mobility on the long term. Last, we are aware that the specific model presented in this article is not one-on-one generalizable to other hospital settings. Differences in care pathways, surgery techniques, and patient characteristics may result in different prediction models, although the predictors may be similar. But the method presented here and the way of presenting the individual probabilities of the speed of inpatient recovery of activities to patients can be useful in other settings.

In conclusion, speed of inpatient recovery of activities after TKR surgery can be predicted from preoperative patient characteristics. The prediction of slow recovery performed better than the prediction of fast recovery. Presentation of probabilities of all possible outcomes - in contrast to a yes or no increased risk of one specific outcome - should provide more insight into the uncertainty of the prediction and should be better understandable for patients to support them in making decisions regarding health care interventions. 


\section{Reference list}

1. World Health Organization. Towards a Common Language for Functioning, Disability and Health ICF. Int Classif. 2002;1149:1-22. doi:WHO/EIP/GPE/CAS/01.3.

2. Pitter FT, Jørgensen CC, Lindberg-Larsen M, Kehlet H. Postoperative morbidity and discharge destinations after fast-track hip and knee arthroplasty in patients older than 85 years. Anesth Analg. 2016;122(6):18071815. doi:10.1213/ANE.0000000000001190.

3. Covinsky KE, Pierluissi E, Story THEPS. Hospitalization-Associated Disability " She Was Probably Able to Ambulate, but I' m Not Sure." J Am Med Assoc A. 2011;306(16):1782-1793. doi:10.1001/jama.2011.1556.

4. Ettinger WH. Can Hospitalization-Associated Disability. 2016;1655:29-30.

5. Sourdet S, Lafont C, Rolland Y, Nourhashemi F, Andrieu S, Vellas B. Preventable latrogenic Disability in Elderly Patients During Hospitalization. J Am Med Dir Assoc. 2015;16(8):674-681. doi:10.1016/j.jamda.2015.03.011.

6. Elings J, van der Sluis G, Goldbohm S, et al. Development of a Risk Stratification Model for Delayed Inpatient Recovery of Physical Activities in Patients Undergoing Total Hip Replacement. J Orthop Sport Phys Ther. 2016;Jan(26):1-34. doi:10.2519/jospt.2016.6124.

7. Gigerenzer G, Edwards A. Simple tools for understanding risks: from innumeracy to insight. BMJ Br Med J. 2003;327(7417):741-744. doi:10.1136/bmj.327.7417.741.

8. Hargraves I, Montori VM. Decision aids, empowerment, and shared decision making. Bmj. 2014;349(sep25 6):g5811-g5811. doi:10.1136/bmj.g5811.

9. Elwyn G, Frosch DL, Kobrin S. Implementing shared decision-making: consider all the consequences. Implement Sci. 2015;11(1):114. doi:10.1186/s13012-016-0480-9.

10. Hoffmann TC, Légaré F, Simmons MB, et al. Shared decision making: what do clinicians need to know and why should they bother? Med J Aust. 2014;201(1):35-39. doi:10.5694/mja14.00002.

11. Edwards A, Elwyn G, Mulley A. Explaining risks: turning numerical data into meaningful pictures. Bmj. 2002;324(7341):827-830. doi:10.1136/bmj.324.7341.827.

12. Thienpont $E$, Lavand'homme $P$, Kehlet $H$. The constraints on day-case total knee arthroplasty: the fastest fast track. Bone Joint J. 2015;97-B(10_Supple_A):40-44. doi:10.1302/0301-620X.97B10.36610.

13. Kehlet H. Fast-track hip and knee arthroplasty. Lancet. 2013;381(9878):1600-1602. doi:10.1016/S01406736(13)61003-X.

14. Specialisten KVM. Richtlijn Totale Knieprothese. 2014.

15. Hoogeboom TJ, Van Meeteren NLU, Schank K, Kim RH, Miner T, Stevens-Lapsley JE. Risk factors for delayed inpatient functional recovery after total knee arthroplasty. Biomed Res Int. 2015;2015:5-9. doi:10.1155/2015/167643.

16. van der Sluis G, Goldbohm R, Elings J, et al. Pre-operative functional mobility as an independent determinant of inpatient functional recovery after TKA during three periods that coincided with changes in clinical pathways. Bone Jt J. 2017;99(2):211-217. doi:10.1302/0301-620X.99B2.BJJ-2016-0508.R1.

17. Jesudason C, Stiller K. Are bed exercises necessary following hip arthroplasty? Aust J Physiother. 2002;48(2):73-81. doi:10.1016/S0004-9514(14)60201-4.

18. Elings J, Hoogeboom T, van der Sluis G, van Meeteren N. What preoperative patient-related factors predict inpatient recovery of physical functioning and length of stay after total hip arthroplasty? A systematic review. Clin Rehabil. October 2014. doi:10.1177/0269215514545349.

19. McCusker J, Bellavance F, Cardin S, Trépanier S, Verdon J, Ardman O. Detection of older people at increased risk of adverse health outcomes after an emergency visit: the ISAR screening tool. J Am Geriatr Soc. 1999;47(10):1229-1237. http://www.ncbi.nlm.nih.gov/pubmed/10522957. Accessed July 27, 2015.

20. Podsiadlo D, Richardson S. The timed "Up \& Go": a test of basic functional mobility for frail elderly persons. J Am Geriatr Soc. 1991;39(2):142-148. http://www.ncbi.nlm.nih.gov/pubmed/1991946. Accessed October 28, 2014.

21. Jans MP, Slootweg VC, Boot CR, de Morton NA, van der Sluis G, van Meeteren NL. Reproducibility and validity of the Dutch translation of the de Morton Mobility Index (DEMMI) used by physiotherapists in older patients with knee or hip osteoarthritis. Arch Phys Med Rehabil. 2011;92(11):1892-1899. doi:10.1016/j.apmr.2011.05.011.

22. de Morton NA, Davidson M, Keating JL. The de Morton Mobility Index (DEMMI): an essential health index for an ageing world. Health Qual Life Outcomes. 2008;6:63. doi:10.1186/1477-7525-6-63.

23. Richards T, Montori VM, Godlee F, Lapsley P, Paul D. Let the patient revolution begin. Bmj. 2013;346(may14 1):f2614-f2614. doi:10.1136/bmj.f2614. 
24. Huber M, Knottnerus JA, Green L, et al. How should we define health? Bmj. 2011;343(jul26 2):d4163-d4163. doi:10.1136/bmj.d4163.

25. Kesternich I, Caro FG, Gottlieb AS, Hoffmann S, Winter JK. The role of outcome forecasts in patients' treatment decisions - Evidence from a survey experiment on knee replacement surgery. Health Serv Res. 2016;51(1):302-313. doi:10.1111/1475-6773.12311.

26. Barlow T, Scott P, Griffin D, Realpe A. How outcome prediction could affect patient decision making in knee replacements: a qualitative study. BMC Musculoskelet Disord. 2016;17:304. doi:10.1186/s12891-0161165-x.

27. Barlow T, Griffin D, Barlow D, Realpe A. Patients' decision making in total knee arthroplasty: a systematic review of qualitative research. Bone Joint Res. 2015;4(10):163-169. doi:10.1302/2046-3758.410.2000420.

28. Oosting E, Jans MP, Dronkers JJ, et al. Preoperative home-based physical therapy versus usual care to improve functional health of frail older adults scheduled for elective total hip arthroplasty: A pilot randomized controlled trial. Arch Phys Med Rehabil. 2012;93(4):610-616. doi:10.1016/j.apmr.2011.11.006.

29. Hoogeboom TJ, Dronkers JJ, van den Ende CHM, Oosting E, van Meeteren NLU. Preoperative therapeutic exercise in frail elderly scheduled for total hip replacement: a randomized pilot trial. Clin Rehabil. 2010;24(10):901-910. doi:10.1177/0269215510371427.

30. Hulzebos EHJ, van Meeteren NLU. Making the elderly fit for surgery. Br J Surg. 2015:n/a-n/a. doi:10.1002/bjs.10033.

31. Kennedy DM, Stratford PW, Hanna SE, Wessel J, Gollish JD. Modeling early recovery of physical function following hip and knee arthroplasty. BMC Musculoskelet Disord. 2006;7:100. doi:10.1186/1471-2474-7100. 
General discussion 


\section{General discussion}

This thesis aimed to describe and investigate the development, implementation and effectiveness of the transition of care for patients undergoing TKR in one hospital in the Netherlands (Nij Smellinghe, Drachten). Our goal was to shift from a care process organized in well-documented clinical care pathways to a well-organized individualized perioperative patient journey, with optimal physical functioning and a beginning towards shared decision making as central issues. ${ }^{1}$

\section{Main results}

Figure 1 simplifies the transition of care at the start and at the current situation at the orthopaedic ward in the Nij Smellinghe hospital. The main results of the thesis will be discussed in detail below by following the key elements of the transition as presented in the introduction of this thesis (i.e., "Aim of cure and care", "Decision making", and "Delivery of care").

Transition of care at the orthopaedic ward in Nij Smellinghe hospital between 2009 and 2016

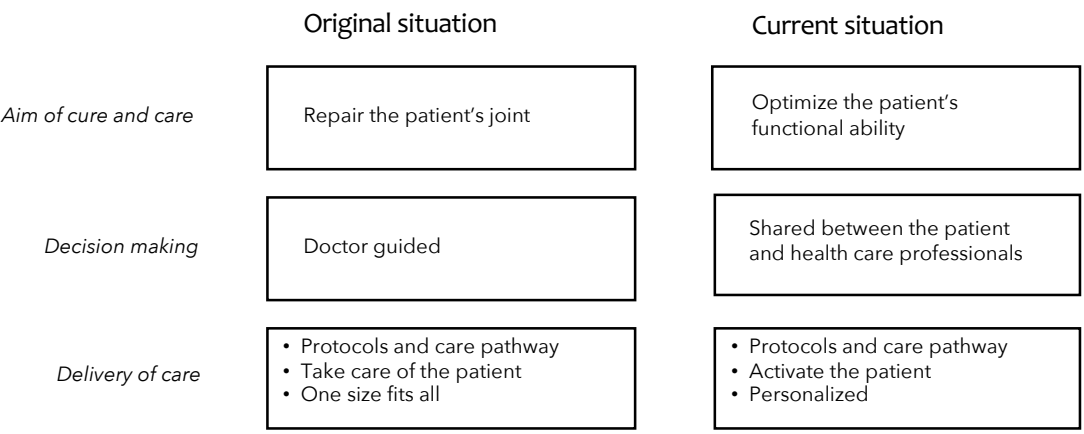

Figure 1. Simplified depiction of the care transition on the orthopaedic ward of the Nij Smellinghe hospital. 


\section{Aim of cure and care}

Several authors advocated to change the focus of the health care system from health as such towards health as a prerequisite for functioning. ${ }^{2-4}$ By changing the focus in the care(pathway) for patients that chose to have TKR from repairing a patient's osteoarthritic knee joint to finding a solution for a arthrosis related problem in a patient's functioning, as stated in the introduction, we changed the care accordingly. Several authors recognize that inactivity during hospitalization is a serious threat for patients during hospital stay. ${ }^{5-8}$ Augmenting activity during the hospitalization period after TKR might therefore be a solution to prevent irreversible loss of functioning among most patients after hospitalization. ${ }^{5-8}$ But today there only limited evidence available that supports the effectiveness of augmenting activity during hospitalization. ${ }^{9,10}$ In chapter 2 we demonstrated that in the newly introduced, function-tailored care pathway, in which stimulation of the patient's activity and personalized functional goalsetting during hospitalisation represented the main changes, a larger proportion of the patients (82\%) undergoing TKR were discharged home when compared with patients who were treated in the period that joint care prevailed (70\%). Also, after statistical correction for differences in patient characteristics, we found that the time to inpatient recovery of activities was shortened by half a day and the period of hospitalization was shortened by one day after the introduction of this new care pathway. ${ }^{11}$

The results described in chapter 2 and further exploration of our perioperative data stimulated us to introduce fast-track surgery as state-of-the-art approach for TKR, as optimal surgery and anaesthetic procedures are important conditions, which help to augment physical activity of patients after TKR surgery. ${ }^{12,13}$ The endocrine metabolic response and the inflammatory response are probably caused by the anaesthesia and surgery leading to a disturbance of the physiological system of the patient. ${ }^{13}$ This phenomenon, known as the "surgical stress response", 1,14 is often leading to undesirable physiological reactions like catabolism, a decreased insulin resistance, and hormonal misbalance. ${ }^{13}$ Although these processes are obviously necessary for wound healing and resistance to infections, they induce an increase of pain, nausea, dizziness, fatigue and sleep disturbance, thereby hampering inpatient recovery of activities. ${ }^{12,13}$ Fast-track surgery, as developed and introduced by Kehlet et al., has proven to be successful by minimizing this surgical stress response, resulting in a decrease of length of stay, morbidity and adverse events (see also table 1). ${ }^{13}$

In the function-tailored pathway as described in chapter 2, we focused on cultural and environmental aspects of hospitalization related to functional recovery. However, the surgical and anaesthetic procedures remained somehow the same as in the joint care pathway. Our hypothesis was that fast-track surgery in a pathway focusing on augmenting activity and functional goalsetting, could enhance patients' recovery even more and better. Therefore, in the third modification of the care pathway, fast-track surgery procedures replaced the surgery procedures used until then. 
Table 1: Factors that are considered to be important in a fast track care pathway as adopted from Kehlet et al. ${ }^{13}$

\begin{tabular}{ll}
\hline preoperative & preoperative risk assessment \\
\hline & information \\
& fluid optimisation \\
& optimisation of organ functions \\
& alcohol / smoking abstinence \\
& no bowel preparation \\
& modern fasting guidelines (preoperative glucose) \\
& Fluid optimisation (avoid hypovolaemia and crystalloid excess) \\
& regional anaesthesia \\
& type of incision \\
& short acting opioids \\
& minimal invasive surgery \\
& multimodal, opioid-sparing analgesia \\
& anti-emetic prophylaxis \\
& minimize use of drains, tubes catheters, monitoring etc. \\
& early oral nutrition and mobilisation \\
& daily care maps, well defined discharge criteria \\
postoperative & rehabilitation plan \\
&
\end{tabular}

As example, in the function-tailored pathway, patients were assisted by a nurse to transfer from bed to a chair about 4 to 6 hours after the operation. In the fast-track pathway, most of the patients are able to start with transfers in and out of bed themselves and start walking already 4 hours after surgery, coached and only assisted if necessary by a physiotherapist. ${ }^{1,12,14,15}$

Although the effectiveness of introduction of the fast-track pathway on inpatient recovery time was not explicitly investigated in this thesis, it is possible to evaluate the effectiveness of the pathway with the available data. The continuously updated database with perioperative data from patients undergoing a total joint replacement in Nij Smellinghe hospital contains the data from all 920 patients that underwent TKR between April 2009 and March 2017, covering the periods in which the Joint-care, function-tailored, and fast-track care pathways-modes were consecutively implemented. Applying the same statistical analysis technique as in chapter 2 (i.e., tobit regression, which takes into account that recovery time is censored if a not yet recovered patient was discharged) on the updated dataset showed that patients needed 1.5 days less to recover on relevant activities during hospitalization if they were treated in the function-tailored care pathway and 2.1 days less if they were treated in the fast-track care pathway when compared to the Joint-care pathway. This has resulted in an average reduction of two days hospital stay, accounting for $€ 1200$ savings per patient. Also, the number of patients discharged to an inpatient rehabilitation centre decreased. In the joint-care period, 
$30 \%$ of the patients were discharged to an inpatient rehabilitation centre, in the functiontailored period this decreased towards $18 \%$ and in the fast-track pathway $9 \%$ of the patients were discharged to an inpatient rehabilitation centre Taking into account that the mean stay of TKR patients in inpatient rehabilitation is 21 days, the reduction from 30 to $9 \%$ of the TKR patients is estimated to have resulted in a saving of $€ 4410$ for each patient that went home instead of to the rehabilitation centre. A crude estimated total cost reduction for all patients undergoing TKR in Nij Smellinghe hospital amounts therefore up to $€ 425,000$ per year (200 patients $x € 1200+21 \%$ of 200 patients $x € 4410=€ 425,220)$. Whereas the results of chapter 2 showed an improvement of recovery time of 0.5 days during the function-tailored pathway compared to the Joint care pathway, we found an improvement of 1.5 days in this updated analysis. This seemingly different result can be entirely attributed to the extension of the number of patients in the function-tailored pathway $(n=360)$ as compared to those included in the dataset used in chapter $2(n=108)$. This finding shows that the full potential of the new care pathway was apparently achieved only sometime after its introduction.

\section{Decision making}

Our long-term goal is to apply SDM throughout the total patient journey with the help of a wellestablished SDM model. Our literature review (chapter 3) revealed, however, that the SDM processes applied among TKR patients, only focussed on the decision to have TKR or not, but not on other relevant elements of the total patient journey. We found in the review that patients may refrain from TKR because they felt too old, are unsure about the outcome of surgery or have more confidence in other treatment options like medication or physical therapy. Moreover, experiences (both positive or negative) of important others and (social) media may be considered as sources of information for a patient in their search for an optimal solution for their complaints in their physical functioning. We identified four relevant themes that specified the relevant factors and preferences of patients to take part in a process of SDM, namely: 1) relevant personal factors, 2) relevant external factors, 3) utilized information sources, and 4) preferences towards prediction tools and presentation of relevant information to enhance SDM. We also studied the literature on how SDM was applied among patients choosing or undergoing TKR. We concluded that needs and preferences as mentioned by patients are not covered by the SDM processes as described in the scientific literature. Therefore it is possible that the SDM processes described in the literature do not have a strong impact on the decisional process between patient and professional and patient outcomes after surgery and will therefore not be so relevant to day-to-day practice. 


\section{Care delivery}

To deliver the right care to the right patient, anticipation of possible scenarios of the outcome for every individual patient is a necessary step. Chapter 4 showed that prediction whether a patient is at high risk for delayed inpatient recovery of functioning after total hip replacement, can be done rather well by using six preoperative determinants; (1) gender male, (2) $\mathrm{BMI}>25$ $\mathrm{kg} / \mathrm{m}^{2},(3)$ age $>70$ years, (4) ASA score of 3, (5) Charnley score B/C and (6) a TUG time $>12.5 \mathrm{~s}$. This result can be considered as a prelude to chapter 5 where preoperative functional mobility indices as the TUG and the De Morton mobility index (DEMMI) were found to be independent determinants of delayed inpatient recovery of activities after TKR in a model including age, $B M I, A S A$ score and ISAR score. Both instruments have been proven to measure the construct of functional mobility ${ }^{16-20}$, and the TUG is also a well-established predictor of several TKR outcomes. ${ }^{17,18,21}$ The TUG can be seen as a quick scan, which gives insight whether patients are functionally hampered. ${ }^{19}$ By using the more extensive DEMMI test it is possible to distinguish between different dimensions of the patient's functional mobility, like transfers, walking capacity, coordination, etc. The outcomes of these measurements provide patient and therapist with information to direct interventions that can positively influence a patient's functional mobility. ${ }^{20,22}$

When functional goalsetting is leading, in discharge planning (moment and destination), instead of a timetable like in the Joint-care period, variation based on the abilities and motivation of patients in the speed of recovery is a logical consequence. ${ }^{12,23,24}$ For some patients it should be possible to opt to have their TKR in day-case surgery, but others need two or even more days to be ready to go home. Prediction of a patient's chances of each possible outcome (i.e., 2, 3 and more than 3 days) could be more informative and appealing than prediction of a negative outcome only. In chapter 6 we developed a prediction model by using multinomial logistic regression with all relevant outcomes and reporting of the absolute probabilities of each outcome instead of relative probabilities, such as odds ratios. Whether this way of presenting the prediction of outcome after TKR is more effective than presenting a prediction of an increased risk for delayed recovery or not, has not yet been investigated.

\section{Methodological considerations}

\section{Establishing effectiveness}

Effectiveness of health care interventions is often evaluated in a dedicated research setting, requiring funding, medical ethical approval and informed consent from the patients for research. In contrast, we started with changing the care for patients undergoing TKR after scrutinizing the available perioperative data. The results of this examination showed a large gap between inpatient recovery of activities and the length of hospital stay. To evaluate the effectiveness of all three care transitions, we used the data available from routine care combined with an observational study design. 
The most important issue when investigating effectiveness of health care interventions is to evaluate if the new intervention is better than the old one. To do so, groups of patients receiving the new and the old treatment have to be compared. A well-established research method to evaluate the effectiveness of a new intervention is the randomized controlled trial (RCT). An important advantage of a RCT is that it controls for confounding influence of intervening variables, other than the experimental intervention, on the outcome variable. In other words, randomization assures that groups of patients that are to be compared are completely comparable with exception of the treatment. For a valid observational study, we have to make the groups of patients comparable, both by choosing a suitable study design and by controlling for confounding in the statistical analysis of the data. For an observational study that evaluates the effectiveness of a specific health care intervention on a specific outcome, it is therefore essential to know the potential confounding factors and how they can be objectified by the use of validated measurement instruments. Therefore, we performed literature reviews to get insight in preoperative factors that have an important influence on inpatient recovery of activities in patients undergoing total hip replacement (THR) and TKR and also on how these could be measured. ${ }^{25}$ To ensure that important pre- and postoperative measurements were accurately and reliably performed, a standardized measurement protocol was developed. All physiotherapists involved in the preoperative screening of a patient's functional mobility were trained according this protocol. Based on the literature, we also defined our outcome parameter, the mILAS, on which we would determine whether our intervention (in our case a new care pathway) was effective. The mILAS was also chosen as it is a short instrument with a few clear-cut categories, which should be less susceptible to differential explanation, thereby minimizing a potential effect of the unavoidable lack of blinding in our research setting. Data in all groups were recorded by physiotherapists who were arbitrarily assigned to patients based on his or her availability; therefore we expect no systematic bias in the data. However, as our studies were based on usual care data, we had to compare the patients treated in the new care pathway with those treated before the introduction of the new care pathway, i.e. a historical cohort. By standardizing the data collection methods, supported by training of all attendant and newly employed physiotherapists at the orthopaedic ward and by monitoring the data at regular intervals, we intended to minimize any systematic drift over time. 
Example:

After scrutinizing the preoperative data, we obtained a significantly better TUG score for patients that were screened by one specific physiotherapist. The average TUG time was 2.5 seconds faster when compared with the patients that were screened by the other physiotherapists. We asked this physiotherapist if he had an explanation for the difference on the TUG. His answer was that he instructed the patients to perform the TUG test as fast as they could and that they had to imagine that a pan with potatoes was boiling over. This instruction was slightly different from the instructions that we had agreed on during the training sessions. To solve the problem, we removed the TUG measurements of patients screened by this specific therapist from the database and instructed the physiotherapist to adjust his instruction according to the agreed protocol.

We showed that good quality effectiveness research is possible and feasible by using well planned and maintained databases derived from routine care. The advantages of such effectiveness research are the optimal generalizability, as we did not apply selection to our study population and use of the data for research purposes is subject to a general opt-out for consent applied by the hospital. Research with anonymized care data does not require approval from a medical ethical committee. In RCTs, in contrast, the inevitable in- and exclusion criteria and required informed consent constrain the generalizability of the results. ${ }^{26,27}$ In addition, a continuously updated database from routine care, containing standardized and valid data, gives the opportunity to evaluate effectiveness of care time after time. A RCT, in contrast, every time requires funding, an extensive preparation and research period, with the development of a research protocol, medical ethical approval procedures, etc. ${ }^{26}$ The type of research that we were able to conduct saves a lot of money and time, which is an important advantage. ${ }^{26}$ The idea that study designs other than RCTs may be valuable is more and more accepted. ${ }^{27}$

\section{Prediction of the speed of inpatient recovery of activities after TKR}

For the development of a prediction model, several methods exist. ${ }^{28-30}$ The method to use strongly depends on the purpose of the model. For example the FRAX for predicting a patient's risk for a hip fracture is a good example of a risk model that can be universally applied. ${ }^{31}$ But a prediction model can also be developed for shared decision making, to personalize the care and for resource planning in a specific hospital. ${ }^{32,33}$ For the first purpose there are three well-established stages that should be followed when developing a prediction model. ${ }^{30}$ The first step is creating the model. In this step researchers identify a list of potential determinants that have some prognostic value on the outcome of interest, test them on a cohort of patients and select and combine them in a multivariate regression model. The second step is to validate this model on a different population of patients, for example on 
patients from another hospital or practice. The last step is to assess whether the prediction model does indeed change the behaviour of health care professionals and improve patients' health care outcomes and costs. Such impact analysis is performed before the final implementation.

The main purpose of our prediction models was to assist in SDM, to personalize the care and for resource planning in our own hospital. Therefore, the validation step was not performed except for the risk stratification model from chapter 4. Originally, the purpose of this model was universal application and therefore cross-validation was applied on patients from another hospital. This exercise showed that, because the setting and context in the two hospitals were not similar, adjustment of the data was necessary to perform the validation. For example, in the index hospital the usual time to recovery was 5 days due to 24 hours bed rest after surgery, whereas in the validation hospital the usual time to recovery was 4 days as the patients were already mobilized 4 hours after surgery. The limitations of the different hospital contexts and cultural aspects for cross-validation of our risk stratification model challenged us to rethink the steps to develop prediction model without using other hospital settings or practices. In chapter 5 we therefore used data from patients who were treated in the same hospital, but where the applied care was changing over time. To test whether important preoperative determinants were stable over time and thus more universal in different contexts, we used a statistical method to evaluate whether the factor time had interaction with the TUG or the DEMMI as determinants of inpatient recovery of activities measured by the mILAS. During the time period of this study, the three different care pathways for TKR were consecutively implemented in our hospital. We found that the factor time did not affect the TUG and DEMMI as determinants of speed of inpatient recovery of activities of patients after TKR. Thus, even with data from one hospital, it is possible to investigate if important preoperative determinants are stable over time and in different situations and therefore more universally applicable.

We did not perform the third step either, i.e. an impact analysis, as the main goal of the development of our prediction models was to assist in personalized functional goalsetting for patients opting for TKR and not to change the care in itself. And the effectiveness of our care transition, in which prediction of outcome is an essential element, was evaluated after its implementation all the same.

In chapter 6 we presented a prediction model of both fast and slow recovery compared to a regular recovery period of three days. As we selected only potential determinants of delayed recovery from the literature for the preoperative screening, we might have missed specific determinants of fast recovery in the database. We observed indeed that the prediction of slow recovery was more precise than the prediction of fast recovery and that the final set of determinants in the prediction model were not similar for slow and fast recovery. However, there are not yet any established preoperative determinants for fast recovery after TKR, other than those for delayed recovery. For example, also Thienpont et al. used determinants that 
predict risk of delayed recovery to exclude patients that are not eligible for undergoing TKR in a day-case surgery pathway. ${ }^{24}$ However, based on our results, selection of patients for day case surgery might be more successful by using determinants that are established for the prediction of fast and uncomplicated recovery after TKR. ${ }^{24}$

\section{The scoping review design}

Scoping reviews aim to map rapidly the key concepts of a specific research area and the main sources and types of evidence available, especially when an area is complex or has not been reviewed comprehensively before. The method identifies all relevant literature regardless of study design in an iterative process. ${ }^{34,35}$ This gives the opportunity to reflect on each step and, when necessary, repeat steps to ensure that the literature is fully covered in a concessive and comprehensive way. In chapter 3 we performed a scoping review that aimed to map the literature with respect to the relative unknown research theme of SDM between patients and healthcare professionals around TKR. ${ }^{34,35}$ In contrast to a scoping review, a systematic review uses a relative narrow range of quality-assessed research to answer specific well-defined research questions, whereas a scoping review does not address specific research questions and does not assess methodological quality either. ${ }^{34,35}$ The established steps for summarizing and collating the information from the available literature for a scoping review were followed. ${ }^{35}$ Additionally, we combined this scoping review approach with the assessment of the methodological quality of the included quantitative studies and with meta ethnography ${ }^{36}$ of the included qualitative studies. Furthermore, a well-known model of SDM was used to analyse the quality of the applied SDM methods in the reviewed quantitative studies. These steps go beyond the methodology of a scoping review but were performed to give more robustness to the results and conclusions. Because of the quality assessment step, we were able to conclude that the studies included in the review were of low quality and therefore limited the conclusions of the review. The scoping review gave us insight into the state-of-the-art on SDM around TKR, by exploring and reviewing all literature on the subject, regardless of study design. Only few scientific articles investigated SDM with heterogeneous study designs and low methodological quality. The observed differences between needs and preferences of patients regarding health care decisions and the content of the applied SDM interventions that were offered by health care professionals were an eye opener, which we will take into account when introducing SDM in our practice.

\section{Practical considerations}

Our challenge was to do high quality scientific research among patients in the daily care setting, without compromising the care for these patients. To do so we needed a research method to fit our wish to achieve a relevant improvement of care for patients undergoing TKR with the routine care situation as starting point. 
Results and conclusions obtained from RCTs do not often provide health care professionals with generalizable information on how to use an intervention in their specific context, or how the research outcomes can be reproduced. ${ }^{37,38}$ When implementing complex interventions, like we did, process evaluation is an essential part of the implementation. This is often a forgotten step in the implementation process of interventions that are based on RCT outcomes. ${ }^{37}$ Complex interventions have a better uptake in daily practice if health care professionals and scientists collaborate in a research-based implementation strategy. ${ }^{37}$ One of the key aspects in such an implementation process is the use of patient data obtained from daily care. Therefore, we used principles of participatory action research and embedded science, in which process evaluation is an important element. Embedded science is based on the premise that knowledge is collected and created "on the ground" through daily interaction and negotiation with practitioners, managers and service users. ${ }^{39}$ This should provide better insight into the issues affecting these stakeholders that are more relevant to the local context and can therefore be more easily incorporated in practice 39,40 and complies with the "learning communities" approach, which will be discussed later in this chapter. Also barriers for implementation are identified and therefore solved more quickly. ${ }^{40}$

\section{Example}

The purpose of enhanced recovery programs is to facilitate patients to be up and running as soon as possible after surgery. One of the barriers to do so are infusion lines and urine catheters attached to the patient. These are typically medical interventions that hamper patients in being active by themselves. The fast-track literature recommend that the standard use of urine catheters is not necessary in patients undergoing TKR. ${ }^{41}$ In our hospital it was the standard to have an urine catheter during the first 24 hours after TKR surgery. Due to the constraints in mobility experienced by patients caused by urine catheters we de-implemented them, after discussion with the nursing staff, anaesthesiologist and orthopaedic surgeons. But after a while we saw that more than half of the patient population needed a urine catheter after all, due to urine retention in the bladder caused by the duration of the spinal anaesthesia used in our hospital, which also affects the bladder function. Therefore nurses were nevertheless forced to place a urine catheter after the anaesthesia had worked out. This was highly uncomfortable for patients and very time consuming for the nursing staff. Thus at a process evaluation after 3 months, we concluded that the idea to omit urine catheters at surgery, which was adopted from the literature, worked counterproductive. We decided that patients undergoing TKR should receive a standard urine catheter as before. But as soon as the patient can walk to the toilet together with the physiotherapist the catheter is removed, which is normally after 4 to 6 hours after surgery. 
Participatory action research is based on data collection, reflection and action by the actors who are involved in the care for patients undergoing TKR in our hospital. ${ }^{42}$ In action research healthcare professionals are learning by experience. ${ }^{42,43}$ This experimental way of learning is seen as an important source to influence and change practice. In the transition process we tried to understand and improve the care delivery by changing it. Therefore we first implemented new interventions in daily practice, before we investigated its impact on patient outcomes. Chapter 2 described how we, driven by the data from our routine care process, implemented interventions and measurements that aimed to improve the short-term functional outcome of patients and at the same time helped us to organize the care more efficiently. For example, one of the purposes of the implementation of functional goalsetting was to create more awareness in the healthcare team about the moment that inpatient recovery of activities was achieved and the importance of functional independency as criterion for discharge readiness.

In such transition processes, in which traditional (old) care delivery or interventions are replaced by new solutions, the essential role of the participants (actors in the healthcare processes) is often overlooked. ${ }^{44}$ The participants involved in the care transitions in our hospital collected and scrutinized the data together and, based on the results, determined what kind of action should be performed. ${ }^{42,45}$ An iterative cycle of data-collection, analysing, reflection and new action was the result. One of the consequences of the iterative cycle was that the orthopaedic surgeons, physiotherapists, nurse practitioners and nurses became important partners in the research or even performed part of the research themselves. Especially the embedded scientist who, in daily practice, collects, creates and reviews knowledge and investigates the effectiveness of newly implemented interventions was successful in creating and implementing the innovations. ${ }^{39,40}$

Implementation of innovations that aim to improve functioning and activity around major surgery such as TKR, can be seen as complex and therefore needs a strategy. When we compare our innovation strategy with the literature about innovation processes, the innovation model by Fleuren et al. can be useful. ${ }^{46}$ This model fits the healthcare context in a single institution better than for example well-established models about system transitions in society. The model describes four groups of innovation determinants: (1) characteristics of the sociopolitical context, (2) characteristics of the organisation, (3) characteristics of the adopting persons (users) and (4) characteristics of the innovation (figure 1). Although the innovation model by Fleuren presumes that an innovation is developed and evaluated for effectiveness before implementation in daily care, in contrast with the participatory action research, which we used in the transition in Drachten's hospital Nij Smellinghe, these intervention determinants apply to our innovation process as well. For example, we had to deal with Dutch legislation and regulations regarding reimbursement of physical therapy, which was a barrier for implementing preoperative screening of functional mobility as essential part of our care transition. As solution for this problem the hospital took the financial risk by paying for the 
screening procedure. This problem and its solution show the importance of the socio-political context for successful implementation. One of the key factors of the success of our transition process was the organisational context, i.e. the hospital management which, recognizing the importance of the innovations, gave financial support and made time available to facilitate the innovation process. An example demonstrating the importance of the characteristics of the adopting persons was the high commitment to the use of the new interventions. As a result, social support emerged between direct colleagues and colleagues with another profession, especially between nursing staff and physiotherapists; this was important for the necessary interdisciplinary collaboration in the new care for TKR patients in the daily care context. Also the properties of the innovations themselves contributed to a smooth implementation. By having knowledge about the literature regarding the care and rehabilitation for patients undergoing TKR and by scrutinizing the available perioperative patient data, we were able to develop clear procedures that were relevant for patients and appealing to health care professionals. The embedded scientist appeared to be an important catalyst, who had the ability to influence in particular the second (characteristics of the organisation) and the third (characteristics of the adopting persons) group of determinants, and had therefore an important role in a successful process of innovations. In hindsight, this whole trajectory complies to some extent quite well with the recommendations by De Haan and Rotmans (2018) in their recently proposed model of transformative change. ${ }^{44}$

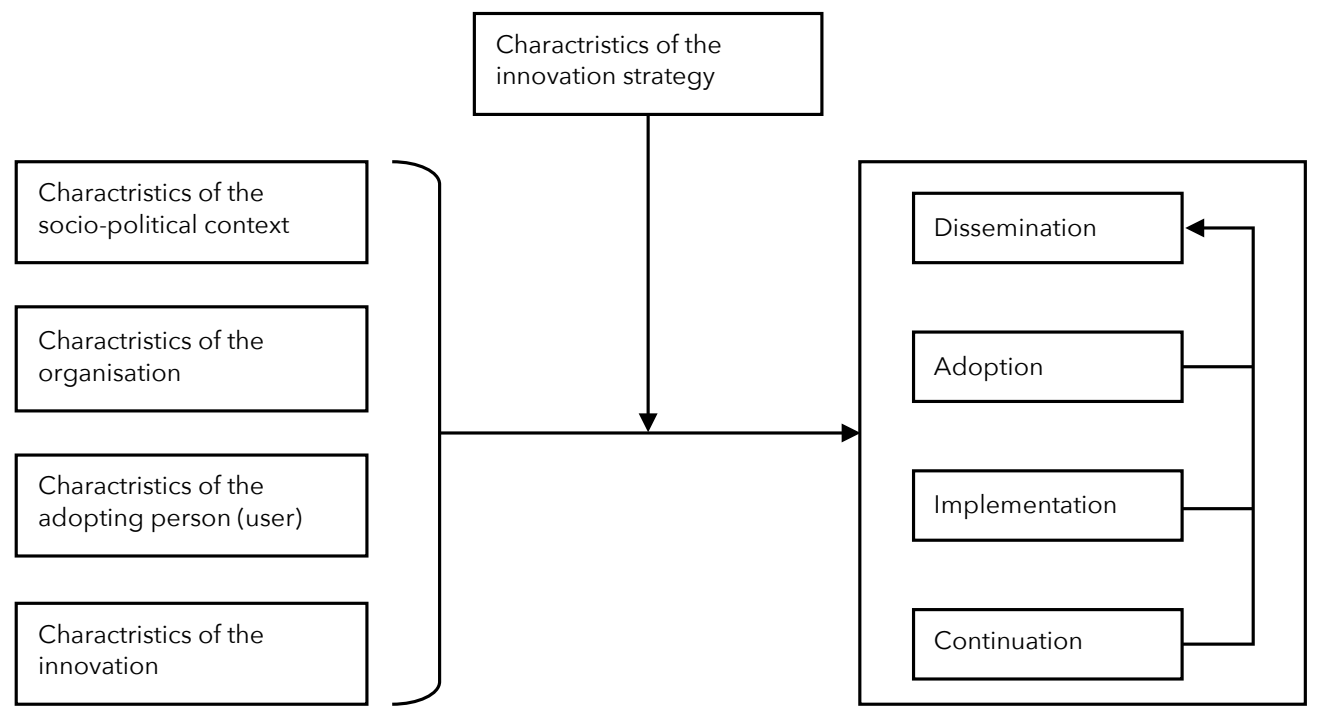

Figure 2. Model with relevant determinants and processes to guide an innovation process, adapted from Fleuren et al. ${ }^{46}$ 


\section{Clinical implications}

Analysis of the data collected throughout the entire period of care transition showed that our patients (1) recovered significantly faster with respect to their relevant functional activities while in hospital, (2) were discharged more often directly homewards, and (3) stayed shorter in the hospital. That patients nowadays are more active during their hospital stay meant a major change in our health care management and the hospital environment.

Chapter 2 showed that, if patients can set their personal goals and follow their own pace for achieving their functional milestones in a much more activating and motivating hospital culture, the speed of inpatient recovery of activities increased and the length of hospital stay decreased substantially. Therefore we recommend that every patient indicated for TKR is screened for functional mobility, performed by a physiotherapist. The DEMMI and the TUG are simple, cheap and valid objective instruments to assess functional mobility and therefore easy to use in other hospitals. ${ }^{16,20,22,47}$ Also an activating and stimulating hospital environment can be achieved with interdisciplinary collaboration and involvement of informal caregivers or family in the care.$^{48} \mathrm{We}$ also would recommend to collect and analyse routine data as basis for the introduction of embedded science in daily practice for patients undergoing TKR. Using these data to evaluate and optimize the care for patients undergoing TKR fits in the concept of a learning health system. ${ }^{49}$ Learning health systems are characterized by capturing and analysing health (care) derived data to generate new knowledge that serves and improves health decision making and daily practice. ${ }^{39,40,49}$ However, an important barrier for embedded science was the digital patient information system in our hospital, as in most of the other hospitals in the Netherlands. There are almost no possibilities to obtain data directly from the information system into a database. Therefore the required patient data had to be retyped from the information system into a database for analysis, which was very time consuming.

Also in upcoming concepts in healthcare such as Value-Based Health Care, introduced by Porter, it is important to have good data recording and management systems. ${ }^{50}$ ValueBased Healthcare is a data driven method to achieve better patients' outcomes and satisfaction with more (time) efficient healthcare. ${ }^{50}$ Our transition of care among patients undergoing TKR is a good example how Value-Based Health Care can be organised and applied in daily practice. ${ }^{50,51}$ However, hospital information systems in most regional hospitals are not yet sufficiently equipped for management and analysis of patient-related data, which is a requirement for the application of Value-Based Healthcare, action research and embedded science.

Chapters 4, 5 and 6 showed that prediction models are valuable for personalizing care and for making decisions around TKR surgery. Although the prediction models were developed in one hospital the list of determinants can be useful in other hospitals or settings. We therefore recommend to use these determinants in combination with the methodology we followed for the development of a hospital- specific prediction model. In other words, the prediction model as presented in this thesis is most useful in the Nij Smellinghe hospital, but 
the determinants and methodology can be universally used and therefore be helpful for other researchers or embedded scientists for the development of a prediction model that is useful in their own hospital. However, for added value, the overall predictive capacity of the model has to be substantially better than a random prediction (a prediction based on the prevalence of the outcomes).

\section{Directions for future research}

There are some questions that remained unanswered in this thesis and could be subject of future research. Because only short-term (inpatient) recovery of activities has been investigated, the question whether there are also some negative effects of the TKR after the patient returns home is still unanswered. Whether patients continued augmenting their activities after discharge or were sitting down and being cared for by their informal caregivers was not assessed. A recommendation for future research is therefore to extend the period of monitoring of the course of relevant functional mobility outcomes throughout a period for at least 3 months after surgery. ${ }^{16}$ Similarly as in the short inpatient period after TKR, such data help to address relevant determinants for long-term recovery of relevant activities and if necessary to develop interventions to establish optimal long-term functional ability for patients after TKR. Therefore the development of optimal strategies that minimize the risk of extended hospital admissions or discharge to inpatient rehabilitation facilities can be a valuable research topic.

Chapter 5 revealed that poor preoperative functional mobility does hamper inpatient recovery of activities in TKR patients, which in turn can lead to hospital-related disability due to prolonged hospital stay. ${ }^{7,52}$ This observation justifies the hypothesis that tailored prehabilitation interventions might prevent a delay in inpatient recovery and a consequently extended hospital stay in this poorly functioning group of patients. The feasibility and effectiveness of tailored prehabilitation programs on recovery of activities after TKR should be subject of research in the future. 1,15,53 


\section{Example}

Mrs. M. about the effect of her prehabilitation intervention:

"I was a very lazy person, couldn't even imagine to walk a few hundred meters, always drove this by car. I'm sharing the newspaper with a friend, Now I'm able to bring the newspaper to her by walking the 500 meters to her house... this is new for me!"

Daughter of Mrs. M.:

"My mother had depressive symptoms, but now she is able to walk around again, that makes her smile."

Mrs. M., a 80 year old female, who was scheduled for a TKR in Nij Smellinghe, had a medical history of a mild AV block, hypertension and morbid obesity. We informed our patient, based on her preoperative screening outcome (BMI $42.1 \mathrm{~kg} / \mathrm{m}^{2}$, age 80 years, TUG $13.1 \mathrm{~s}$, and a DEMMI score of 57 points), about her high risk to develop a delayed inpatient recovery of activities after her TKR. Based on the pre-operative screening outcome we suggested her to prepare for surgery by going through an intensive home-based training intervention, using the principles of functional task training for elderly. We discussed the benefits and harms with her and she decided to go through this period of training prior to her surgery. During a period of 4 weeks her functional ability measured by the TUG and the DEMMI increased. The TUG score showed a clinically relevant decrease from $13.1 \mathrm{~s}$ to $9.6 \mathrm{~s}$ and the DEMMI had a clinically relevant increase from 57 to 74 points. During her hospital stay she reached the functional milestones for recovery, as measured by the mILAS, after 1.5 days and on the second post-operative day she decided that she wanted to go home.

From the RCT by Skou et al. we know that patients with an indication for a TKR showed meaningful functional improvements after a rigorous non-surgical treatment consisting of intensive exercise therapy, pain medication and dietary advice. ${ }^{54}$ Thus, it is possible that a substantial part of patients experiences enough benefit from non-surgical interventions. Future research should study the effect of non-surgical treatment options respecting specific needs and preferences among fragile elderly patients with chronic knee complaints. Patients for whom the effect of the exercise therapy is sufficient need not be exposed to surgical stress with its possible negative consequences. 
In the scoping review we showed that the literature on SDM is characterized by heterogeneity in the underlying rationales, the interventions and the outcomes. Also patients' needs and preferences are hardly taken into account and the current evidence is limited to the decision to have the surgery or not. We think that for a valuable SDM process collaboration between patients and health care providers in making decisions together and awareness of patient preferences and values are essential for optional medical treatments such as TKR surgery. ${ }^{55,56}$ However, the review showed that in patients undergoing TKR most studies were on decision aids that were applied outside the encounter between patient and doctor. ${ }^{57-61} \mathrm{We}$ think that methods and aids that stimulate the interactional process within the clinical encounter between patient and health care provider, such as the one presented in chapter 6, should be subject of implementation and further research. ${ }^{32,33}$

\section{Future perspectives for care improvement}

As in most healthcare innovation processes the involvement of patients, who are the main users of care, is currently mostly overlooked. We learned from our scoping review, but also from the case study from Oosting ${ }^{62}$ that patient perspectives often differ from those of health care professionals. Therefore it would be valuable to develop initiatives to actively involve patients in care innovation processes and development of protocols, besides the decisions concerning their own health. ${ }^{63,34}$

Furthermore, for future care improvements we have to consider that other determinants than the ones we investigated affect postoperative inpatient recovery of activities. For example, the role behaviour of patients (patient empowerment) and their coping flexibility, nutritional status, or $\mathrm{VO}_{2} \mathrm{max}_{\text {, }}$ and besides these the mind set and actions of health care professionals and the system they are part of, could be determinants of speed and quality of recovery for patients opting for TKR. By use of embedded science such determinants may appear to improve the prediction of recovery, but may also provide handles to develop and implement interventions that improve recovery and prevent adverse effects. For example, the standard mode of transport to the operating room, where the patient is laying supine in bed before and after surgery, has attention in Nij Smellinghe. Most patients are able to walk before, and by the use of state-of-the-art anaesthetic procedures, possibly also after surgery. ${ }^{41,65}$ Therefore, to enhance patient empowerment, we already stimulate patients to walk to the operation room in our hospital. Patients on our children's department transport themselves to surgery by driving a small electric car. These initiatives fit current ideas about health(care), where patients display more and more self-management strategies regarding their health(care). 2,4 However, logistic procedures, difficulties in finding the most suitable anaesthetic procedure and difficulties in changing habits of patients and professionals regarding ideas around postoperative care, are currently barriers for a more active and intensive approach immediately after surgery, which need attention in the near future. 
In the future we may also have to completely reconsider the role of the physiotherapist working in the hospital for patients admitted to the hospital for TKR. After all, the goal is to find an optimum length of stay for each individual patient, which means that, for a substantial part of the patients, the length of stay will shorten even further and outpatient surgery might become the norm. ${ }^{67}$ Perhaps the role of the hospital physiotherapist, at least during the postoperative phase, will become obsolete or replaced by cheaper alternatives. It is imaginable that the patient's primary care physiotherapist will visit the patient in the hospital; this will directly solve many of the issues related to care transitions. ${ }^{68}$ So what becomes of the hospital physiotherapists? Already in 1999, Lopopolo recommended that hospital physiotherapists need to re-invent themselves and need to explore (and cross) the boundaries of their profession. ${ }^{69}$ Based on the results of this thesis, physiotherapists working in a hospital might need to become more involved in the risk assessment before surgery and/or serve as mobility officers; not just at the Orthopaedic department for patients with a physiotherapy referral, but perhaps for every patient and employee at the hospital.

The transition of our care process in the Nij Smellinghe hospital was conducted along the lines of participatory action research; where the innovation was driven by going through several iterative cycles (i.e., plan, do, check, act). We, however did not use established theories or models regarding systemic transitions to guide our own local transition. When developing and implementing care innovations in the future, it might be helpful to follow established transition methods and models. Two recently proposed frameworks or models might be particularly useful. First, De Haan and Rotmans (2018) proposed a framework that models a transition as a fluid development of network activities, with several actors with specific roles. ${ }^{44}$ They argue that typical transition methods are a sort of fight between the existing dominant systems (current regime) and alternative or emerging systems. Changes of societal systems (also the healthcare system) should however be a consequence of strategic actions of people rather than a consequence of systems or technologies. ${ }^{44}$ The proposed framework can stimulate debate about transition processes in which the actors play a central role. Second, the 'mission-oriented' approach as recommended by Mazzucato (2018).66 The mission-oriented approach is a problem-solving approach aimed to have a large and meaningful impact by fostering cross-disciplinary, cross-sectoral and cross-actor innovation with a measurable and time-bound direction, ideally initiated from bottom-up solutions. ${ }^{66}$ As mentioned earlier, for physical therapists these types of transitions do require to further explore the boundaries of our profession and to cross it in order to innovate. The use of more robust and extensive models or frameworks can be a useful guide for innovation processes and can lead to a sustainable change of a (healthcare) system. 


\section{Main conclusions}

- Patients opting for TKR who enter in care pathways with an inherent focus on augmenting activity and functional goalsetting during hospitalization, recover their activities faster, have a shorter length of stay in the hospital and go less often to inpatient rehabilitation institutes compared with patients treated in a more traditional pathway.

- A patient's functional mobility assessed before surgery is an important predictor of inpatient recovery of activities in patients undergoing TKR.

- Patients show substantial interpersonal variation in their capacity to recover activities after TKR surgery. The patients' speed of recovery can predicted quite well from preoperative characteristics and such prediction was essential to set individual functional goals and tailor the care for patients undergoing TKR.

- The availability of baseline information of patients opting for TKR, prospectively collected with validated instruments according to scientific standards at the preoperative functional screening, and availability of well-monitored outcome information were key elements to develop, implement, and evaluate innovative care pathways.

- The most important facilitators for the successful transitions of our care for patients opting for TKR were the interdisciplinary team effort, the use of embedded science, and the active support of the hospital management.

- An important barrier for embedded science and action research, and thus transition of care and value based healthcare is the hospital information systems in hospitals, as they provide almost no possibility to extract data directly from the information system into a database for research.

- Review of the literature on SDM in patients opting for TKR revealed heterogeneous study rationales, designs and effects of how SDM affect patients' ideas about TKR and its outcome. The limited scope in which SDM is being employed in the care surrounding these patients as well as the lack of accounting for patients' needs and preferences might explain the conflicting study results among the available effect studies.

- The merit of SDM in daily practice for patients and their (informal) caregivers with advanced osteoarthritis of the knee is currently unknown, according to the limited literature available. 


\section{References}

1. Hulzebos EHJ, van Meeteren NLU. Making the elderly fit for surgery. Br J Surg. 2015:n/a-n/a. doi:10.1002/bjs.10033.

2. Huber M, Knottnerus JA, Green L, et al. How should we define health? Bmj. 2011;343(jul26 2):d4163-d4163. doi:10.1136/bmj.d4163.

3. Kaljouw. Naar nieuwe zorg en zorgberoepen: de contouren. Rapp zorginstituut Ned. 2015.

4. Heerkens YF, de Weerd M, Huber M, et al. Reconsideration of the scheme of the international classification of functioning, disability and health: incentives from the Netherlands for a global debate. Disabil Rehabil. 2017;0(0):1-9. doi:10.1080/09638288.2016.1277404.

5. Brown CJ, Redden DT, Flood KL, Allman RM. The Underrecognized Epidemic of Low Mobility During Hospitalization of Older Adults. J Am Geriatr Soc. 2009;57(9):1660-1665. doi:10.1111/j.15325415.2009.02393.x.

6. Kortebein P, Symons TB, Ferrando A, et al. Functional Impact of 10 Days of Bed Rest in Healthy Older Adults. 2017;63(10):1076-1081.

7. Sourdet S, Lafont C, Rolland Y, Nourhashemi F, Andrieu S, Vellas B. Preventable latrogenic Disability in Elderly Patients During Hospitalization. J Am Med Dir Assoc. 2015;16(8):674-681. doi:10.1016/j.jamda.2015.03.011.

8. Covinsky KE, Pierluissi E, Story THEPS. Hospitalization-Associated Disability " She Was Probably Able to Ambulate, but I' m Not Sure." J Am Med Assoc A. 2011;306(16):1782-1793. doi:10.1001/jama.2011.1556.

9. Hoyer EH, Friedman M, Lavezza A, Wagner-kosmakos K. Promoting Mobility and Reducing Length of Stay in Hospitalized General Medicine Patients: A Quality-Improvement Project. 2016;11(5):341-347. doi:10.1002/jhm.2546.

10. Abeles A, Kwasnicki RM, Pettengell C, Murphy J, Darzi A. The relationship between physical activity and post-operative length of hospital stay: A systematic review *. Int J Surg. 2018;44(2017):295-302. doi:10.1016/j.ijsu.2017.06.085.

11. van der Sluis G, Goldbohm RA, Bimmel R, et al. What augmented physical activity and empowerment can bring to patients receiving total knee replacement: content, implementation, and comparative effectiveness of a new function-tailored care pathway in a routine care setting. Biomed Res Int. 2015;2015:745864. doi:10.1155/2015/745864.

12. Husted H, Lunn TH, Troelsen A, Gaarn-Larsen L, Kristensen BB, Kehlet H. Why still in hospital after fast-track hip and knee arthroplasty? Acta Orthop. 2011;82(6):679-684. doi:10.3109/17453674.2011.636682.

13. Kehlet H. Fast-track surgery - an update on physiological care principles to enhance recovery. 2011:585590. doi:10.1007/s00423-011-0790-y.

14. Kehlet H. Fast-track hip and knee arthroplasty. Lancet. 2013;381(9878):1600-1602. doi:10.1016/S01406736(13)61003-X.

15. Hoogeboom TJ, Dronkers JJ, Hulzebos EHJ, van Meeteren NLU. Merits of exercise therapy before and after major surgery. Curr Opin Anaesthesiol. 2014;27(2):161-166. doi:10.1097/ACO.0000000000000062.

16. Kennedy DM, Stratford PW, Hanna SE, Wessel J, Gollish JD. Modeling early recovery of physical function following hip and knee arthroplasty. BMC Musculoskelet Disord. 2006;7:100. doi:10.1186/1471-2474-7100.

17. Bade MJ, Kittelson JM, Kohrt WM, Stevens-Lapsley JE. Predicting functional performance and range of motion outcomes after total knee arthroplasty. Am J Phys Med Rehabil. 2014;93(7):579-585. doi:10.1097/PHM.0000000000000065.

18. Bade MJ, Wolfe P, Zeni JA, Stevens-Lapsley JE, Snyder-Mackler L. Predicting poor physical performance after total knee arthroplasty. J Orthop Res. 2012;30(11):1805-1810. doi:10.1002/jor.22140.

19. Podsiadlo D, Richardson S. The timed "Up \& Go": a test of basic functional mobility for frail elderly persons. J Am Geriatr Soc. 1991;39(2):142-148. http://www.ncbi.nlm.nih.gov/pubmed/1991946. Accessed October 28, 2014.

20. de Morton NA, Davidson M, Keating JL. The de Morton Mobility Index (DEMMI): an essential health index for an ageing world. Health Qual Life Outcomes. 2008;6:63. doi:10.1186/1477-7525-6-63.

21. Hoogeboom TJ, Van Meeteren NLU, Schank K, Kim RH, Miner T, Stevens-Lapsley JE. Risk factors for delayed inpatient functional recovery after total knee arthroplasty. Biomed Res Int. 2015;2015:5-9. doi:10.1155/2015/167643. 
22. Jans MP, Slootweg VC, Boot CR, de Morton NA, van der Sluis G, van Meeteren NL. Reproducibility and validity of the Dutch translation of the de Morton Mobility Index (DEMMI) used by physiotherapists in older patients with knee or hip osteoarthritis. Arch Phys Med Rehabil. 2011;92(11):1892-1899. doi:10.1016/j.apmr.2011.05.011.

23. Holm B, Bandholm T, Lunn TH, et al. Role of preoperative pain, muscle function, and activity level in discharge readiness after fast-track hip and knee arthroplasty. Acta Orthop. 2014;85(5):488-492. doi:10.3109/17453674.2014.934186.

24. Thienpont $\mathrm{E}$, Lavand'homme $\mathrm{P}$, Kehlet $\mathrm{H}$. The constraints on day-case total knee arthroplasty: the fastest fast track. Bone Joint J. 2015;97-B(10_Supple_A):40-44. doi:10.1302/0301-620X.97B10.36610.

25. Elings J, Hoogeboom T, van der Sluis G, van Meeteren N. What preoperative patient-related factors predict inpatient recovery of physical functioning and length of stay after total hip arthroplasty? A systematic review. Clin Rehabil. October 2014. doi:10.1177/0269215514545349.

26. loannidis JPA, Hlatky MA, Khoury MJ, et al. Research : increasing value, reducing waste 2 Increasing value and reducing waste in research design, conduct, and analysis. Lancet. 2014;383(9912):166-175. doi:10.1016/S0140-6736(13)62227-8.

27. Volksgezondheid R voor samenleving en. zonder context geen bewijs. rapport. 2017.

28. Beneciuk JM, Bishop MD, George SZ. Clinical prediction rules for physical therapy interventions: a systematic review. Phys Ther. 2009;89(2):114-124. doi:10.2522/ptj.20080239.

29. Lee Y, Bang H, Kim DJ. Review Article How to Establish Clinical Prediction Models. 2016:38-44. doi:10.3803/EnM.2016.31.1.38.

30. Childs JD, Cleland JA. Development and application of clinical prediction rules to improve decision making in physical therapist practice. Phys Ther. 2006;86(1):122-131. http://www.ncbi.nlm.nih.gov/pubmed/16386067. Accessed June 25, 2015.

31. Unnanuntana BA, Gladnick BP, Donnelly E, Lane JM. The Assessment of Fracture Risk. 2010:743-753. doi:10.2106/JBJS.I.00919.

32. Gigerenzer G, Edwards A. Simple tools for understanding risks: from innumeracy to insight. BMJ Br Med J. 2003;327(7417):741-744. doi:10.1136/bmj.327.7417.741.

33. Edwards A, Elwyn G, Mulley A. Explaining risks: turning numerical data into meaningful pictures. Bmj. 2002;324(7341):827-830. doi:10.1136/bmj.324.7341.827.

34. Arksey H, Malley LO. Scoping Studies: Towards a Methodological Framework. Int J Soc Res Methodol. 2005;8(1):19-32. doi:10.1080/1364557032000119616.

35. Briggs J. JBI_Reviewers-Manual_Methodology-for-JBI-Scoping-Reviews_2015_v2. 2015:1-24. doi:10.1080/00918369.2016.1172893.

36. Walsh D, Downe S. Meta-synthesis method for qualitative research: A literature review. J Adv Nurs. 2005;50(2). doi:10.1111/j.1365-2648.2005.03380.x.

37. Moore GF, Audrey S, Barker M, et al. Process evaluation of complex interventions: Medical Research Council guidance. :1-7. doi:10.1136/bmj.h1258.

38. Greenhalgh T, Howick J, Maskrey N. Evidence based medicine : a movement in crisis ? with context and professional expertise so that individual patients get optimal treatment. 2014;3725(June):1-7. doi:10.1136/bmj.g3725.

39. Vindrola-Padros C, Pape T, Utley M, Fulop NJ. The role of embedded research in quality improvement: a narrative review. BMJ Qual Saf. 2016:bmjqs-2015-004877. doi:10.1136/BMJQS-2015-004877.

40. Marshall M, Pagel C, French C, et al. Moving improvement research closer to practice: the Researcher-inResidence model. BMJ Qual Saf. 2014;23(10):801-805. doi:10.1136/bmjqs-2013-002779.

41. Harsten $A$, Kehlet $H$. Recovery after total intravenous general anaesthesia or spinal anaesthesia for total knee arthroplasty : a randomized trial †. Br J Anaesth. 2013;111(3):391-399. doi:10.1093/bja/aet104.

42. Baum F, Macdougall C, Smith D. Participatory action research. 2006:854-857. doi:10.1136/jech.2004.028662.

43. Macdonald C. UNDERSTANDING PARTICIPATORY ACTION RESEARCH: A QUALITATIVE RESEARCH METHODOLOGY OPTION. 2012;13(2):34-50.

44. Haan FJ De, Rotmans J. Technological Forecasting \& Social Change A proposed theoretical framework for actors in transformative change. Technol Forecast Soc Chang. 2018;128(December 2017):275-286. doi:10.1016/j.techfore.2017.12.017.

45. Jette AM. Face Into the Storm. Phys Ther. 2012;92(9):1221-1229. doi:10.2522/ptj.2012.mcmillan.lecture.

46. Fleuren MAH, Paulussen TGWM, Dommelen PVAN, Van S. Towards a measurement instrument for determinants of innovations. 2017;26(5):501-510. 
47. Malani PN. Functional status assessment in the preoperative evaluation of older adults. JAMA. 2009;302(14):1582-1583. doi:10.1001/jama.2009.1453.

48. Glasziou P, Irwig L, Mant D. Monitoring in chronic disease: a rational approach. BMJ. 2005;330(7492):644648. doi:10.1136/bmj.330.7492.644.

49. Nwaru BI, Friedman C, Halamka J, Sheikh A. Can learning health systems help organisations deliver personalised care? 2017:1-8. doi:10.1186/s12916-017-0935-0.

50. Porter M. What is the value in health care? N Engl J Med. 2010;363(26):2477-2481.

51. Hillary W, Justin G, Bharat M, Jitendra M. Value based Healthcare. 2016;9(1):49504.

52. Guccione AA, Fagerson TL, Anderson JJ. Regaining functional independence in the acute care setting following hip fracture. Phys Ther. 1996;76(8):818-826.

53. Topp R, Ditmyer M, King K, Doherty K, Hornyak J. The effect of bed rest and potential of prehabilitation on patients in the intensive care unit. AACN Clin Issues. 2002;13(2):263-276. doi:10.1097/00044067$200205000-00018$.

54. Skou ST, Roos EM, Laursen MB, Rathleff MS, Arendt-Nielsen L, Simonsen O. A Randomized, Controlled Trial of Total Knee Replacement. N Engl J Med. 2015;373(17):1597-1606. doi:10.1056/NEJMoa1505467.

55. Elwyn G, Frosch DL, Kobrin S. Implementing shared decision-making: consider all the consequences. Implement Sci. 2015;11(1):114. doi:10.1186/s13012-016-0480-9.

56. Barry MJ, Edgman-Levitan S. Shared Decision Making - The Pinnacle of Patient-Centered Care. N Engl J Med. 2012;(366):780-781. doi:10.1056/NEJMp1109283.

57. Arterburn D, Wellman R, Westbrook E, et al. Introducing decision aids at group health was linked to sharply lower hip and knee surgery rates and costs. Health Aff. 2012;31(9):2094-2104. doi:10.1377/hlthaff.2011.0686.

58. Ibrahim SA, Blum M, Lee G-C, et al. Effect of a Decision Aid on Access to Total Knee Replacement for Black Patients With Osteoarthritis of the Knee. JAMA Surg. 2017;152(1):e164225. doi:10.1001/jamasurg.2016.4225.

59. Sofia de Achaval, Liana Fraenkel, Robert J. Volk, Vanessa Cox MES-A. Impact of educational and patient decision aids on decisional conflict associated with total knee arthroplasty. Arthiritis Care Res. 2013;64(2):229-237. doi:10.1002/acr.20646.Impact.

60. Stacey D, Hawker G, Dervin G, et al. Decision aid for patients considering total knee arthroplasty with preference report for surgeons: a pilot randomized controlled trial. BMC Musculoskelet Disord. 2014;15:54. doi:10.1186/1471-2474-15-54.

61. Volkmann ER, FitzGerald JD. Reducing gender disparities in post-total knee arthroplasty expectations through a decision aid. BMC Musculoskelet Disord. 2015;16:16. doi:10.1186/s12891-015-0473-x.

62. Oosting E, Dronkers J, Hoogeboom T, et al. Personal meaning in relation to daily functioning of a patient in physical therapy practice : narratives of a patient, a family member, and physical therapist. Disabil Rehabil. 2017;0(0):000. doi:10.1080/09638288.2017.1290153.

63. Patienten participatie in een ziekenhuis.pdf.

64. Hoogeboom TJ, Kittelson AJ, van der Sluis G, van Meeteren NLU. Evidence-based practice in physiotherapy: Time to involve the patient? Physiother (United Kingdom). 2014;100(4):363-364. doi:10.1016/j.physio.2014.08.001.

65. Joshi GP, Kehlet H, Working P. Guidelines for perioperative pain management: need for re-evaluation. 2017;119(4):720-722. doi:10.1093/bja/aex304.

66. Mazzucato M. Mission-Oriented Research in the European Union. doi:10.2777/36546.

67. Gromov K, Kjærsgaard-andersen P, Revald P, et al. Feasibility of outpatient total hip and knee arthroplasty in unselected patients Feasibility of outpatient total hip and knee arthroplasty in unselected patients $A$ prospective 2-center study. 2017;3674. doi:10.1080/17453674.2017.1314158.

68. Falvey JR, Burke RE, Malone D, Ridgeway KJ, Mcmanus BM, Stevens-lapsley JE. Role of Physical Therapists in Reducing Hospital Readmissions: Optimizing Outcomes for Older Adults to Community. 2018;96(8):1125-1134.

69. Lopopolo. Changing Nature of the Physical. Phys Ther. 1999;79(2). 


\section{Valorisation}




\section{Valorisation}

In this chapter, we will focus on the valorisation (potential) of the clinical innovation and research as presented in this $\mathrm{PhD}$ thesis. The primary goal was to improve surgical outcomes in patients who chose to have total knee replacement (TKR) by focusing on individual patient preferences and values concerning their daily (physical) functioning and, more in general, preventing functional decline during the hospitalization period. To do so, we undertook actions aimed to optimize patients' physical functioning throughout the whole trajectory, from indication up until recovery of physical functioning. These actions were augmented by elements of shared decision making as part of the care continuum. As a result, patients, their relatives and healthcare professionals constantly collaborate on well-defined, personal goals related to the patients physical, social and mental living context. ${ }^{1}$

In this chapter, we will estimate the impact of the research for the Nij Smellinghe hospital (NS). First, we will outline the original situation and care transition in the Nij Smellinghe hospital. Then we will present the methods that we have used to determine this impact. Finally, we will present and discuss the potential impact for other hospitals in the Netherlands and valorisation possibilities elsewhere.

\section{Original situation}

The author of this thesis has worked as a physiotherapist and clinical health scientist in the Nij Smellinghe hospital in Drachten, the Netherlands. Nij Smellinghe is a regional hospital with 320 beds. The orthopaedic ward has 17 clinical beds and provides primary TKR to 150 patients and primary total hip replacement to 250 patients annually. The healthcare team in charge of the treatment of patients scheduled for elective total joint replacement and other major elective and traumatic orthopaedic surgery consists of 5 orthopaedic surgeons, 2 nurse practitioners, 1 physician assistant, 3 physiotherapists, and 35 nurses.

At the start of the healthcare transition, the Joint Care ${ }^{\circledR}$ clinical pathway was the care regime in NS. Working with this clinical pathway meant that patients and healthcare professionals worked together on discharge homewards or an inpatient rehabilitation facility, following a rather strict timetable for all patients. Certain activities took place at certain time points. For example, patients transferred from their bed for the first time on the day after surgery between 10:00 am and 11:30 am. They walked for the first time with crutches on the second day after surgery. Climbing stairs was not allowed before the third day after surgery. If no complications arose, patients were discharged from the hospital after five days. Organising the care following a timetable already meant a big change of the care process and progress in the planning of care logistics and available resources. ${ }^{2,3}$ Before the introduction of the Joint Care ${ }^{\circledR}$ pathway, the care for patients who underwent TKR surgery was organized fragmentarily and financed accordingly. There was almost no cooperation between the different healthcare professionals. Moreover, no overall treatment goals were defined. The length of stay for 
patients after TKR in the period before the introduction of Joint Care ${ }^{\circledR}$ was, however, 11 days on average, indicating that the Joint Care ${ }^{\circledR}$ pathway was already a big improvement.

In 2008, Oosting et al. showed that physiotherapy regimes for patients who were treated in Joint Care ${ }^{\circledR}$ pathways had ample room for improvement. This publication and consecutive debates formed the start of the projects and processes described in this thesis.

\section{Care transition}

In line with the recommendations of Oosting et al., we set out to further optimise the clinical care pathway in NS for patients having TJR, with the department of Physiotherapy as initiator and driving force. As outlined in more detail in the general discussion, we took the following steps:

1. Preoperative risk stratification

We developed and consequently implemented a preoperative screening tool -complementary to the medical screening performed by the anaesthesiologist- to determine whether patients have an increased risk for delayed recovery. This model has been described in a Dutch guideline for physiotherapists on the management of patients having TKR surgery.

2. Monitor progression of functional recovery

We implemented the modified lowa Levels of Assistance Scale (mILAS). This scale measures delayed functional recovery and allows physiotherapists to monitor a patient's discharge readiness.

3. Personalized functional goal-setting

Based on the previous step, we were able to introduce personalized functional goalsetting during hospitalisation. This goal-setting strategy helped stimulate patients to be more physically active and to achieve meaningful goals that needed to be reached in order to be discharged home.

4. Focussed and tailored peri-operative information

We replaced the one-size-fits all group session before the TKR surgery with continuous shared decision-making -on the basis of functional outcome measurements- throughout the peri-operative care process.

5. Early mobilization

We introduced fast-track mobilization at the orthopaedic ward. Mobilization now starts four hours after surgery at the latest.

6. Adequate pre- and postoperative personalized therapeutic regimes

These regimes are based on the risk stratification and introduction of fast-track surgery and pre- and postoperative therapeutic training. They aim to optimize and personalize the patient's functional outcomes and to prevent a complicated recovery process. 


\section{Determining the impact of the care transition for Nij Smellinghe hospital}

Since the start of the pre- and postoperative screening, we have stored all the data obtained from the measurements in a database. These data gave us valuable insight into the entire patient population and into the characteristics and experiences of each individual patient during his or her care trajectory. Moreover, the database has allowed us to continuously monitor the effectiveness of the care transition over time.

\section{Implications of the transition of care}

We have already shown in chapter 2 that stimulation of the patient's activities aligned by personalized functional goal-setting during hospitalisation resulted in a larger proportion of the patients (82\%) undergoing TKR being discharged home compared with the Joint Care ${ }^{\circledR}$ period (70\%). Moreover, we found that the time to inpatient recovery of activities was shortened by half a day and the period of hospitalization was shortened by one day after the introduction of this function-tailored pathway. ${ }^{4}$

To date, the database contains data from all 958 patients who underwent TKR between April 2009 and May 2017. During this eight-year period, the clinical care pathway was updated twice. First, it was changed from a Joint Care pathway ${ }^{3}$ (May 2009 - Dec 2010) to a functiontailored pathway ${ }^{4}$ (Jan 2011 - Oct 2013). Then, it was changed from the function-tailored pathway to a fast-track pathway ${ }^{5}$ (Nov 2013 - May 2017). To investigate the implications of these transitions of care on patient outcomes and costs, we repeated the research methodology and statistical analysis described in chapter 2 but this time using our extended database. The goal was to investigate the comparative effectiveness of the care transition to the fast-track pathway compared with the original situation at the start of the data collection in 2009.

\section{How did we investigate the comparative effectiveness?}

We used the same observational study design that was described in chapter 2. We compared outcome measures of the TKR patient groups taken in for surgery before and after introduction of the function-tailored pathway and the fast-track pathway respectively. Preoperative characteristics, prospectively collected during the screening, were used in the analysis to ensure comparability of the patient groups over time. Data were anonymously retrieved from the medical files of all 958 patients who underwent elective primary TKR between 1 April 2009 and 1 May 2017 ( $n=171$ in the Joint Care period, $n=360$ in the function-tailored period and $\mathrm{n}=427$ in the fast-track period). 


\section{Results}

\section{Comparative effectiveness}

The preoperative characteristics and postoperative outcomes of the patients who underwent TKR in the Joint Care period, in the function-tailored care period and in the fast-track period are presented in Table 1.

Table 1. Characteristics of the patients scheduled for TKR at preoperative screening and during their postoperative recovery, divided over the three clinical pathways.

\begin{tabular}{|c|c|c|c|c|c|c|c|c|c|}
\hline & \multicolumn{3}{|c|}{$\begin{array}{c}\text { Joint Care }{ }^{\circledR} \text { period } \\
2009-2010 \\
\end{array}$} & \multicolumn{3}{|c|}{$\begin{array}{c}\text { function-tailored period } \\
2010-2013\end{array}$} & \multicolumn{3}{|c|}{$\begin{array}{c}\text { fast-track period } \\
2013-2017\end{array}$} \\
\hline & $\mathrm{n}$ & mean $/ \%$ & SD & $\mathrm{n}$ & mean/\% & SD & $n$ & mean $/ \%$ & SD \\
\hline age (years) & 171 & 71.0 & 8.4 & 360 & 69.2 & 9.8 & 427 & 70.1 & 8.5 \\
\hline $\operatorname{BMI}\left(\mathrm{kg} / \mathrm{m}^{2}\right)$ & 169 & 29.8 & 5.3 & 357 & 30.1 & 5.0 & 427 & 29.2 & 4.5 \\
\hline ISAR (0-6 points) & 156 & 1.2 & 1.2 & 353 & 0.9 & 1.0 & 422 & 0.8 & 0.9 \\
\hline TUG (time in s) & 170 & 12.1 & 7.1 & 353 & 11.4 & 5.8 & 419 & 9.2 & 5.7 \\
\hline DEMMI (0-100 points) & 155 & 77.1 & 17.1 & 344 & 76.2 & 16.6 & 410 & 83 & 15.0 \\
\hline LOS (days) & 124 & 4.8 & 1.3 & 295 & 4.0 & 1.2 & 388 & 3.4 & 1.1 \\
\hline IROA ( days) & 124 & 4.3 & 0.9 & 295 & 3.5 & 0.9 & 388 & 2.9 & 0.9 \\
\hline $\begin{array}{l}\text { discharge destination } \\
\text { (\% home) }\end{array}$ & 171 & 69.6 & & 338 & 82.0 & & 388 & 91.0 & \\
\hline
\end{tabular}

BMI: Body mass index; DEMMI: De Morton Mobility Index; IROA: time to inpatient recovery of activities, measured by mILAS; ISAR: identification of seniors at risk; LOS: length of hospital stay; TUG: Timed up and Go test

Between May 2009 and May 2017, a total of 958 people underwent primary TKR and were screened preoperatively (Table 1$)$. Characteristics of patients who were included during the Joint Care ${ }^{\circledast}(n=171)$, function-tailored $(n=360)$ or fast-track $(n=427)$ period are presented in Table 1.

To investigate what the impact of the care transition was on the speed of inpatient recovery of activities, we have to adjust for baseline differences between the three groups of patients (Joint Care ${ }^{\circledast}$, function-tailored care and fast-track care) in the analysis. Therefore, we used a multivariate regression model to test if the tailored-care pathway and the fast-track pathway reduced the number of days needed for recovery of relevant inpatient activities. We used tobit regression because some patients left the hospital (to a nursing home or rehabilitation facility) before they completely recovered their activities and had therefore a missing IROA that was treated as right-censored in the tobit analysis.

Due to several preoperative missing values (mostly on the DEMMI), 895 patients were included in the regression analysis. In the analysis there were 136 right-censored observations in total. This means that data for recovery of physical functioning after surgery, as assessed with the mILAS, was available for $84 \%$ of the patients $\left(70 \%, 82 \%\right.$ and $91 \%$ in the Joint Care ${ }^{\circledast}$, 
function-tailored care and fast-track care groups, respectively). Table 2 shows that patients in the tailored care group attained inpatient recovery of activities 1.5 days earlier than the patients in the Joint Care ${ }^{\circledR}$ group $(p<0.01$ ). The patients in the fast-track care group attained inpatient recovery of activities 2.1 days earlier than the patients in the Joint Care group ( $p<$ 0.01) (Table 2).

Table 2. Differences in the number of days to inpatient recovery of activities (IROA) before and after the introduction of the function-tailored care pathway and the fast-track pathway respectively compared to Joint Care, adjusted for preoperative patient characteristics (multivariate tobit regression, $\mathrm{n}=895$ ).

\begin{tabular}{lcccc}
\hline independent variable & coefficient (days) & $\mathrm{P}$ & \multicolumn{2}{c}{$95 \% \mathrm{Cl}$} \\
\hline & & & & \\
& & & & \\
Patient groups/periods & -1.45 & $<0.01$ & -2.00 & -0.90 \\
function-tailored vs Joint Care & -2.07 & $<0.01$ & -2.61 & -1.53 \\
fast-track vs Joint Care & & & & \\
Preoperative patient characteristics & 0.16 & $<0.01$ & 0.11 & 0.21 \\
TUG time (s) & 0.01 & 0.81 & -0.04 & 0.05 \\
BMI (Kg/m ${ }^{2}$ ) & -0.02 & $<0.01$ & -0.04 & -0.01 \\
DEMMI score (0-100 points) & 0.47 & $<0.01$ & 0.25 & 0.69 \\
ISAR score (0-6 points) & 0.05 & $<0.01$ & 0.02 & 0.07 \\
age (y) & & & &
\end{tabular}

BMI: Body mass index; DEMMI: De Morton Mobility Index; ISAR: identification of seniors at risk; TUG: Timed up and Go test

A multivariate logistic regression model was used to test whether the proportion of people going to an inpatient rehabilitation facility changed after implementation of the functiontailored care pathway and the fast-track pathway. In total, data of 895 patients were included in the analysis. Both the function-tailored care pathway and the fast-track pathway were associated with a change in the probability of discharge to a rehabilitation facility (odds ratio $0.49,95 \% \mathrm{Cl} 0.29-0.83$ and odds ratio $0.31,95 \% \mathrm{Cl} 0.18-0.55$ respectively). For details see Table 3. 
Table 3. Odds ratios for referral to an inpatient rehabilitation facility before and after the introduction of respectively the function-tailored care pathway and the fast-track pathway compared to Joint Care, adjusted for preoperative factors (multivariate logistic regression, $n=895$ ).

\begin{tabular}{lcccc}
\hline independent variable & Odds ratio & $\mathrm{P}$ & \multicolumn{2}{c}{$95 \% \mathrm{Cl}$} \\
\hline Patient groups/periods & & & & \\
function-tailored vs Joint Care & 0.49 & $<0.01$ & 0.29 & 0.83 \\
fast-track vs Joint Care & 0.31 & $<0.01$ & 0.18 & 0.55 \\
Preoperative patient characteristics & & & & \\
TUG time (s) & 1.08 & $<0.01$ & 1.03 & 1.13 \\
BMI (Kg $/ \mathrm{m}^{2}$ ) & 1.02 & 0.50 & 0.97 & 1.06 \\
DEMMI score (0-100 points) & 0.98 & $<0.05$ & 0.96 & 0.99 \\
ISAR score (0-6 points) & 1.37 & $<0.01$ & 1.10 & 1.69 \\
age (y) & 1.05 & $<0.01$ & 1.02 & 1.09 \\
\hline BM: Body
\end{tabular}

BMI: Body mass index; DEMMI: De Morton Mobility Index; ISAR: identification of seniors at risk; TUG:

Timed up and Go test

\section{Economic impact}

In 2010, approximately 20,000 patients in the Netherlands choose to have a TKR 6 .

The total cost of TKR is about $€ 10,000$ per patient. Additional costs are caused by discharging patients to a nursing home or an inpatient rehabilitation centre (approximately $30 \%$ of the patients) ${ }^{4}$. But also more general costs are caused by remaining hospitalization-related disability of mostly frail elderly patients that affects their independency in daily activities.

The transitional process in NS has resulted in, on average, a two-day reduction of the time it takes to achieve inpatient recovery of activities. If patients are discharged two days earlier due to this increased recovery speed, this amounts to a savings of $€ 1,200$ per patient (one day in NS costs approximately $€ 600$ per patient). In addition, the number of patients discharged to an inpatient rehabilitation centre decreased. In the Joint Care period, 30\% of the patients were discharged to an inpatient rehabilitation centre; in the function-tailored period this decreased to $18 \%$ and in the fast-track pathway only $9 \%$ of the patients were discharged to an inpatient rehabilitation centre. From a report published in 2013 (Zorgverzekeraars Nederland) we know that the price for one day in a rehabilitation centre is $€$ 254 per patient and mean stay of TKR patients in inpatient rehabilitation is 42 days. ${ }^{7}$ Patients from our hospital that were discharged to an inpatient rehabilitation centre stayed there however 21 days on average (source: hospital information system). The reduction from 30 to $9 \%$ of the TKR patients is estimated to have resulted in a savings of $€ 5,334$ ( $€ 254 \times 21$ days) for each patient who went home instead of to the rehabilitation centre. Therefore a crude estimate of the total cost reduction for all patients undergoing TKR in Nij Smellinghe hospital amounts to $€ 348,0021$ per year ( 150 patients $x € 1,200+21 \%$ of 150 patients $x € 5,334=$ $€ 348,021)$. 
By extrapolating the economic results of $\mathrm{Nij}$ Smellinghe to the 20,000 patients undergoing TKR surgery in the Netherlands every year, we see that the possible benefits could be $€ 26,240,280$ per year $(20,000$ patients $x € 1,200+21 \%$ of 20,000 patients $x € 5,334=$ $€ 26,240,280)$.

\section{Sharing knowledge, insights and experiences}

During the development of this thesis, we created knowledge and insights that possibly could be relevant for national and international care improvement initiatives. By being a learning health system, in which all the healthcare professionals involved gain insight and experience together, knowledge and insights are widely supported in our organization. Due to this broad support in our hospital, we were able to organise several national and international educational initiatives both in our hospital as well as in other hospitals or universities.

Moreover, results and recommendations obtained from our studies are shared within scientific journals and national and international symposia or congresses (see for an overview appendix 1).

Embedded science is a learning-by-doing approach in which co-creation and integration are the key issues. Besides co-creation and integration on a micro level (the physiotherapy department of Nij Smellinghe) or on a meso level (interdisciplinary teams in Nij Smellinghe), this co-creation can also be organized on a macro level (regional or national). For valorisation of our scientific progression on a larger scale, the Dutch BiBo "community of practice" (CoP) is a good example. In this CoP, 25 embedded scientists in 14 other hospitals in the Netherlands are involved and are sharing knowledge and experiences together, aiming to enhance the quality of research and therefore the quality of care for patients undergoing major surgery. This initiative started 10 years ago, on the initiative and under the supervision of Nico van Meeteren (formerly of TNO, nowadays of Maastricht University). The community of practice meetings are organized every 6 weeks in Utrecht, the Diakonessenhuis, where one of the BiBo CoP-members works as a physiotherapist and embedded scientist as well.

A specific product of this community of practice is the development of a national physiotherapy guideline "Better in Better out", a prehabilitation program for patients undergoing total hip or total knee replacement. ${ }^{8}$

Besides sharing knowledge and experiences with other care professionals, it is perhaps even more important to share this knowledge with (potential) patients. Therefore, we organized in Nij Smellinghe, in cooperation with the NDC media group (Leeuwarden), a public academy with a focus on personalization of peri-operative care and how patients can improve their self-management possibilities in their own patient journey. This event gained 700 visitors from the Drachten community on the 20th of March 2017. 
The fact that Nij Smellinghe hospital has become a model of how perioperative care can be organized is demonstrated by the attention it has received from national and international media. Besides articles in regional and national newspapers, it also received attention from National Dutch TV and radio broadcasting. Moreover, the German ZDF and ARD made items about the peri-operative care in Nij Smellinghe for TV broadcasting.

\section{Preoperative physiotherapy interventions}

We hypothesised that fragile older patients can prevent adverse events and a complicated recovery by participating in focused prehabilitation interventions. However, it is known that there is conclusive evidence that for the low risk patients prehabilitation does not improve their outcomes and there is inconclusive evidence for the merit of prehabilitation in people with high risk profiles undergoing TKR. ${ }^{9-12}$ According to Hoogeboom et al., the main reasons for the limited evidence of the latter are the scarce experiments in high risk patients and the moderate methodological quality of these clinical trials and of the physiotherapy interventions applied in these trials. ${ }^{13}$

In chapter 5, we have shown that poor preoperative functional mobility does hamper inpatient recovery of activities in TKR patients, which can lead to hospital-related disability due to prolonged hospital stay. ${ }^{14,15} \mathrm{We}$ are one of the first who researched preoperative functional mobility as a determinant of inpatient recovery of activities. Functional mobility is modifiable in physically frail patients by tailored, supervised physical therapy interventions. ${ }^{16-18}$ As hypothesized by Hoogeboom et al. in 2012 and preliminarily demonstrated by Hansen et al., ${ }^{19,20}$ we think that tailored prehabilitation might prevent a delay in inpatient recovery and a consequently extended hospital stay in this poorly functioning group of patients. As the upcoming Better in Better out prehabilitation program can be a possible solution, it is therefore already implemented in Nij Smellinghe as usual care. The perioperative therapeutic exercise intervention is based on previous work, as this intervention was determined safe and effective at enhancing preoperative functional abilities. ${ }^{21}$ In general, the exercise program is characterized by personalized and contextualized, neuromuscular, functional training along the methods of de Vreede et al. ${ }^{16}$ Exercise is provided twice a week at a high intensity (Borg Scale: $13-15)$ in the living situation of the patient ${ }^{18}$. Exercise in the patient's own living environment is deemed essential to: (1) ensure that frail elderly patients will join in the exercise program and (2) facilitate the transition of exercises into practice. ${ }^{21}$ 


\section{Conclusion}

To reach successful surgical outcomes after TKR, state of the art anaesthetic and surgical approaches are essential. But only successful surgery does not ensure satisfying patient outcomes. The results of this thesis give suggestions on how the care process of patients around TKR can be improved, by taking patients' needs and preferences into account.

By implementing a stimulating and activating culture and infrastructure on the orthopaedic ward and by directing additional personalized pre and postoperative interventions based on screening of preoperative functional mobility (TUG, DEMMI) and postoperative personalized functional goal setting after surgery we showed that patients outcomes can be improved.

However, a continuous cycle of evaluation and innovation is needed to identify new points of improvement and to further optimize the cure and care of patients after TKR surgery in the future. 


\section{Appendix 1}

International publications:

1. Van der Sluis G, Goldbohm R, Elings J, et al. Prediction and visual presentation of inpatient recovery of functional activities after total knee replacement based on preoperative patient characteristics; submitted to Journal of physiotherapy

2. Van der Sluis G, Goldbohm R, Elings J, et al. Pre-operative functional mobility as an independent determinant of inpatient functional recovery after TKA during three periods that coincided with changes in clinical pathways. Bone Jt J. 2017;99(2):211-217

3. Elings J, van der Sluis G, Goldbohm S, et al. Development of a Risk Stratification Model for Delayed Inpatient Recovery of Physical Activities in Patients Undergoing Total Hip Replacement. J Orthop Sport Phys Ther. 2016;Jan(26)

4. Van der Sluis G, Goldbohm RA, Bimmel R, et al. What augmented physical activity and empowerment can bring to patients receiving total knee replacement: content, implementation, and comparative effectiveness of a new function-tailored care pathway in a routine care setting. Biomed Res Int. 2015

5. Elings J, Hoogeboom T, van der Sluis G, van Meeteren N. What preoperative patientrelated factors predict inpatient recovery of physical functioning and length of stay after total hip arthroplasty? A systematic review. Clin Rehabil. October 2014.

6. Hoogeboom TJ, Kittelson AJ, van der Sluis G, van Meeteren NL. Evidence-based practice in physiotherapy: time to involve the patient? Physiotherapy. 2014 Dec; 100(4):363-4

7. Jans MP, Slootweg VC, Boot CR, de Morton NA, van der Sluis G, van Meeteren NL. Reproducibility and validity of the Dutch translation of the de Morton Mobility Index (DEMMI) used by physiotherapists in older patients with knee or hip osteoarthritis. Arch Phys Med Rehabil. 2011 Nov;92(11):1892-9.

8. Hoogeboom TJ, van den Ende CH, van der Sluis G, Elings J, Dronkers JJ, Aiken AB, van Meeteren NL. The impact of waiting for total joint replacement on pain and functional status: a systematic review. Osteoarthritis Cartilage. 2009 Nov;17(11):1420-7.

\section{National publications:}

1. Oosting E, Hoogeboom TJ, Elings J, van der Sluis G, et al. Inhoud en methodologische kwaliteit van ziekenhuisprotocollen fysiotherapie na TKA. NTvF. 2009;119(6), 186-192.

2. Van der Sluis G, et al. Fysiotherapie bij THA of TKA: ook een pré? Fysiopraxis. 16 (2): 24-27, 2007.

3. Van der Sluis G, et al. Het goede doen, doet er toe. Fysiopraxis 19 (8): 26-28. 


\section{International podium presentations:}

1. Van der Sluis $G$, et al. Prediction and viual presentation of speed of inpatient rcovery of functinal activities after total knee replacement based on preoperative patient characteristics, European Federation of Orthopedics' and Traumatology (EFFORT) congress (June 2018), Barcelona, Spain.

2. Van der Sluis $G$, et al. Preoperative functional mobility as an independent determinant of inpatient functional recovery after total knee replacement during pathway changes, World confederation of physical therapy (WCPT) congress (July 2017), Cape town, South Africa.

3. Van der Sluis G, Goldbohm R, Elings J, et al. Pre-operative functional mobility as an independent determinant of inpatient functional recovery after TKA during three periods that coincided with changes in clinical pathways, European Geriatric Medicine society (EUGMS) congress (October 2016), Lisbon, Portugal.

4. Van der Sluis $G$, et al. What augmented physical activity and empowerment can bring patients receiving total knee replacement: Development, implementation and comparative effectiveness of a new function-tailored care pathway in a routine care setting, European Federation of Orthopedics' and Traumatology (EFORT) congress (June 2014), London, UK.

5. Van der Sluis $G$, et al. Preoperative prediction of inpatient functional recovery after a total knee arthroplasty, development of a clinical prediction rule, European Federation of Orthopedics' and Traumatology (EFORT) congress (June 2014), London, UK.

6. Van der Sluis $G$ and Bimmel R. Prediction of functional recovery after TKA, London Knee meeting October 2012 (invited speaker), London, UK.

7. Van der Sluis $G$, et al. Functional goalsetting after a TKA allows earlier discharge home, British Orthopedic Association Congress (September 2012), Manchester, UK.

\section{National podium presentations:}

1. Van der Sluis G, Elings J, Van Lieshout MR, Praktische vertaling van de Better in Better out (BiBo) standaard, Nationaal fysiotherapie congres november 2012 (invited speaker), Maastricht.

2. Van der Sluis G, Bimmel R, Goldbohm RA, Hoogeboom TJ, Elings J, van Meeteren NLU, Creëren van functionele doelen rondom een totale knie artrplastiek, een kwaliteitsverbetering. Jaarcongres Nederlandse vereniging voor ziekenhuis fysiotherapie, Juni 2012, Breda.

3. Van der Sluis G, Bimmel R, Goldbohm RA, Hoogeboom TJ, Elings J, van Meeteren NLU, prediction of clinical functional recovery after Total knee artroplasty, Jaarcongres Nederlandse orthopedische vereniging (NOV) Januari 2012 (nominated for the de NOV-Ortomed price), Den Haag.

4. Van der Sluis G, Elings J, Oosting E, Hoogeboom TJ, Fysieke fitheid rondom een Totale heup- of Totale knie artroplastiek, Better in Better out congres, Bohn stafleu en van Loghum (BSL), December 2011, Utrecht. 


\section{Reference list}

1. Hulzebos EHJ, van Meeteren NLU. Making the elderly fit for surgery. Br J Surg. 2015:n/a-n/a. doi:10.1002/bjs.10033.

2. Pilot P, Engelen M, Dreessen F. Critical pathway for hip and knee arthroplasty: Faster home due to multidisciplinary cooperation. J Integr Care Pathways. 2006;10:59-62. http://icp.sagepub.com/content/10/2/59.short.

3. Pilot $P$, Bogie R, Draijer WF, Verburg AD, van Os JJ, Kuipers $H$. Experience in the first four years of rapid recovery; is it safe? Injury. 2006;37 Suppl 5:S37-40. doi:10.1016/S0020-1383(07)70010-4.

4. van der Sluis G, Goldbohm RA, Bimmel R, et al. What augmented physical activity and empowerment can bring to patients receiving total knee replacement: content, implementation, and comparative effectiveness of a new function-tailored care pathway in a routine care setting. Biomed Res Int. 2015;2015:745864. doi:10.1155/2015/745864.

5. Kehlet H. Fast-track hip and knee arthroplasty. Lancet. 2013;381(9878):1600-1602. doi:10.1016/S01406736(13)61003-X.

6. Otten R, van Roermund PM, Picavet HSJ. [Trends in the number of knee and hip arthroplasties: considerably more knee and hip prostheses due to osteoarthritis in 2030]. Ned Tijdschr Geneeskd. 2010;154:A1534.

7. Nederland Z. Inkoopgids Geriatrische Revalidatiezorg (GRZ) 2013. 2013:1-8.

8. Hoogeboom T. "Better in, Better out Standaard TKA En THA."

9. Hoogeboom TJ, Oosting E, Vriezekolk JE, et al. Therapeutic validity and effectiveness of preoperative exercise on functional recovery after joint replacement: A systematic review and meta-analysis. PLoS One. 2012;7(5):1-12. doi:10.1371/journal.pone.0038031.

10. Ackerman IN, Bennell KL. Does pre-operative physiotherapy improve outcomes from lower limb joint replacement surgery? A systematic review. Aust J Physiother. 2004;50(1):25-30. doi:10.1016/S00049514(14)60245-2.

11. Kwok IHY, Paton B, Haddad FS. Does Pre-Operative Physiotherapy Improve Outcomes in Primary Total Knee Arthroplasty? - A Systematic Review. J Arthroplasty. 2015;30(9):1657-1663. doi:10.1016/j.arth.2015.04.013.

12. Jordan RW, Smith NA, Chahal GS, Casson C, Reed MR, Sprowson AP. Enhanced education and physiotherapy before knee replacement; is it worth it? A systematic review. Physiother (United Kingdom). 2014;100(4):305-312. doi:10.1016/j.physio.2014.03.003.

13. Hoogeboom TJ, Van Meeteren NLU, Schank K, Kim RH, Miner T, Stevens-Lapsley JE. Risk factors for delayed inpatient functional recovery after total knee arthroplasty. Biomed Res Int. 2015;2015:5-9. doi:10.1155/2015/167643.

14. Sourdet S, Lafont C, Rolland Y, Nourhashemi F, Andrieu S, Vellas B. Preventable latrogenic Disability in Elderly Patients During Hospitalization. J Am Med Dir Assoc. 2015;16(8):674-681. doi:10.1016/j.jamda.2015.03.011.

15. Guccione AA, Fagerson TL, Anderson JJ. Regaining functional independence in the acute care setting following hip fracture. Phys Ther. 1996;76(8):818-826.

16. de Vreede PL, Samson MM, NI. . Functional-Task Exercise Versus Resistance Strength Exercise to. J. 2005:210. http://scholar.google.com/scholar?hl=en\&btnG=Search\&q=intitle:FunctionalTask+Exercise+Versus+Resistance+Strength+Exercise+to\#4.

17. Fleuren $\mathrm{M} \mathrm{a} \mathrm{H}$, Vrijkotte $\mathrm{S}$, Jans MP, et al. The implementation of the functional task exercise programme for elderly people living at home. BMC Musculoskelet Disord. 2012;13(1):128. doi:10.1186/1471-2474-13-128.

18. Siemonsma PC, Blom JW, Hofstetter $\mathrm{H}$, et al. The effectiveness of functional task exercise and physical therapy as prevention of functional decline in community dwelling older people with complex health problems. 2018:1-8.

19. Hansen TB, Bredtoft HK, Larsen K. Preoperative physical optimization in fast-track hip and knee arthroplasty. Dan Med J. 2012;59(2):A4381. doi:A4381 [pii].

20. Hoogeboom TJ, Oosting E, Vriezekolk JE, et al. Therapeutic validity and effectiveness of preoperative exercise on functional recovery after joint replacement: A systematic review and meta-analysis. PLoS One. 2012;7(5). doi:10.1371/journal.pone.0038031.

21. Oosting E, Jans MP, Dronkers JJ, et al. Preoperative home-based physical therapy versus usual care to improve functional health of frail older adults scheduled for elective total hip arthroplasty: A pilot randomized controlled trial. Arch Phys Med Rehabil. 2012;93(4):610-616. doi:10.1016/j.apmr.2011.11.006. 


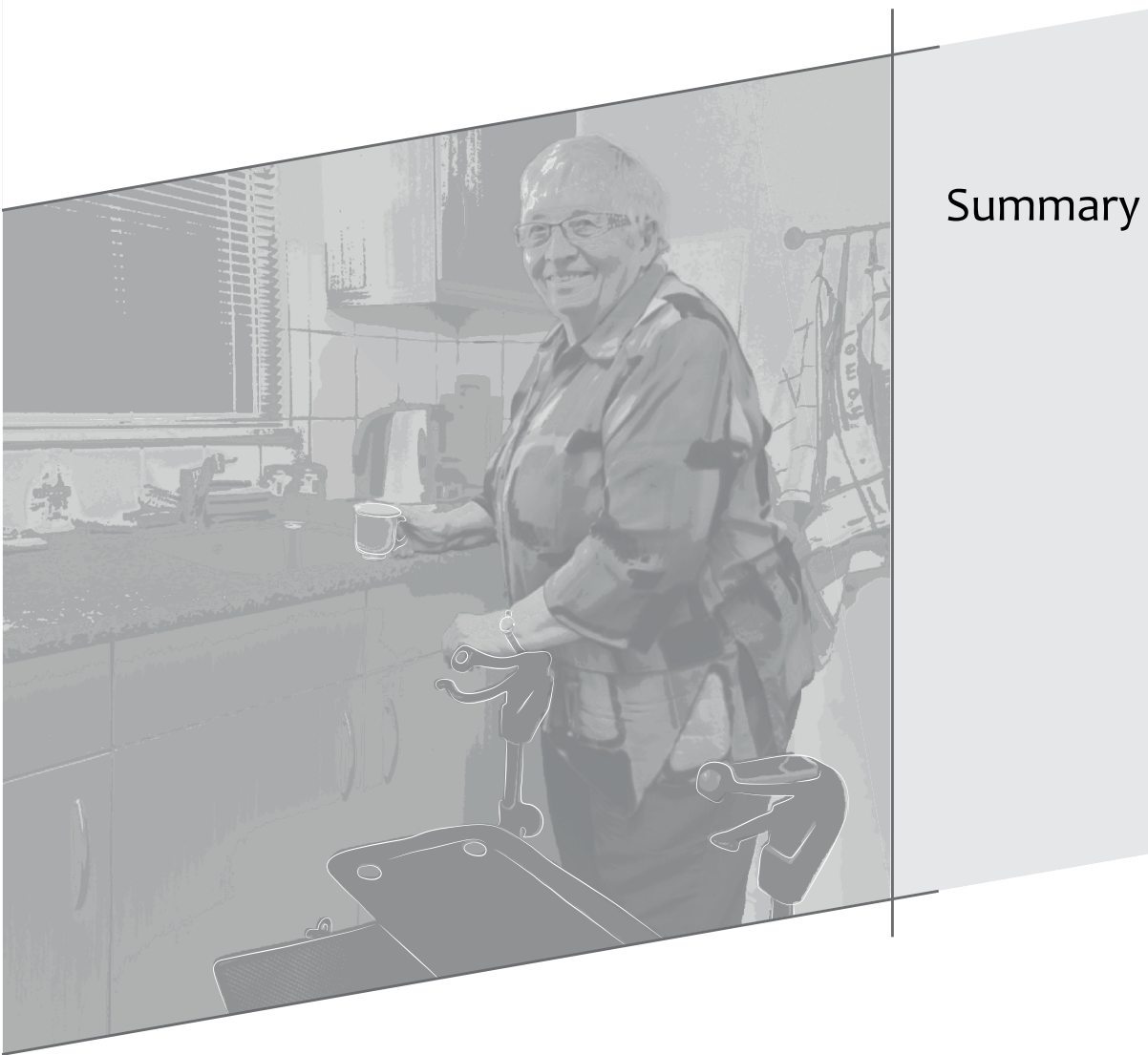




\section{Summary}

Chapter 1 is the introduction of this thesis. People who choose to have a total knee replacement (TKR) to solve the functioning problem that they experience as a result of knee osteoarthritis choose to undergo a major surgical procedure. The diversity in patients is increasing for this procedure (on the one hand becoming younger and fitter, on the other hand becoming older and frailer). In addition - and partly because of this - the incidence of total knee operations will increase significantly in the coming years.

The surgical intervention and the unavoidable hospital admission can have a negative influence on the recovery of physical functioning, particularly for older and frail patients. It is precisely because of this that the outcome of the surgery for patients could be negative.

In this PHD thesis the development, implementation and effectiveness of a change of care pathway for patients undergoing TKR surgery is described. In this change, the focus shifted from more biomedical thinking (repairing the affected knee) to optimizing the physical and functional possibilities of a patient. In the new care path the patient is encouraged to take control himself. In addition, the individual needs and preferences of the patient lead to the shared decisions that are made to solve the patient's functioning problem. The aim of the care pathway transition was to move from a care process that was mainly aimed at optimal patient logistics and the timely organization of care activities (Joint Care ${ }^{\circledR}$ ) to a personalized care pathway that aims to keep patients optimally active before and after the surgical intervention, while minimizing the complications and negative consequences of medical treatment.

\section{Aim of cure and care}

By changing the focus in the care (and the care pathway) for patients choosing a TKR from repairing an osteoarthritic knee joint to finding a solution for an osteoarthritis-related functional problem, the care for these patients has changed accordingly. Chapter 2 describes, starting with the former Joint Care ${ }^{\circledR}$ care pathway, the implementation and effectiveness of a new, more functional and personalized care pathway. Within this new care pathway, providing an activating culture and infrastructure during hospital admission and setting personal functional goals is the most important change. In order to put this vision into practice, physiotherapists and nurses in particular have been trained and made aware of their new role in the orthopaedic ward. The transition from Joint Care ${ }^{\circledR}$ to this more functional approach resulted, after correction for baseline differences, in a significant decrease in hospital stay of an average of 1 day and a significant increase in the speed of control of functional milestones averaging half a day. Also, more patients went home directly from the hospital (from $70 \%$ to $82 \%)$. 


\section{Shared decision making with patients undergoing TKR surgery}

The long-term goal is to apply shared decision making throughout the care pathway in patients undergoing a TKR surgery. For this, preference should be given to well-known models of shared decision making (SDM). However, our scoping review (chapter 3) shows that currently SDM is only used to help patients choose whether or not to have the surgical procedure carried out; it is not used with other important decisions, such as those about discharge time from the hospital, discharge destination, rehabilitation options etc.

The review provided insight into which sources and themes are considered important for patients and are the basis of their decision regarding whether to opt for a TKR intervention, namely: (1) relevant personal factors (anxiety, other diseases, religion, etc.), 2) relevant external factors (patient-doctor relationship, financial issues, etc.), (3) sources of information (media, experiences of significant others, personal experiences), (4) information from prediction models (choice aids, prediction rule, etc.). The review also provided insight into which methods of shared decision making are known in the literature for patients who opt for TKP surgery. However, the themes and sources that were deemed important by patients for an adequate decision were not recognized in the literature. This could mean that the methods of SDM known from the literature do not have a strong impact on their application in daily practice.

\section{Delivering care to patients undergoing TKP surgery}

In order to provide the right care to the right patient, one must be able to anticipate the possible scenarios of the surgery outcome of each individual patient. Prediction models can help gain insight into these scenarios. Chapter 4 shows that with 6 preoperative determinants (1. male gender, 2. BMI $>25 \mathrm{~kg} / \mathrm{m}^{2}$, 3. age $>70$ years, 4. ASA score of 3, 5. Charnley score B/C and 6. a TUG time $>12.5 \mathrm{~s}$ ) a good prediction can be made regarding for which patients there is an increased risk of delayed recovery of relevant activities during hospitalization. From this result, chapter 5 looked further at preoperative functional mobility as a predictor of the speed of functional recovery during the clinical phase. This study showed that preoperative functional mobility, measured by both the Timed up and Go (TUG) test and the De Morton Mobility Index (DEMMI), appears to be an independent determinant for delayed inpatient recovery of activities in a model with ASA, BMI, Identification of Seniors At Risk (ISAR) and age. The TUG and the DEMMI both appear to be instruments that can measure the construct of preoperative mobility well. Moreover, the TUG can be regarded as a quick scan and the more extensive DEMMI is able to distinguish between different dimensions of functional mobility. Information from this test therefore provides immediate points of attention for interventions aimed at maintaining or optimizing functional mobility before and after surgery. 
In order to be able to better estimate scenarios regarding the possible speed of inpatient recovery of functional mobility after the operation, it may help to provide a patient with his chances of more than one outcome. In chapter 6, a prediction model was developed that shows for each patient the probabilities of 3 outcomes of recovery speed: (1) fast recovery (within 2 days), (2) normal recovery (within 3 days) and (3) delayed recovery (longer than 3 days). This may be more informative for a patient than just his probability of having a negative outcome (in this case a delayed recovery). The predictions of the probabilities for all 3 outcomes are presented graphically to a patient as absolute opportunities in a pie chart. In the future it should be investigated whether this method of prediction is also more effective than the prediction of only the chance of delayed recovery.

\section{Discussion and conclusion}

Chapter 7 is the discussion of this thesis and it reflects on the methodology and results and examines the practical possibilities offered by the outcomes of this dissertation. All the scientific research included has been carried out in the daily care practice of one hospital. We have shown that high-quality scientific research can be carried out well in this way. In this, it has proved indispensable to create a good data set as a first step, in which data from day-to-day practice is measured and collected in a scientifically sound manner. By ensuring this process is done well, the effect of a health care innovation could be continuously tested. An additional advantage of doing research and developing new care in day-to-day practice is that with the proven effect of an innovation, its implementation is already ensured.

Paying attention to preoperative functional mobility, optimizing functional mobility before and after the operation and having personal functional goals ultimately resulted in an increase in the speed of inpatient recovery of activities of an average of 2 days. The use of inpatient rehabilitation by TKR patients of $\mathrm{Nij}$ Smellinghe has also been reduced from 30\% to 9\% during the period of the transition. In addition to the fact that these outcomes have big potential to reduce healthcare costs, it is especially profitable for the patients. This is because they have a shorter stay in the harmful hospital environment and can return earlier and often in better condition to their own environment and often immediately function optimally again, which is an important health gain. 
Samenvatting 


\section{Samenvatting}

Hoofdstuk 1 is de introductie van dit proefschrift. Mensen die kiezen om een totale knie prothese (TKP) te laten plaatsen als oplossing voor het functioneringsprobleem dat ze ervaren als gevolg van knie artrose, kiezen ervoor om een zware chirurgische ingreep te ondergaan. De diversiteit in patiënten wordt steeds groter bij deze ingreep (aan de ene kant steeds jonger en fitter, aan de andere kant steeds ouder en brozer). Daarnaast en mede daardoor zal de incidentie van totale knieoperaties de komende jaren flink stijgen.

Doordat de chirurgische ingreep en de onvermijdelijke ziekenhuisopname een negatieve invloed kunnen hebben op het herstel van fysiek functioneren, bij met name oudere en kwetsbare patiënten, zou juist daardoor de uitkomst van de operatie voor patiënten negatief uit kunnen pakken. In dit proefschrift wordt de ontwikkeling, implementatie en effectiviteit beschreven van een zorgpad verandering voor patiënten die een TKP ingreep ondergaan. Daarbij werd de focus verlegd van meer biomedisch denken (het repareren van de aangedane knie) naar het optimaliseren van fysieke en functionele mogelijkheden van een patiënt. De patiënt wordt in het nieuwe zorgpad gestimuleerd om zelf regie te nemen. Daarnaast zijn individuele behoeftes en voorkeuren van de patiënt leidend voor de gezamenlijke keuzes die gemaakt worden om zijn of haar functioneringsprobleem op te lossen. Doel van de zorgpad transitie was om van een zorgproces dat met name gericht was op optimale patiënten logistiek en op het tijdig organiseren van zorgactiviteiten (Joint Care ${ }^{\circledR}$ ) te komen tot een gepersonaliseerd zorgpad dat als doel heeft om patiënten rondom de ingreep optimaal actief te laten zijn, terwijl complicaties en negatieve gevolgen van de medische behandeling zoveel mogelijk worden beperkt.

\section{Doelstelling van behandeling en zorg}

Door de focus in de zorg (en het zorgpad) voor patiënten die voor een TKP kiezen te veranderen van het repareren van een artrotisch kniegewricht naar het vinden van een oplossing voor een artrose gerelateerd functioneringsprobleem, is ook de zorg voor deze patiënten in dezelfde lijn veranderd. In hoofdstuk 2 wordt vanuit het toen geldende Joint Care ${ }^{\circledR}$ zorgpad, de implementatie en effectiviteit van een nieuw meer op functioneren gericht en gepersonaliseerd zorgpad beschreven. Binnen dit nieuwe zorgpad is het bieden van een activerende cultuur en infrastructuur tijdens de ziekenhuis opname en het stellen van persoonlijke functionele doelen de belangrijkste verandering. Om deze visie in de praktijk te brengen zijn met name fysiotherapeuten en verpleegkundigen geschoold en zich bewust geworden van een andere rol op de verpleegafdeling. De transitie van Joint Care ${ }^{\circledR}$ naar deze meer op functioneren gerichte benadering leverde na correctie voor baseline verschillen een significante daling in opnameduur op van gemiddeld 1 dag en een significante toename in de snelheid van beheersing van de functionele mijlpalen van gemiddeld een halve dag. 
Ook gingen er gemiddeld meer patiënten direct vanuit het ziekenhuis (van $70 \%$ naar $82 \%$ ) naar huis.

\section{Gezamenlijke besluitvorming bij patiënten die TKP ingreep ondergaan}

Het lange termijn doel is om gezamenlijke besluitvorming door het hele zorgpad toe te passen bij patiënten die een TKP-operatie (zullen) ondergaan. Daarvoor zou bij voorkeur gebruik gemaakt moeten worden van welbekende modellen van gezamenlijke besluitvorming. Onze scoping review (hoofdstuk 3) laat echter zien dat gezamenlijke besluitvorming tot op heden alleen wordt toegepast om patiënten te helpen bij de keuze om wel of niet de chirurgische ingreep uit te laten voeren en niet bij andere belangrijke beslissingen zoals over ontslagmoment uit het ziekenhuis, ontslagbestemming, revalidatieopties etc.

De review heeft inzicht gegeven in wat voor patiënten belangrijke bronnen en thema's zijn waarop zij de beslissing baseren om wel of niet voor een TKP ingreep te kiezen, te weten: (1) relevante persoonlijke factoren (angst, andere ziekten, godsdienst etc.), (2) relevante externe factoren (patiënt-arts relatie, financiële issues, etc.), (3) gebruikte bronnen van informatie (media, ervaringen van belangrijke anderen, eigen ervaringen), (4) Informatie van voorspellingsmodellen (keuzehulpen, predictieregel, etc.). De review heeft ook inzicht gegeven in welke methodes van gezamenlijke besluitvorming er bekend zijn in de literatuur bij patiënten die kiezen voor een TKP ingreep. Echter werden de thema's en bronnen, zoals door patiënten belangrijk gevonden voor een adequate beslissing, daarin niet herkend. Dat zou kunnen betekenen dat de uit de literatuur bekende methodes van gezamenlijke besluitvorming geen grote impact hebben op de toepassing ervan in de dagelijkse praktijk.

\section{Leveren van de zorg aan patiënten die een TKP operatie ondergaan}

Om de juiste zorg te leveren aan de juiste patiënt, is het kunnen anticiperen op de mogelijke scenario's van de operatie uitkomst van iedere individuele patiënt een belangrijke voorwaarde. Om inzicht in die scenario's te krijgen kunnen predictiemodellen behulpzaam zijn. In hoofdstuk 4 is te zien dat met behulp van 6 preoperatieve determinanten (1. geslacht man, 2. BMI $>25 \mathrm{~kg} / \mathrm{m}^{2}$, 3. leeftijd $>70$ jaar, 4. ASA score van 3, 5. Charnley score B/C en 6 . een TUG tijd > $12.5 \mathrm{~s}$ ) een goede voorspelling gedaan kan worden bij welke patiënten er een verhoogd risico is op vertraagd herstel van relevante activiteiten tijdens de ziekenhuisopname. Vanuit dit resultaat is in hoofdstuk 5 verder gekeken naar preoperatieve functionele mobiliteit als voorspeller van de snelheid van functioneel herstel tijdens de klinische fase. Uit deze studie is gebleken dat preoperatieve functionele mobiliteit, gemeten met zowel de Timed up and Go (TUG) test als met de De Morton Mobility Index (DEMMI) een onafhankelijke determinant voor vertraagd herstel blijkt te zijn in een model met ASA, BMI, Indentification of Seniors At Risk (ISAR) en leeftijd. De TUG en de DEMMI blijken beide instrumenten te zijn die het construct 
van preoperatieve mobiliteit goed kunnen meten. Daarbij kan de TUG als een quick scan worden beschouwd en is de uitgebreidere DEMMI in staat om te onderscheiden in verschillende dimensies van functionele mobiliteit. Informatie uit deze test geeft daarom meteen aanknopingspunten voor interventies die gericht zijn om de functionele mobiliteit te onderhouden dan wel te optimaliseren rondom de ingreep.

Om nog beter scenario's te kunnen schetsen van de mogelijke snelheid van herstel van functionele mobiliteit na de operatie, zou het mogelijk kunnen helpen om patiënten te voorzien van zijn of haar kansen op meerdere uitkomsten. In hoofdstuk 6 is een voorspellingsmodel ontwikkeld wat voor iedere patiënt de kansen laat zien op 3 uitkomsten van snelheid van herstel (1) snel herstel (binnen 2 dagen), (2) normaal herstel (binnen 3 dagen) en (3) vertraagd herstel (langer dan 3 dagen). Dit is voor een patiënt mogelijk meer informatief dan alleen z'n kans op het krijgen van een negatieve uitkomst (in dit geval vertraagd herstel). De voorspellingen van de kansen voor al de 3 uitkomsten worden grafisch aan een patiënt gepresenteerd als absolute kansen in een taartdiagram. Of deze wijze van predictie ook meer effectief is dan de predictie van alleen de kans op vertraagd herstel moet in de toekomst nog onderzocht worden.

\section{Discussie en conclusie}

Hoofdstuk 7 is de discussie van dit proefschrift en reflecteert op de methodologie en resultaten van dit proefschrift en gaat in op de praktische mogelijkheden die de uitkomsten van dit proefschrift bieden. Al het wetenschappelijk onderzoek dat is opgenomen in dit proefschrift is in de dagelijkse zorgpraktijk van 1 ziekenhuis uitgevoerd. We hebben laten zien dat kwalitatief goed wetenschappelijk onderzoek op deze manier goed is uit te voeren. Daarbij is het onontbeerlijk gebleken om als eerste stap een goede dataset te creëren, waarbij data uit de dagelijkse praktijk op een wetenschappelijk verantwoorde manier verzameld en opgeslagen wordt. Door dit proces goed te borgen, kon continu het effect van een zorginnovatie getoetst worden. Bijkomend voordeel van zorginnovatie en onderzoek in de dagelijkse praktijk is dat bij gebleken effect van de innovatie, ook de implementatie ervan meteen verzekerd is.

Aandacht hebben voor preoperatieve functionele mobiliteit, het optimaliseren van functionele mobiliteit rondom de operatie en persoonlijke functionele doelen levert uiteindelijk een toename van de snelheid van herstel van relevante klinische activiteiten van gemiddeld 2 dagen op. Ook is het gebruik van intramurale revalidatie door TKR-patiënten van $\mathrm{Nij}$ Smellinghe in de periode van de transitie teruggedrongen van 30\% naar 9\%. Naast dat deze uitkomsten een enorme potentie hebben in het terugdringen van zorgkosten, is het met name voor de patiënt winst. Want hij of zij verblijft korter in de schadelijke ziekenhuisomgeving en kan eerder en vaak beter in z'n eigen leefomgeving terugkeren en vaak meteen weer redelijk optimaal functioneren, wat een enorme gezondheidswinst is. 


\section{Dankwoord}

Zo de allerlaatste klus... het dankwoord schrijven. Want promotieonderzoek doen en dit proefschrift schrijven had ik nooit gekund zonder de hulp van veel mensen. Daarom wil ik graag van de gelegenheid gebruik maken om deze mensen te bedanken.

Allereerst zou ik heel graag "thuis" willen bedanken. Want zonder de onvoorwaardelijke steun van Sylvia, Eline en Arne was het mij nooit gelukt om mijn promotie te voltooien. Lieve Sylvia, jouw steun, liefde, humor, aanmoediging, kritische noot en op iedere andere manier dat je me hebt geholpen heb ik zeer gewaardeerd! Ook toen het allemaal even wat moeilijker was... Dank je wel. Ik hou van jou.

Lieve Arne en Eline, wat ongezellig was het soms voor jullie. Moest ik weer met dat stomme verslag bezig. Het is klaar nu hoor!! Arne dank je wel dat je me hebt geholpen met de getalletjes in de vakjes te zetten. En Eline bedankt voor je goede opmerkingen! Een nieuwe knie, hoe moeilijk kan het allemaal zijn. Je zet er gewoon een nieuwe in, pleister erop en klaar! Daar hoef je toch niet zo vaak voor achter de computer te zitten...? Dank jullie wel lieverds!

Nico van Meeteren, Sandra Bausch en Thomas Hoogeboom, bedankt voor jullie begeleiding. Ik heb door jullie steun en begeleiding een enorm plezierig en leerzaam traject beleefd. Soms kritisch, maar vaak erg inspirerend. Ik heb van jullie veel ruimte en vrijheid ervaren om dit promotietraject op mijn eigen manier te kunnen doen. Nico, jouw bevlogenheid en manier van mensen inspireren heeft altijd erg aanstekelijk voor mij gewerkt. Het maakte dat ik er echt voor wilde gaan. Het was je nooit te gek om op de meest onmogelijke momenten toch even te bellen om nog even een stuk van mij door te lezen. Ik heb je als een erg betrokken en inspirerende promotor ervaren, die constant kritisch mee bleef denken en vaak de zaken weer even in een ander perspectief kon plaatsen.

Sandra, ik denk dat ik me in mijn handen heb mogen knijpen met zo'n betrokken copromotor. Wat heb ik veel van jou mogen leren. De vele gesprekken die we hebben gevoerd, de sessies bij jou thuis, waarbij we mijn stukken tekst soms woord voor woord doornamen en jouw uitgebreide commentaren via de mail. Het heeft er allemaal aan bijgedragen om met trots op mijn promotietraject terug te kijken. Ik heb het vooral erg gewaardeerd dat je je geloof in mij altijd bent blijven uitspreken! Ik heb zelf wel twijfel gehad, maar dat wist jij altijd zorgvuldig weer de kop in te drukken. 
Thomas, jouw bevlogenheid, inhoudelijke kennis, kritische noot, de maandagochtend belafspraak en vooral ook je humor hebben mij erg geholpen. Je wist me ook vaak met mensen in contact te brengen die de op dat moment benodigde kennis of ervaring in huis hadden. Dat was erg fijn. Ik heb het erg gewaardeerd dat je ondanks dat je halverwege mijn traject een andere baan kreeg me toch bent blijven begeleiden. Dat zal niet altijd even makkelijk voor je zijn geweest, daarom door mij juist des te meer gewaardeerd. Door zo intensief met jullie te hebben mogen samenwerken ligt er nu een proefschrift waar ik erg trots op ben. Volgens mij kan het een waardevolle bijdrage leveren aan de verdere ontwikkeling van de perioperatieve zorg voor patiënten die een nieuwe knie zullen krijgen.

Heit en mem, jullie ook erg bedankt voor al jullie steun, liefde, vertrouwen en aanmoediging. Dat was ook echt wel eens even nodig om vol te blijven houden. De gesprekken, glaasjes wijn, lekkere eten, vriendschap en de soms praktische hulp waren voor mij erg belangrijk en ben ik jullie erg dankbaar voor. Heit bedankt dat je mijn Paranymf wilt zijn.

Schoonouders, jullie ook erg bedankt voor de hulp in de periode van mijn promotie. Opvang van de kinderen, aanschuiven aan de eettafel wanneer het allemaal wat later was geworden dan gepland, praktische hulp en jullie gezelligheid hebben me enorm geholpen.

Lieve vrienden, ook jullie allemaal erg bedankt voor jullie steun en interesse in mijn promotietraject. Ik vond het fijn te ervaren dat iedereen achter me stond. Ik kreeg hier en daar wel eens een spiegel voorgehouden, maar dat heeft me alleen maar weer verder geholpen. Vaak heb ik echter waardering en interesse ervaren en dat heeft me enorm goed gedaan.

Dennis, ik ben erg blij dat je mijn paranymf wilt zijn. Jouw kijk op levenszaken en dus ook op de gezondheidszorg, humor, gezelligheid en vooral jouw vriendschap zijn de afgelopen jaren erg belangrijk voor mij geweest.

Jaap Dronkers, ook jou wil ik graag bedanken. Je was in mijn beleving toch zijdelings betrokken bij de totstandkoming van mijn proefschrift. Ik kon regelmatig even bij jou spiegelen of inhoudelijk met je sparren. Je relativerend vermogen, soms zelfs ook over het promoveren, en wijsheid heb ik erg gewaardeerd. Voor mij is onze trip naar Kaapstad een hoogtepunt. Ik vond het heel bijzonder om dat samen met je te mogen beleven.

Ellen Oosting en Jordi Elings, we zijn met z'n drieën aan dit avontuur begonnen. Fijn om inhoudelijk met jullie te mogen discussiëren, soms ook gewoon hulp te krijgen om bijvoorbeeld STATA onder de knie te krijgen of gewoon even de beslommeringen rondom de promotie te kunnen delen. Ik hoop in de toekomst nog veel met jullie te mogen samenwerken. 
Collega's van de afdeling fysiotherapie van Nij Smellinghe, ook jullie ben ik dank verschuldigd. Want ik heb van jullie veel aanmoediging, ruimte, interesse en gezelligheid mogen ontvangen. Fijn dat er een cultuur op onze afdeling heerst waarin ook innovatie en onderzoek goed mogelijk is. Graag wil ik Margreet Euwes en Ad Hendrickx als mijn leidinggevenden in het bijzonder bedanken. Ik ben blij dat ik van jullie het vertrouwen en de ruimte heb gekregen om, ook deels in werktijd, mijn promotie te mogen doen. Ook jullie kritische meedenken en meelezen heeft me geïnspireerd en verder geholpen.

Richard Bimmel en Pieter Buwalda, bedankt dat ik samen met jullie zo heb kunnen pionieren en dat we het hebben aangedurfd om de perioperatieve zorg voor onze orthopedie patiënten zo impactvol te veranderen. Ik denk dat we alle drie vanuit onze verschillende invalshoeken dit tot zo'n succes hebben kunnen maken. Dit alles is voor mij de basis en inspiratiebron geweest om tot dit proefschrift te komen. Dus erg bedankt voor deze mooie samenwerking. Richard, erg fijn dat je op alle artikelen als co-auteur hebt meegewerkt en dat je, zoals je dat zelf vaak noemde, als "klinisch geweten" alle stukken steeds kritisch bekeken hebt. Dat is erg waardevol geweest. Pieter, fijn dat ik regelmatig met je kon brainstormen en sparren. De soms niet meer voor buitenstaanders te begrijpen tekeningen op je whiteboard hielpen mij dan weer verder in mijn denkproces.

Verpleegkundigen van afdeling B3, maatschap leden van de orthopedie, verpleegkundig specialisten en Physisian assistant, afdelingssecretaresses, polimedewerkers, managers en de rest van de betrokken mensen van ziekenhuis Nij Smellinghe, fijn dat er zoveel enthousiasme, openheid en interesse is geweest in BiBo en mijn promotieonderzoek. Dat heeft erg geholpen om het vol te houden. Het was een verademing om op de verpleegafdeling (de proeftuin van mijn onderzoek) zoveel geduld, humor, flexibiliteit en soms ook incasseringsvermogen te vinden. Jullie inbreng en medewerking is erg waardevol geweest.

Alle coauteurs dank voor jullie bijdrage aan het tot stand komen van mijn artikelen en het kritisch meelezen en schrijven ervan.

Last but not least... zonder patiënten natuurlijk nooit dit proefschrift. Daarom ben ik mevrouw Geertje Meijer en alle andere patiënten veel dank verschuldigd. Ik heb veel van onze patiënten mogen leren. De dankbaarheid, maar de soms ook eerlijke en oprechte kritische noten hebben bijgedragen aan het verder optimaliseren van ons zorgproces. 


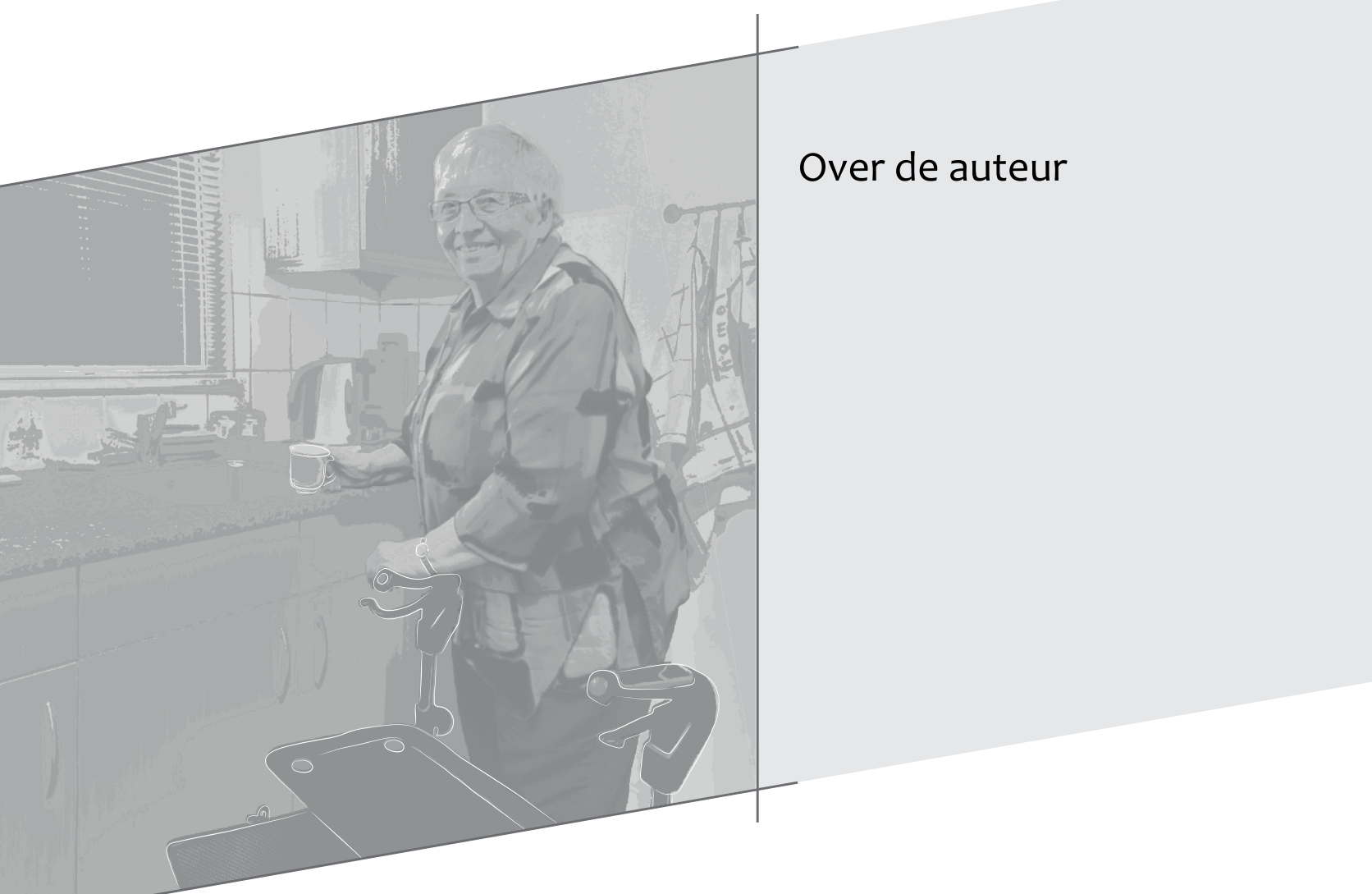




\section{Over de auteur}

Geert van der Sluis werd op 2 maart 1977 geboren in Drachten. Na het afronden van de Havo aan het Stellingwerfcollege te Oosterwolde ging hij in 1994 fysiotherapie studeren aan de Hanzehogeschool Groningen en ronde deze opleiding in 1998 af. Van 1998 tot 2002 stuurde hij Medische beeldvormende en radiotherapeutische technieken (MBRT) aan de Hanzehogeschool Groningen. Na het afstuderen aan de MBRT heeft hij 1.5 jaar in Oslo op de afdeling radiotherapie gewerkt van Det Norske Radiumhospitalet. Eind 2003 keerde hij terug naar Nederland om als fysiotherapeut in ziekenhuis Nij Smellinghe te Drachten te gaan werken. In 2004 is hij gestart met de Master of Science Fysiotherapiewetenschap aan de universiteit van Utrecht en heeft deze in 2007 afgerond. Daar kwam hij voor het eerst in aanraking met het doen van wetenschappelijk georiënteerd onderzoek en voerde in het kader van de masterthesis een cohortstudie uit op de afdeling orthopedie van Nij Smellinghe. Vanaf 2009 raakte hij steeds meer betrokken bij zorgvernieuwing en onderzoek bij patiënten die een geplande totale knie of totale heuparthroplastiek moesten ondergaan. Met name het optimaliseren van de zorg voor kwetsbare oudere patiënten hadden zijn focus. Het voor de operatie kunnen voorspellen van de uitkomsten van de ingreep en het optimaal activeren van met name kwetsbare ouderen rondom de ziekenhuisopname kregen hierin de volledige aandacht. In 2015 leidde dat uiteindelijk tot zijn eerste internationale publicatie en dat was de opmaat naar zijn proefschrift dat in april 2018 is afgerond. Ook is de auteur betrokken geweest bij regionale en landelijke initiatieven rondom Better in Better out (BiBo) en richtlijnontwikkelingen. Hij geeft op regelmatige basis gastcolleges op verschillende hogescholen over zorgvernieuwing en verbetering voor patiënten rondom een chirurgische ingreep. De resultaten van zijn proefschrift zijn nationaal en internationaal gedeeld op symposia en congressen, o.a. British Orthopeadic association (BOA) congres, London Knee meeting, World Confederation of Physical Therapy (WCPT) congres, European Federation of Orthopedics' and Traumatology (EFORT) congres en het European Geriatric Medicine society (EUGMS) congres. Momenteel is hij werkzaam als projectleider Value based healthcare in OLVG te Amsterdam.

De auteur is sinds 2009 getrouwd met Sylvia Lulofs en is vader van Eline en Arne. 